\title{
Total Synthesis via Biomimetic Late-stage Heterocyclization, Assignment of the Relative Configuration and Biological Evaluation of the Nitraria Alkaloid ( \pm )-Nitrabirine.
}

Mervic D. Kagho, ${ }^{\ddagger},{ }^{*}$ Helen Hintersatz,,${ }^{\S}$ Andreas Ihle, ${ }^{\S}$ Haoxuan Zeng, ${ }^{*}$ Hedda Schrey, ${ }^{\ddagger}$ Wera Colisi, ${ }^{¥}$ Philipp Klahn, ${ }^{\ddagger, \star}$ Marc Stadler, ${ }^{\ddagger}, \|$ Clemens Bruhn, ${ }^{\#}$ Tobias Rüffer, ${ }^{\dagger}$ Heinrich Lang, ${ }^{\dagger}$ Klaus Banert $\$$,a

‡Institute of Organic Chemistry, Technische Universität Braunschweig, Hagenring 30, D38106 Braunschweig, Germany.

§Organic Chemistry, Technische Universität Chemnitz, Straße der Nationen 62, 09111 Chemnitz, Germany.

¥Department of Microbial Drugs, Helmholtz Centre for Infection Research and German Centre for Infection Research (DZIF), Partner Site Hannover-Braunschweig, Inhoffenstraße 7, 38124 Braunschweig, Germany.

"Institute of Microbiology, Technische Universität Braunschweig, Spielmannstraße 7, 38106 Braunschweig, Germany.

†'Inorganic Chemistry, Technische Universität Chemnitz, Faculty of Natural Sciences, Institute of Chemistry, 09107 Chemnitz, Germany.

\#Institut für Chemie und CINSaT, Universität Kassel, Heinrich-Plett-Strasse 40, 34132

Kassel, Germany.

aDeceased 09/2020.

E-mail: p.klahn@tu-braunschweig.de,m.kagho@tu-braunschweig.de 


\section{Table of Contents}

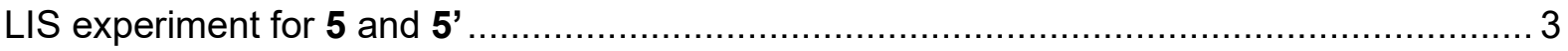

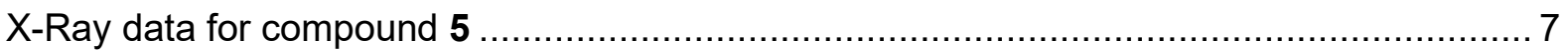

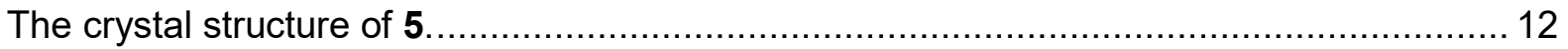

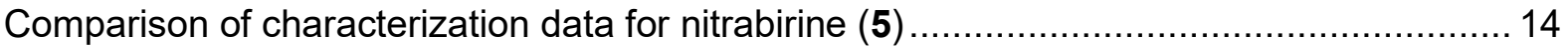

Table S5: Comparison table of characterization data for nitrabirine (5)......................... 14

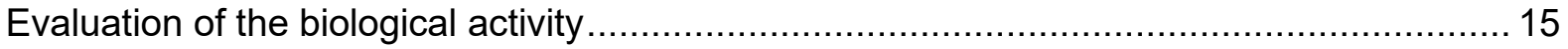

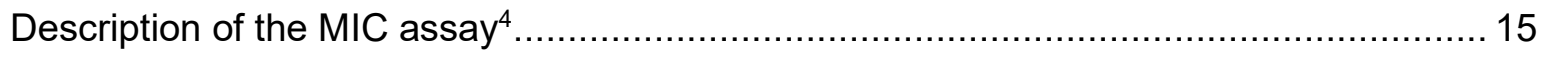

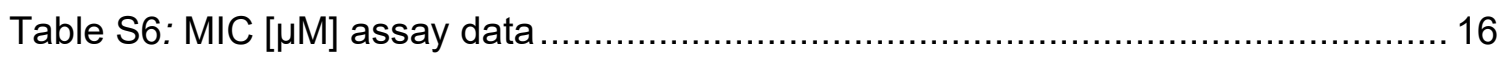

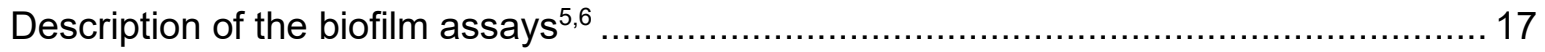

Table S7: Biofilms and preformed biofilm inhibition of $S$. aureus and biofilm inhibition of

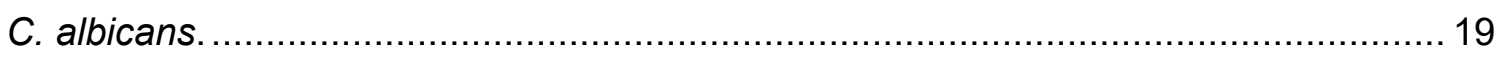

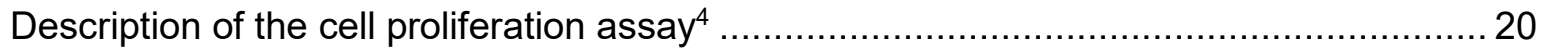

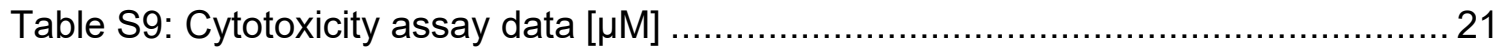

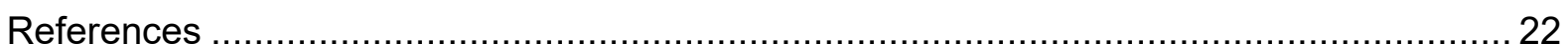

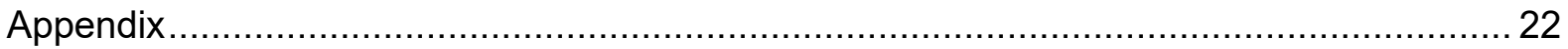

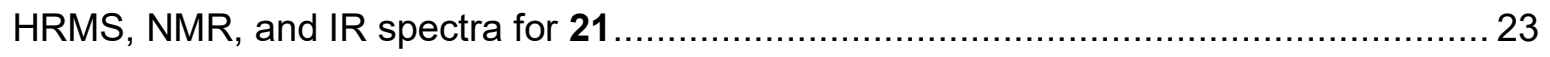

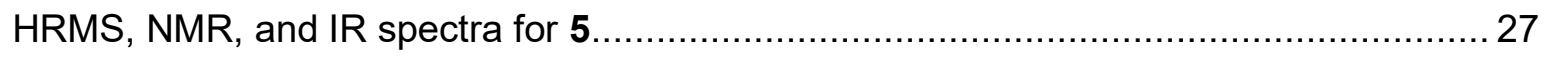

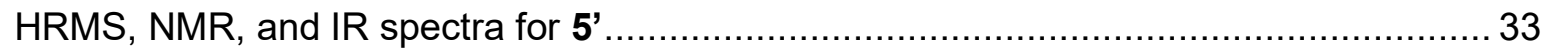

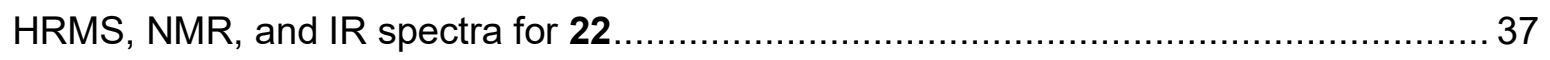

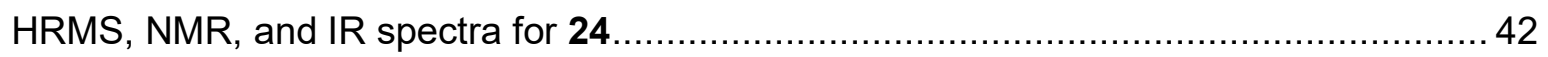

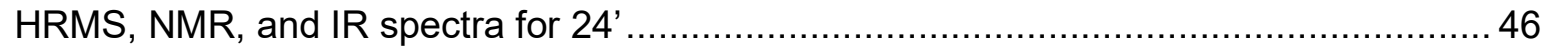

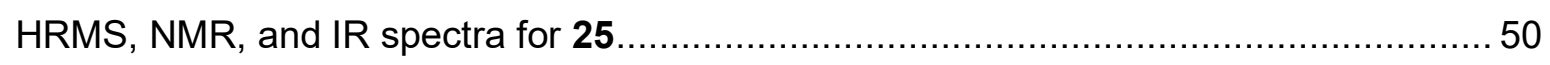

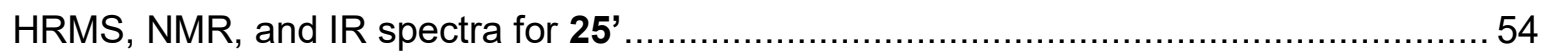

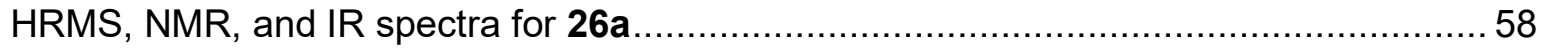

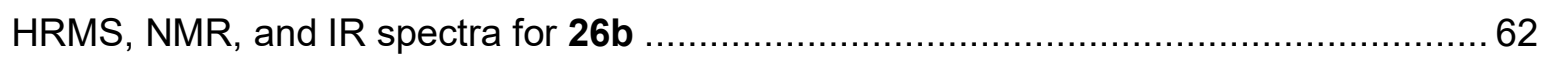

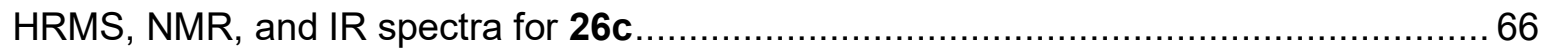

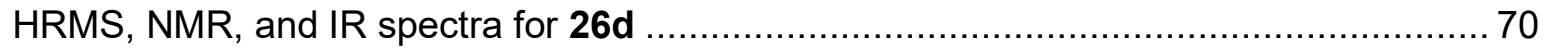




\section{LIS experiment for 5 and 5 '}

Table S1: Data collected and calculated from the LIS experiment for nitrabirine (5)

\begin{tabular}{|c|c|c|c|c|c|c|c|c|c|}
\hline \multirow[t]{2}{*}{ Entry } & \multirow{2}{*}{$\begin{array}{l}\text { Volume of } \\
\text { Eu(fod })_{3} \\
(\mu L)\end{array}$} & \multirow{2}{*}{$\begin{array}{c}\text { Moles } \\
\text { of } \\
\text { Eu(fod) } 3 \\
\text { (umol) }\end{array}$} & \multirow{2}{*}{$\frac{n\left(E u(f o d)_{3}\right)}{n(\text { nitrabirine }(5))}$} & \multicolumn{6}{|c|}{ Chemical shift differences ${ }^{1} \mathrm{H} \Delta \delta(\mathrm{ppm})$} \\
\hline & & & & 2'-H & $3^{\prime}-\mathrm{H}$ & $5 \cdot \mathrm{a}-\mathrm{H}$ & $5^{\prime} \mathrm{b}-\mathrm{H}$ & $2-\mathrm{H}$ & $\mathrm{HoH}$ \\
\hline 1 & 0 & 0.000 & 0.000 & 0.000 & 0.000 & 0.000 & 0.000 & 0.000 & 0.000 \\
\hline 2 & 5 & 1.000 & 0.020 & 0.060 & 0.010 & 0.030 & 0.010 & 0.200 & 0.360 \\
\hline 3 & 9 & 1.800 & 0.036 & 0.140 & 0.020 & 0.050 & 0.030 & 0.400 & 0.690 \\
\hline 4 & 13 & 2.600 & 0.052 & 0.220 & 0.040 & 0.090 & 0.040 & 0.640 & 1.080 \\
\hline 5 & 17 & 3.400 & 0.068 & 0.280 & 0.050 & 0.110 & 0.060 & 0.830 & 1.440 \\
\hline 6 & 21 & 4.200 & 0.084 & 0.340 & 0.060 & 0.130 & 0.070 & 0.980 & 1.690 \\
\hline 7 & 25 & 5.000 & 0.100 & 0.390 & 0.070 & 0.160 & 0.080 & 1.160 & 1.990 \\
\hline 8 & 31 & 6.200 & 0.124 & 0.490 & 0.090 & 0.190 & 0.090 & 1.470 & 2.490 \\
\hline 9 & 39 & 7.800 & 0.156 & 0.630 & 0.120 & 0.250 & 0.120 & 1.880 & 3.200 \\
\hline 10 & 47 & 9.400 & 0.188 & 0.750 & 0.140 & 0.300 & 0.150 & 2.300 & 3.870 \\
\hline
\end{tabular}

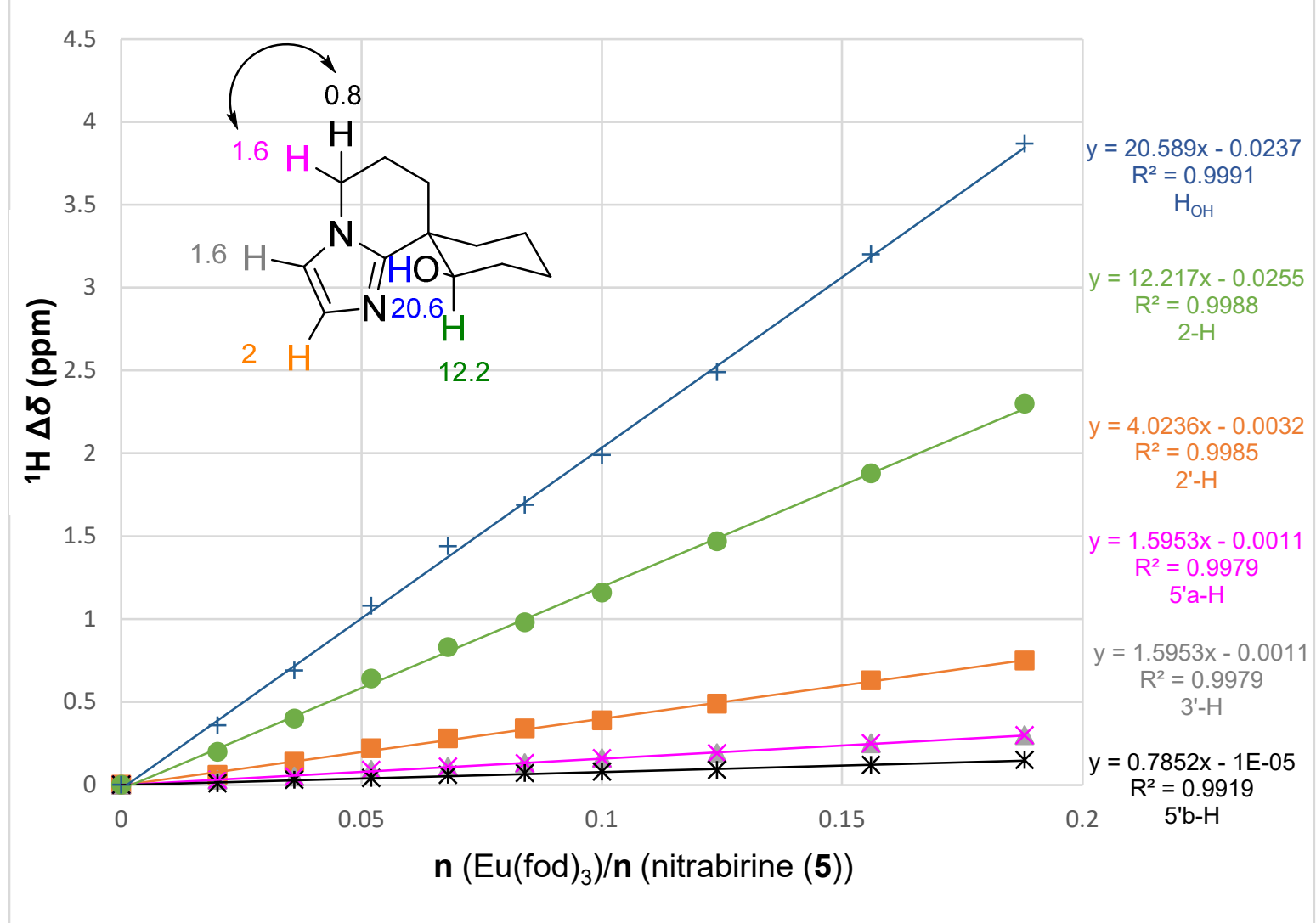

Figure S1: Europium-shift influence on protons of 5; Plot ${ }^{1} \mathrm{H} \Delta \delta(\mathrm{ppm})$ vs $\mathrm{n}\left(\mathrm{Eu}(\mathrm{fod})_{3}\right) / \mathrm{n}$ (nitrabirine (5)). 
D
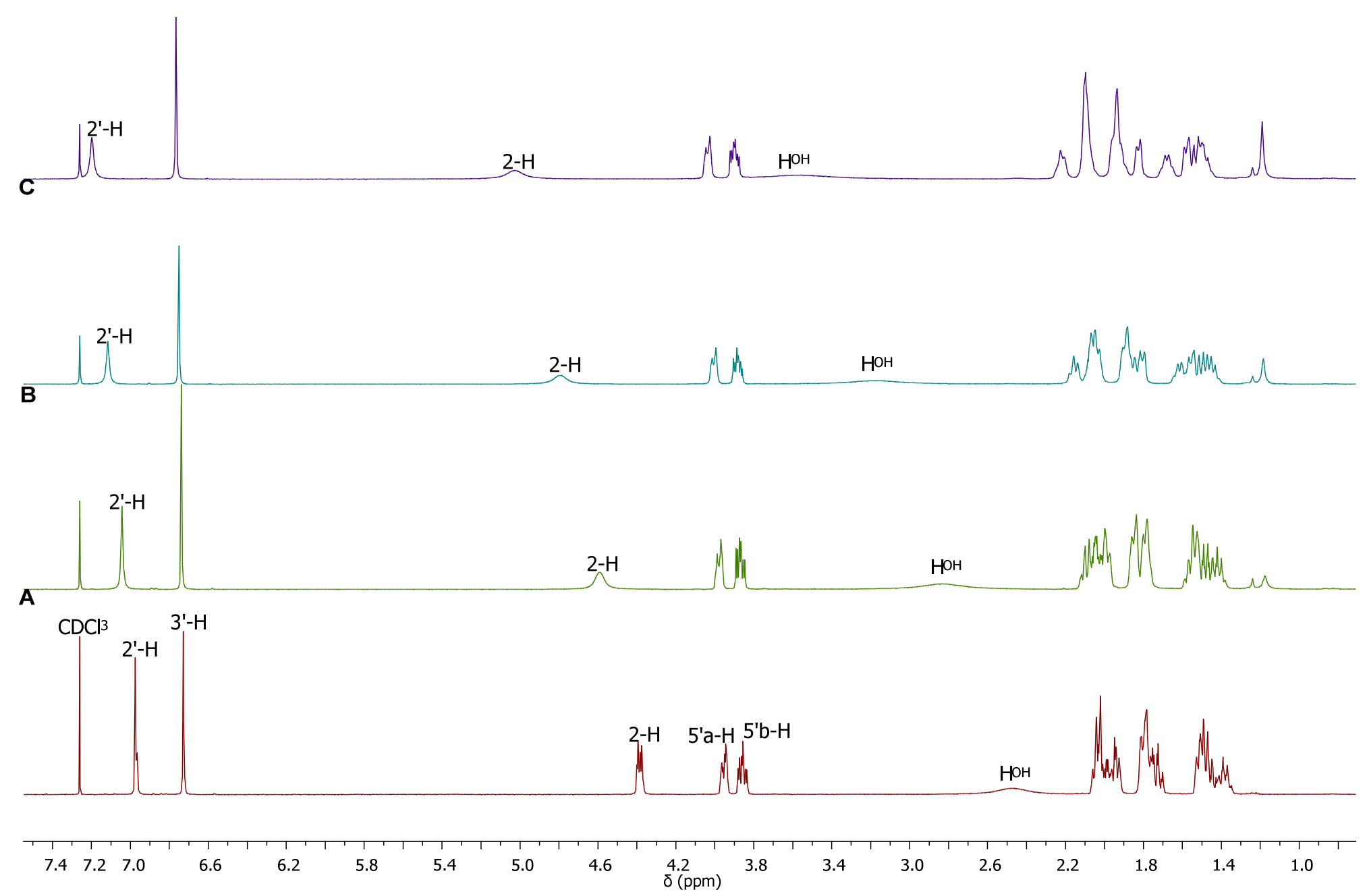

Figure S2: Some ${ }^{1} \mathrm{H} \mathrm{NMR}\left(\mathrm{CDCl}_{3}, 600 \mathrm{MHz}\right)$ spectra collected from the LIS experiment of $\mathbf{5} . \mathbf{A}=\mathbf{5}$ in $\mathrm{CDCl}_{3} ; \mathbf{B}=\mathbf{5}+5.0 \mu \mathrm{L}$ of Eu(fod $)_{3}(0.2 \mathrm{M}$ in $\left.\mathrm{CDCl}_{3}\right) ; \mathbf{C}=\mathbf{5}+9.0 \mu \mathrm{L}$ of Eu(fod) $)_{3}\left(0.2 \mathrm{M}\right.$ in $\left.\mathrm{CDCl}_{3}\right) ; \mathbf{D}=\mathbf{5}+13.0 \mu \mathrm{L}$ of $\mathrm{Eu}(\text { fod })_{3}\left(0.2 \mathrm{M}\right.$ in $\left.\mathrm{CDCl}_{3}\right)$. 
Table S2: Data collected and calculated from the LIS experiment 5'

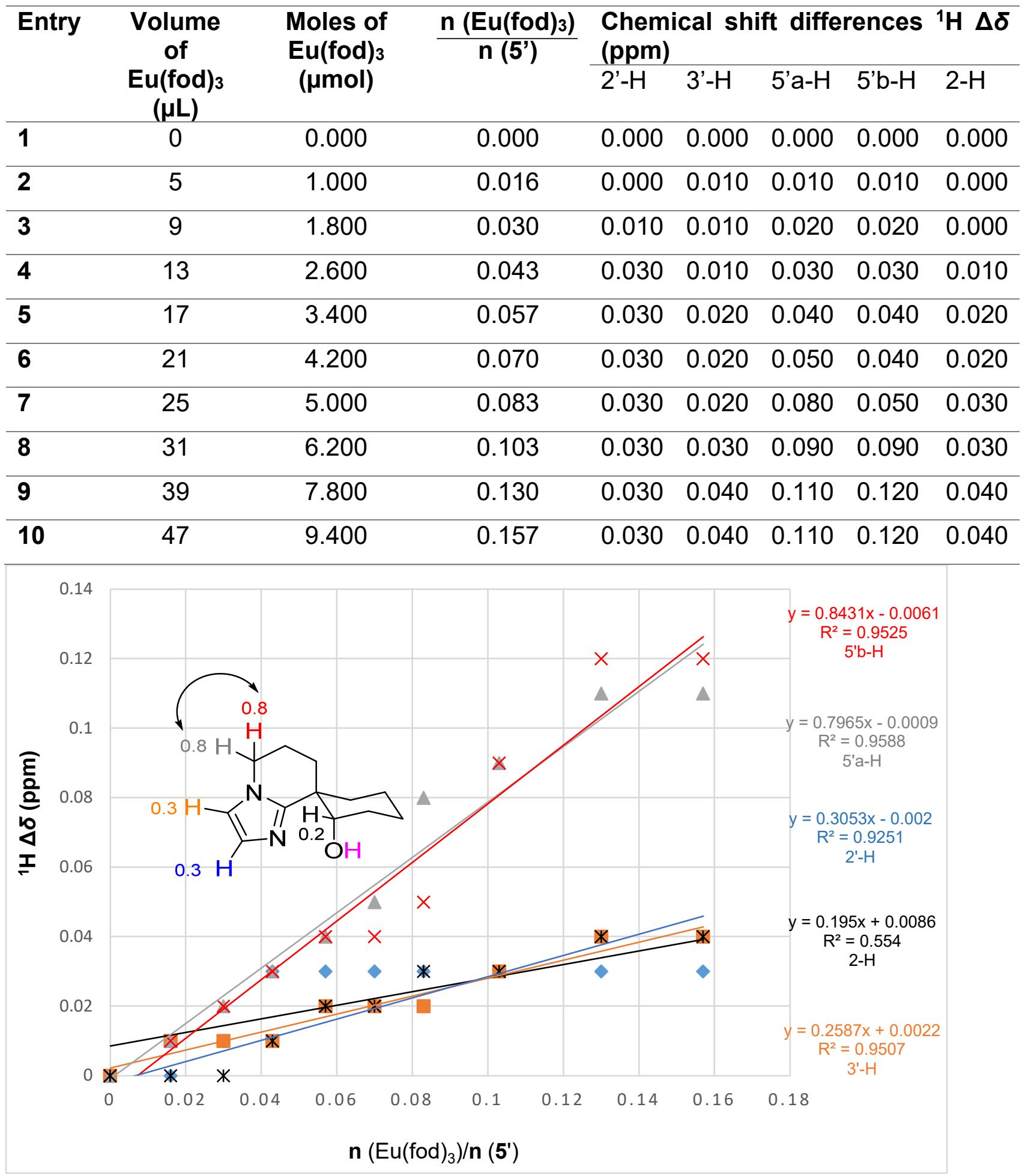

Figure S3: Europium-shift influence on protons of 5'; Plot ${ }^{1} \mathrm{H} \Delta \delta(\mathrm{ppm})$ vs $\mathrm{n}\left(\mathrm{Eu}(\mathrm{fod})_{3}\right) / \mathrm{n}\left(\mathbf{5}^{\prime}\right)$. 
D
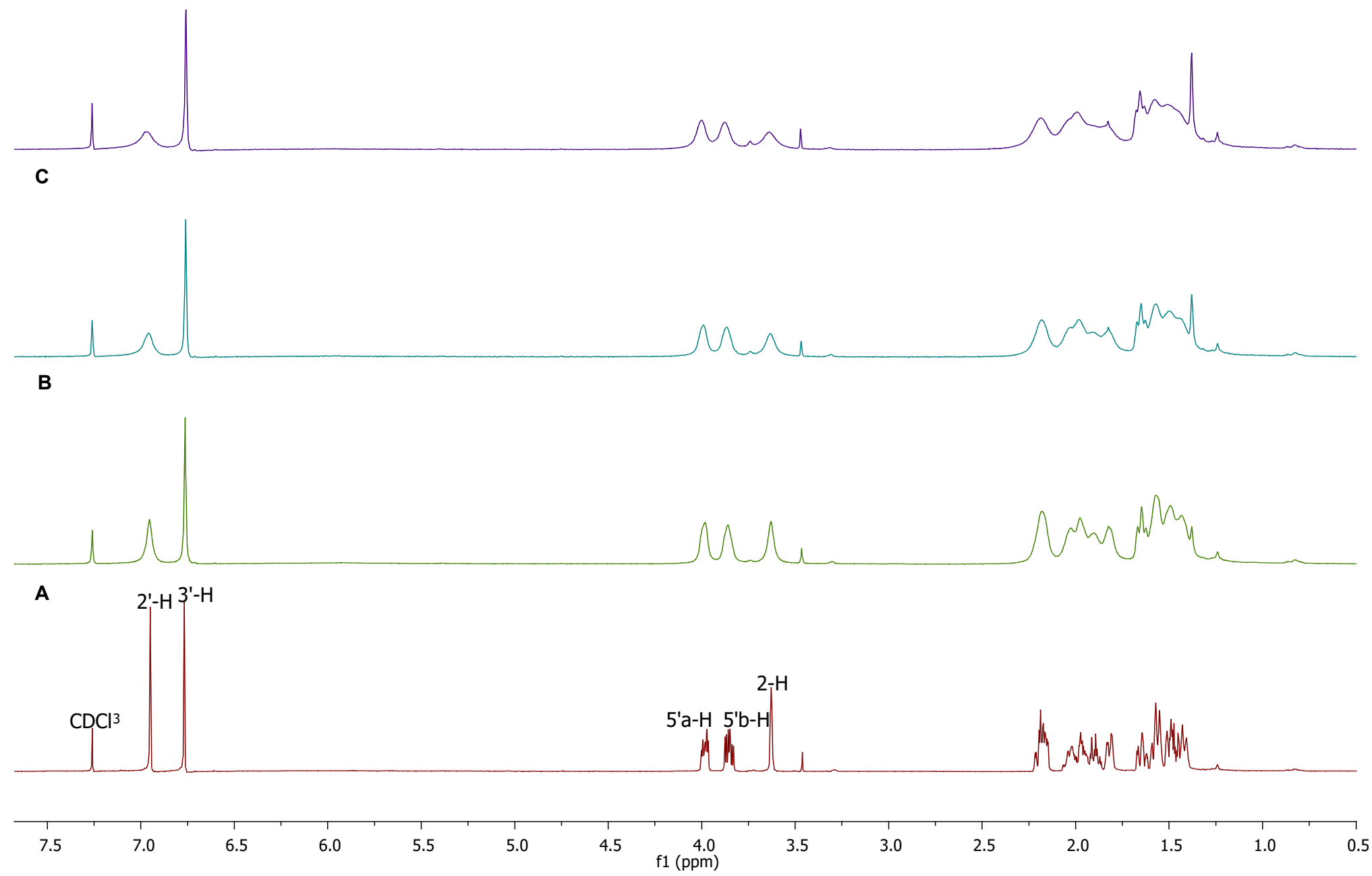

Figure S4: Some ${ }^{1} \mathrm{H}$ NMR $\left(\mathrm{CDCl}_{3}, 600 \mathrm{MHz}\right)$ spectra collected from the LIS experiment of $\mathbf{5}^{\prime}$. $\mathbf{A}=\mathbf{5}^{\prime}$ in $\mathrm{CDCl}_{3} ; \mathbf{B}=\mathbf{5}^{\prime}+5.0 \mu \mathrm{L}$ of Eu(fod $)_{3}(0.2 \mathrm{M}$ in $\left.\mathrm{CDCl}_{3}\right) ; \mathbf{C}=\mathbf{5}^{\prime}+9.0 \mu \mathrm{L}$ of Eu(fod) $)_{3}\left(0.2 \mathrm{M}\right.$ in $\left.\mathrm{CDCl}_{3}\right) ; \mathbf{D}=\mathbf{5}^{\prime}+13.0 \mu \mathrm{L}$ of $\mathrm{Eu}(\mathrm{fod})_{3}\left(0.2 \mathrm{M}\right.$ in $\left.\mathrm{CDCl}_{3}\right)$. 


\section{X-Ray data for compound 5}

\section{Single-crystal X-ray diffraction analyses - Technical details}

A suitable crystal of 5 with measures of $0.36 \times 0.34 \times 0.3$ was selected and mounted in Krytox® on an Rigaku-Oxford Gemini S diffractometer by choosing graphite monochromated Mo Ka radiation $(\lambda=0.71073 \AA)$ at $\mathrm{T}=100 \mathrm{~K}$. The structure was solved by Direct Methods implemented within SHELXS-2013 (Sheldrick 2008, Version 2013/1) ${ }^{1}$ using the WinGX software platform (Farrugia 2012, Version 2014.1)2. The model was refined with SHELXL-2013 (Sheldrick 2008, Version 2013/4) ${ }^{1}$, whereby all non-hydrogen atoms were refined anisotropically. The atoms $\mathrm{C} 5$ and $\mathrm{C} 12$ and their accompanying hydrogen atoms are disordered and were refined to split occupancies of $0.778 / 0.222$ for C5/C12 and C5'/C12'. All hydrogen atoms were refined isotropically as riding on their parent carbon atoms. 


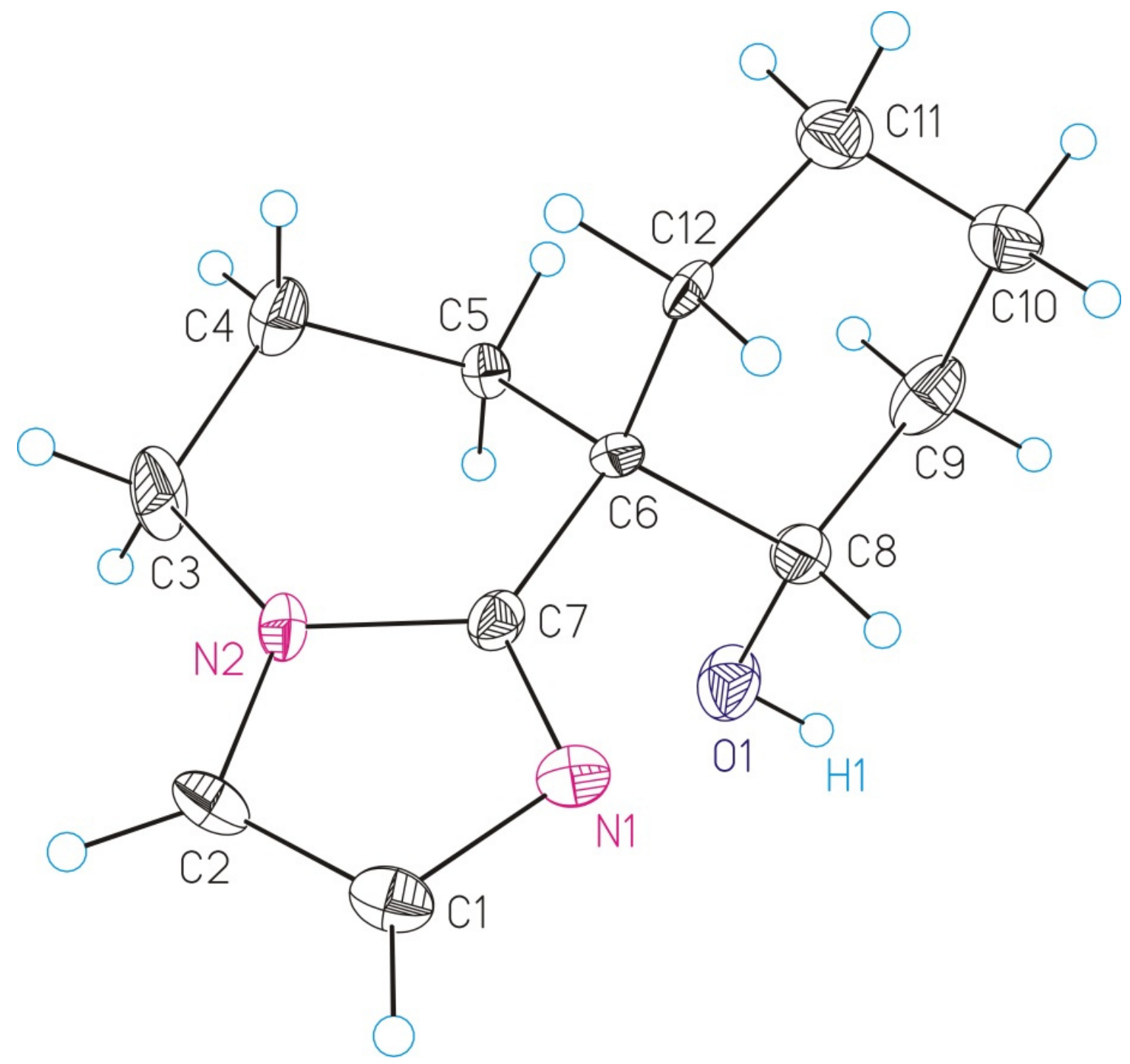

Figure S5: ORTEP diagram (50\% probability ellipsoids) of the molecular structure of 5 . Of disordered atoms only one atomic position is shown. 
Table S3:Table of crystal data and structure refinement for nitrabirine (5)

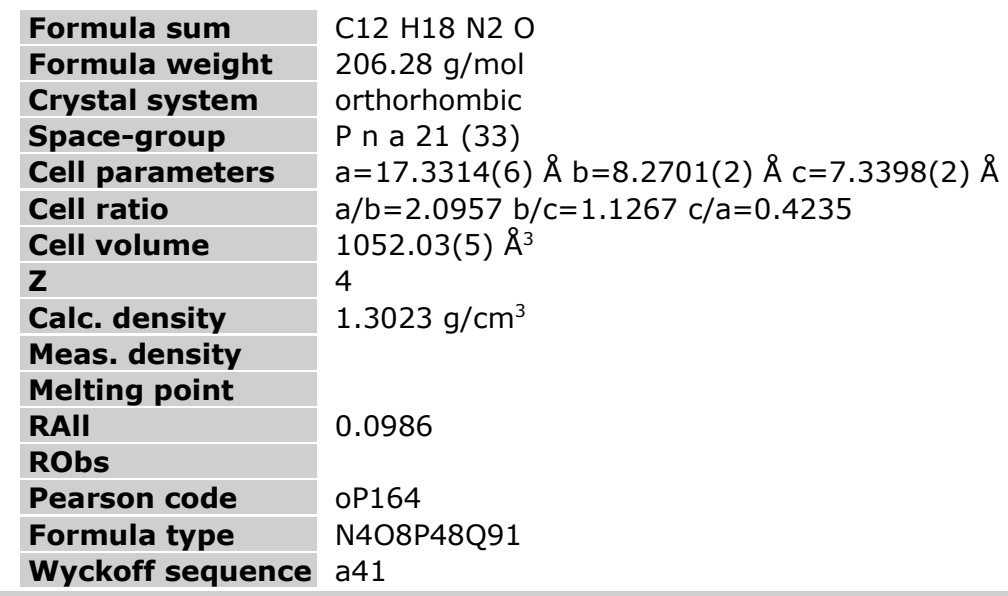

Atomic parameters

\begin{tabular}{|c|c|c|c|c|c|c|c|}
\hline Atom Ox. & Wyck & Site & S.O.F. & $\mathbf{x} / \mathbf{a}$ & y/b & z/c & $\mathbf{U}\left[\AA^{2}\right]$ \\
\hline $\mathrm{O} 1$ & $4 a$ & 1 & & $1.0832(3)$ & $0.1140(6)$ & $0.4255(7)$ & \\
\hline $\mathrm{H} 1$ & $4 a$ & 1 & & 1.08510 & 0.03740 & 0.35470 & 0.0400 \\
\hline $\mathrm{C} 1$ & $4 a$ & 1 & & $0.8878(3)$ & $0.3015(8)$ & $0.7435(9)$ & \\
\hline $\mathrm{H} 1 \mathrm{~A}$ & $4 a$ & 1 & & 0.83550 & 0.27680 & 0.74450 & 0.0230 \\
\hline C2 & $4 a$ & 1 & & $0.9172(4)$ & $0.4534(8)$ & $0.7403(10)$ & \\
\hline $\mathrm{H} 2$ & $4 a$ & 1 & & 0.88950 & 0.54970 & 0.74030 & 0.0250 \\
\hline C3 & $4 a$ & 1 & & $1.0524(4)$ & $0.5671(8)$ & $0.7282(14)$ & \\
\hline H3A & $4 a$ & 1 & & 1.03980 & 0.64840 & 0.81860 & 0.0330 \\
\hline H3B & $4 a$ & 1 & & 1.05020 & 0.61750 & 0.60900 & 0.0330 \\
\hline C4 & $4 a$ & 1 & & $1.1335(4)$ & $0.5042(8)$ & $0.7625(11)$ & \\
\hline $\mathrm{H} 4 \mathrm{~A}$ & $4 a$ & 1 & 0.78 & 1.14180 & 0.49500 & 0.89270 & 0.0290 \\
\hline $\mathrm{H} 4 \mathrm{~B}$ & $4 a$ & 1 & 0.78 & 1.17050 & 0.58140 & 0.71510 & 0.0290 \\
\hline $\mathrm{H} 4 \mathrm{C}$ & $4 a$ & 1 & 0.22 & 1.16230 & 0.52420 & 0.65140 & 0.0290 \\
\hline $\mathrm{H} 4 \mathrm{D}$ & $4 a$ & 1 & 0.22 & 1.15560 & 0.57400 & 0.85480 & 0.0290 \\
\hline C6 & $4 a$ & 1 & & $1.0923(3)$ & $0.2071(7)$ & $0.7417(9)$ & \\
\hline C7 & $4 a$ & 1 & & $1.0112(3)$ & $0.2734(7)$ & $0.7376(9)$ & \\
\hline C8 & $4 a$ & 1 & & $1.0978(4)$ & $0.0587(8)$ & $0.6052(10)$ & \\
\hline $\mathrm{H} 8$ & $4 a$ & 1 & & 1.05730 & -0.01860 & 0.63760 & 0.0260 \\
\hline C9 & $4 a$ & 1 & & $62(4)$ & $-0.0262(10)$ & $0.6293(11)$ & \\
\hline H9A & $4 a$ & 1 & & 790 & 2070 & 0.55110 & 0.0330 \\
\hline H9B & $4 a$ & 1 & & 1.2 & 660 & 0.59070 & 0.0330 \\
\hline $\mathrm{C} 10$ & $4 a$ & 1 & & $1.1913(5)$ & $-0.0781(9)$ & $0.8250(12)$ & \\
\hline $\mathrm{H} 10 \mathrm{~A}$ & $4 a$ & 1 & & 1.15380 & -0.15950 & 0.86010 & 0.0350 \\
\hline $\mathrm{H} 10 \mathrm{~B}$ & $4 a$ & 1 & & 1.24220 & -0.12610 & 0.83340 & 0.0350 \\
\hline C11 & $4 a$ & 1 & & $1.1861(4)$ & $0.0625(9)$ & $0.9531(11)$ & \\
\hline $\mathrm{H} 11 \mathrm{~A}$ & $4 a$ & 1 & & 1.22860 & 0.13600 & 0.92940 & 0.0290 \\
\hline $\mathrm{H} 11 \mathrm{~B}$ & $4 a$ & 1 & & 1.19120 & 0.02380 & 1.07730 & 0.0290 \\
\hline C12 & $4 a$ & 1 & 0.78 & $1.1103(5)$ & $0.1538(12)$ & $0.9338(12)$ & \\
\hline $\mathrm{H} 12 \mathrm{~A}$ & $4 a$ & 1 & 0.78 & 1.06870 & 0.08500 & 0.97670 & 0.0160 \\
\hline H12B & $4 a$ & 1 & 0.78 & 1.11190 & 0.24840 & 1.01170 & 0.0160 \\
\hline C5 & $4 a$ & 1 & 0.78 & $1.1476(4)$ & $0.3402(9)$ & $0.6741(12)$ & \\
\hline H5A & $4 a$ & 1 & 0.78 & 1.20030 & 0.30710 & 0.69870 & 0.0140 \\
\hline H5B & $4 a$ & 1 & 0.78 & 1.14 & 5110 & 0.54310 & 0.0140 \\
\hline C12' & $4 a$ & 1 & & $2(16)$ & & $8(4)$ & \\
\hline $\mathrm{H} 12 \mathrm{C}$ & $4 a$ & 1 & 0.22 & 1.08430 & 0.18250 & 1.02800 & 0.032 \\
\hline$H 12 D$ & $4 a$ & 1 & 0.22 & 1.06740 & 0.01840 & 0.92730 & 0.0320 \\
\hline C5' & $4 a$ & 1 & 0.22 & $1.150(2)$ & $0.352(4)$ & $0.813(6)$ & \\
\hline H5'1 & $4 a$ & 1 & 0.22 & 1.15180 & 0.34840 & 0.94490 & 0.0360 \\
\hline H5'2 & $4 a$ & 1 & 0.22 & 1.20210 & 0.32740 & 0.76980 & 0.0360 \\
\hline N1 & $4 a$ & 1 & & $0.9468(3)$ & $0.1883(6)$ & $0.7452(9)$ & \\
\hline N2 & $4 a$ & 1 & & $0.9963(3)$ & $0.4365(6)$ & $0.7371(9)$ & \\
\hline
\end{tabular}




\begin{tabular}{c|llllll} 
Atom & \multicolumn{1}{c}{$\mathbf{U}_{\mathbf{1 1}}$} & \multicolumn{1}{c}{$\mathbf{U}_{\mathbf{2 2}}$} & \multicolumn{1}{c}{$\mathbf{U}_{\mathbf{3 3}}$} & \multicolumn{1}{c}{$\mathbf{U}_{\mathbf{1 2}}$} & \multicolumn{1}{c}{$\mathbf{U}_{\mathbf{1 3}}$} & \multicolumn{1}{c}{$\mathbf{U}_{\mathbf{2 3}}$} \\
O1 & $0.038(3)$ & $0.021(2)$ & $0.021(2)$ & $0.001(2)$ & $-0.002(2)$ & $-0.003(2)$ \\
C1 & $0.014(3)$ & $0.029(3)$ & $0.015(3)$ & $0.002(2)$ & $0.002(3)$ & $0.001(3)$ \\
C2 & $0.017(3)$ & $0.025(3)$ & $0.020(3)$ & $0.005(2)$ & $-0.004(3)$ & $0.006(3)$ \\
C3 & $0.026(3)$ & $0.011(3)$ & $0.045(4)$ & $-0.001(3)$ & $0.008(3)$ & $0.011(3)$ \\
C4 & $0.027(3)$ & $0.016(3)$ & $0.030(4)$ & $-0.003(3)$ & $0.003(3)$ & $-0.003(3)$ \\
C6 & $0.012(3)$ & $0.013(2)$ & $0.018(3)$ & $-0.002(2)$ & $-0.005(3)$ & $0.000(3)$ \\
C7 & $0.020(3)$ & $0.012(3)$ & $0.015(3)$ & $-0.003(2)$ & $-0.002(3)$ & $0.001(3)$ \\
C8 & $0.023(3)$ & $0.019(3)$ & $0.023(3)$ & $0.004(3)$ & $-0.006(3)$ & $-0.006(3)$ \\
C9 & $0.025(3)$ & $0.026(4)$ & $0.031(4)$ & $-0.008(3)$ & $0.009(3)$ & $-0.009(3)$ \\
C10 & $0.023(4)$ & $0.026(4)$ & $0.037(4)$ & $-0.001(3)$ & $-0.008(3)$ & $0.004(3)$ \\
C11 & $0.023(3)$ & $0.025(3)$ & $0.025(3)$ & $-0.004(3)$ & $-0.004(3)$ & $0.005(3)$ \\
C12 & $0.017(4)$ & $0.009(4)$ & $0.014(4)$ & $-0.005(3)$ & $0.000(3)$ & $-0.002(3)$ \\
C5 & $0.010(4)$ & $0.012(4)$ & $0.013(4)$ & $0.001(3)$ & $0.004(3)$ & $0.000(3)$ \\
C12' & $0.02(1)$ & $0.029(13)$ & $0.032(9)$ & $0.001(8)$ & $-0.008(7)$ & $0.011(8)$ \\
C5' & $0.030(15)$ & $0.021(10)$ & $0.04(2)$ & $-0.004(10)$ & $-0.022(13)$ & $0.003(10)$ \\
N1 & $0.016(2)$ & $0.021(3)$ & $0.013(2)$ & $-0.002(2)$ & $0.001(2)$ & $-0.001(3)$ \\
N2 & $0.019(3)$ & $0.012(2)$ & $0.023(3)$ & $0.0034(19)$ & $0.000(2)$ & $-0.004(2)$
\end{tabular}

\section{Selected geometric informations}

\begin{tabular}{|c|c|c|c|}
\hline Atoms 1,2 & d $1,2[\AA]$ & Atoms 1,2 & d $1,2[\AA]$ \\
\hline $\mathrm{O} 1-\mathrm{C} 8$ & $1.419(9)$ & $\mathrm{C} 7-\mathrm{N} 1$ & $1.321(8)$ \\
\hline $\mathrm{O} 1-\mathrm{H} 1$ & 0.8200 & $\mathrm{C} 7-\mathrm{N} 2$ & $1.373(7)$ \\
\hline $\mathrm{C} 1-\mathrm{C} 2$ & $1.355(9)$ & $\mathrm{C} 8-\mathrm{C} 9$ & $1.539(10)$ \\
\hline $\mathrm{C} 1-\mathrm{N} 1$ & $1.387(8)$ & $\mathrm{C} 8-\mathrm{H} 8$ & 0.9800 \\
\hline $\mathrm{C} 1-\mathrm{H} 1 \mathrm{~A}$ & 0.9300 & C9-C10 & $1.521(11)$ \\
\hline $\mathrm{C} 2-\mathrm{N} 2$ & $1.379(8)$ & С9-H9A & 0.9700 \\
\hline $\mathrm{C} 2-\mathrm{H}_{2}$ & 0.9300 & С9-H9B & 0.9700 \\
\hline $\mathrm{C} 3-\mathrm{N} 2$ & $1.454(8)$ & C10-C11 & $1.498(11)$ \\
\hline C3-C4 & $1.519(10)$ & $\mathrm{C} 10-\mathrm{H} 10 \mathrm{~A}$ & 0.9700 \\
\hline $\mathrm{C} 3-\mathrm{H} 3 \mathrm{~A}$ & 0.9700 & $\mathrm{C} 10-\mathrm{H} 10 \mathrm{~B}$ & 0.9700 \\
\hline $\mathrm{C} 3-\mathrm{H} 3 \mathrm{~B}$ & 0.9700 & $\mathrm{C} 11-\mathrm{C} 12$ & $1.522(10)$ \\
\hline $\mathrm{C} 4-\mathrm{C5}^{\prime}$ & $1.34(3)$ & C11-C12' & $1.56(2)$ \\
\hline C4-C5 & $1.523(10)$ & $\mathrm{C} 11-\mathrm{H} 11 \mathrm{~A}$ & 0.9700 \\
\hline $\mathrm{C} 4-\mathrm{H} 4 \mathrm{~A}$ & 0.9700 & $\mathrm{C} 11-\mathrm{H} 11 \mathrm{~B}$ & 0.9700 \\
\hline $\mathrm{C} 4-\mathrm{H} 4 \mathrm{~B}$ & 0.9700 & $\mathrm{C} 12-\mathrm{H} 12 \mathrm{~A}$ & 0.9700 \\
\hline $\mathrm{C} 4-\mathrm{H} 4 \mathrm{C}$ & 0.9700 & $\mathrm{C} 12-\mathrm{H} 12 \mathrm{~B}$ & 0.9700 \\
\hline C4-H4D & 0.9700 & $\mathrm{C} 5-\mathrm{H} 5 \mathrm{~A}$ & 0.9700 \\
\hline C6-C7 & $1.508(8)$ & C5-H5B & 0.9700 \\
\hline $\mathrm{C} 6-\mathrm{C} 12$ & $1.510(11)$ & $\mathrm{C} 12^{\prime}-\mathrm{H} 12 \mathrm{C}$ & 0.9700 \\
\hline C6-C5 & $1.542(9)$ & $\mathrm{C} 12^{\prime}-\mathrm{H} 12 \mathrm{D}$ & 0.9700 \\
\hline C6-C12' & $1.58(2)$ & $\mathrm{C} 5^{\prime}-\mathrm{H} 5^{\prime} 1$ & 0.9700 \\
\hline $\mathrm{C} 6-\mathrm{C} 8$ & $1.587(9)$ & $\mathrm{C}^{\prime}-\mathrm{H} 5^{\prime} 2$ & 0.9700 \\
\hline C6-C5' & $1.65(3)$ & & \\
\hline
\end{tabular}

\begin{tabular}{|c|c|c|c|}
\hline Atoms 1,2,3 & Angle $1,2,3\left[^{\circ}\right]$ & Atoms 1,2,3 & Angle 1,2,3 $\left[^{\circ}\right]$ \\
\hline $\mathrm{C} 8-\mathrm{O} 1-\mathrm{H} 1$ & 109.500 & $\mathrm{C} 10-\mathrm{C} 9-\mathrm{H} 9 \mathrm{~A}$ & 109.000 \\
\hline $\mathrm{C} 2-\mathrm{C} 1-\mathrm{N} 1$ & $110.4(5)$ & C8-C9-H9A & 109.000 \\
\hline $\mathrm{C} 2-\mathrm{C} 1-\mathrm{H} 1 \mathrm{~A}$ & 124.800 & $\mathrm{C} 10-\mathrm{C} 9-\mathrm{H} 9 \mathrm{~B}$ & 109.000 \\
\hline $\mathrm{N} 1-\mathrm{C} 1-\mathrm{H} 1 \mathrm{~A}$ & 124.800 & $\mathrm{C} 8-\mathrm{C} 9-\mathrm{H} 9 \mathrm{~B}$ & 109.000 \\
\hline $\mathrm{C} 1-\mathrm{C} 2-\mathrm{N} 2$ & $106.3(5)$ & $\mathrm{H} 9 \mathrm{~A}-\mathrm{C} 9-\mathrm{H} 9 \mathrm{~B}$ & 107.800 \\
\hline $\mathrm{C} 1-\mathrm{C} 2-\mathrm{H} 2$ & 126.800 & $\mathrm{C} 11-\mathrm{C} 10-\mathrm{C} 9$ & $111.3(6)$ \\
\hline $\mathrm{N} 2-\mathrm{C} 2-\mathrm{H} 2$ & 126.800 & $\mathrm{C} 11-\mathrm{C} 10-\mathrm{H} 10 \mathrm{~A}$ & 109.400 \\
\hline $\mathrm{N} 2-\mathrm{C} 3-\mathrm{C} 4$ & $110.9(5)$ & $\mathrm{C} 9-\mathrm{C} 10-\mathrm{H} 10 \mathrm{~A}$ & 109.400 \\
\hline $\mathrm{N} 2-\mathrm{C} 3-\mathrm{H} 3 \mathrm{~A}$ & 109.500 & $\mathrm{C} 11-\mathrm{C} 10-\mathrm{H} 10 \mathrm{~B}$ & 109.400 \\
\hline $\mathrm{C} 4-\mathrm{C} 3-\mathrm{H} 3 \mathrm{~A}$ & 109.500 & $\mathrm{C} 9-\mathrm{C} 10-\mathrm{H} 10 \mathrm{~B}$ & 109.400 \\
\hline $\mathrm{N} 2-\mathrm{C} 3-\mathrm{H} 3 \mathrm{~B}$ & 109.500 & $\mathrm{H} 10 \mathrm{~A}-\mathrm{C} 10-\mathrm{H} 10 \mathrm{~B}$ & 108.000 \\
\hline $\mathrm{C} 4-\mathrm{C} 3-\mathrm{H} 3 \mathrm{~B}$ & 109.500 & $\mathrm{C} 10-\mathrm{C} 11-\mathrm{C} 12$ & $112.2(7)$ \\
\hline $\mathrm{H} 3 \mathrm{~A}-\mathrm{C} 3-\mathrm{H} 3 \mathrm{~B}$ & 108.100 & $\mathrm{C} 10-\mathrm{C} 11-\mathrm{C} 12^{\prime}$ & $101.1(16)$ \\
\hline C5'-C4-C3 & $124.7(16)$ & $\mathrm{C} 10-\mathrm{C} 11-\mathrm{H} 11 \mathrm{~A}$ & 109.200 \\
\hline $\mathrm{C} 3-\mathrm{C} 4-\mathrm{C} 5$ & $112.5(6)$ & $\mathrm{C} 12-\mathrm{C} 11-\mathrm{H} 11 \mathrm{~A}$ & 109.200 \\
\hline $\mathrm{C} 3-\mathrm{C} 4-\mathrm{H} 4 \mathrm{~A}$ & 109.100 & $\mathrm{C} 10-\mathrm{C} 11-\mathrm{H} 11 \mathrm{~B}$ & 109.200 \\
\hline $\mathrm{C} 5-\mathrm{C} 4-\mathrm{H} 4 \mathrm{~A}$ & 109.100 & $\mathrm{C} 12-\mathrm{C} 11-\mathrm{H} 11 \mathrm{~B}$ & 109.200 \\
\hline $\mathrm{C} 3-\mathrm{C} 4-\mathrm{H} 4 \mathrm{~B}$ & 109.100 & $\mathrm{H} 11 \mathrm{~A}-\mathrm{C} 11-\mathrm{H} 11 \mathrm{~B}$ & 107.900 \\
\hline $\mathrm{C} 5-\mathrm{C} 4-\mathrm{H} 4 \mathrm{~B}$ & 109.100 & $\mathrm{C} 6-\mathrm{C} 12-\mathrm{C} 11$ & $114.2(7)$ \\
\hline $\mathrm{H} 4 \mathrm{~A}-\mathrm{C} 4-\mathrm{H} 4 \mathrm{~B}$ & 107.800 & $\mathrm{C} 6-\mathrm{C} 12-\mathrm{H} 12 \mathrm{~A}$ & 108.700 \\
\hline
\end{tabular}




\begin{tabular}{|c|c|c|c|}
\hline $\mathrm{C}^{\prime}-\mathrm{C} 4-\mathrm{H} 4 \mathrm{C}$ & 106.200 & $\mathrm{C} 11-\mathrm{C} 12-\mathrm{H} 12 \mathrm{~A}$ & 108.700 \\
\hline $\mathrm{C} 3-\mathrm{C} 4-\mathrm{H} 4 \mathrm{C}$ & 106.200 & $\mathrm{C} 6-\mathrm{C} 12-\mathrm{H} 12 \mathrm{~B}$ & 108.700 \\
\hline $\mathrm{C} 5^{\prime}-\mathrm{C} 4-\mathrm{H} 4 \mathrm{D}$ & 106.200 & $\mathrm{C} 11-\mathrm{C} 12-\mathrm{H} 12 \mathrm{~B}$ & 108.700 \\
\hline $\mathrm{C} 3-\mathrm{C} 4-\mathrm{H} 4 \mathrm{D}$ & 106.200 & $\mathrm{H} 12 \mathrm{~A}-\mathrm{C} 12-\mathrm{H} 12 \mathrm{~B}$ & 107.600 \\
\hline $\mathrm{H} 4 \mathrm{C}-\mathrm{C} 4-\mathrm{H} 4 \mathrm{D}$ & 106.400 & $\mathrm{C} 4-\mathrm{C} 5-\mathrm{C} 6$ & $113.5(6)$ \\
\hline C7-C6-C12 & $108.5(6)$ & $\mathrm{C} 4-\mathrm{C} 5-\mathrm{H} 5 \mathrm{~A}$ & 108.900 \\
\hline $\mathrm{C} 7-\mathrm{C} 6-\mathrm{C} 5$ & $108.2(5)$ & $\mathrm{C} 6-\mathrm{C} 5-\mathrm{H} 5 \mathrm{~A}$ & 108.900 \\
\hline $\mathrm{C} 12-\mathrm{C} 6-\mathrm{C} 5$ & $112.4(6)$ & $\mathrm{C} 4-\mathrm{C} 5-\mathrm{H} 5 \mathrm{~B}$ & 108.900 \\
\hline $\mathrm{C} 7-\mathrm{C} 6-\mathrm{C} 12^{\prime}$ & $106.1(10)$ & $\mathrm{C} 6-\mathrm{C} 5-\mathrm{H} 5 \mathrm{~B}$ & 108.900 \\
\hline $\mathrm{C} 7-\mathrm{C} 6-\mathrm{C} 8$ & $109.0(5)$ & $\mathrm{H} 5 \mathrm{~A}-\mathrm{C} 5-\mathrm{H} 5 \mathrm{~B}$ & 107.700 \\
\hline $\mathrm{C} 12-\mathrm{C} 6-\mathrm{C} 8$ & $110.6(5)$ & $\mathrm{C} 11-\mathrm{C} 12^{\prime}-\mathrm{C} 6$ & $108.5(17)$ \\
\hline $\mathrm{C} 5-\mathrm{C} 6-\mathrm{C} 8$ & $108.1(6)$ & $\mathrm{C} 11-\mathrm{C} 12^{\prime}-\mathrm{H} 12 \mathrm{C}$ & 110.000 \\
\hline $\mathrm{C} 12^{\prime}-\mathrm{C} 6-\mathrm{C} 8$ & $99.4(16)$ & $\mathrm{C} 6-\mathrm{C} 12^{\prime}-\mathrm{H} 12 \mathrm{C}$ & 110.000 \\
\hline $\mathrm{C} 7-\mathrm{C} 6-\mathrm{C5}^{\prime}$ & $108.1(14)$ & $\mathrm{C} 11-\mathrm{C} 12^{\prime}-\mathrm{H} 12 \mathrm{D}$ & 110.000 \\
\hline $\mathrm{C} 12^{\prime}-\mathrm{C} 6-\mathrm{C} 5^{\prime}$ & $91.7(18)$ & $\mathrm{C} 6-\mathrm{C} 12^{\prime}-\mathrm{H} 12 \mathrm{D}$ & 110.000 \\
\hline $\mathrm{C} 8-\mathrm{C} 6-\mathrm{C}^{\prime}$ & $136.4(16)$ & $\mathrm{H} 12 \mathrm{C}-\mathrm{C} 12^{\prime}-\mathrm{H} 12 \mathrm{D}$ & 108.400 \\
\hline $\mathrm{N} 1-\mathrm{C} 7-\mathrm{N} 2$ & $111.4(5)$ & $\mathrm{C} 4-\mathrm{C} 5^{\prime}-\mathrm{C} 6$ & $117 .(2)$ \\
\hline $\mathrm{N} 1-\mathrm{C} 7-\mathrm{C} 6$ & $126.3(5)$ & $\mathrm{C} 4-\mathrm{C} 5^{\prime}-\mathrm{H} 5^{\prime} 1$ & 108.000 \\
\hline $\mathrm{N} 2-\mathrm{C} 7-\mathrm{C} 6$ & $122.2(5)$ & $\mathrm{C} 6-\mathrm{C} 5^{\prime}-\mathrm{H} 5^{\prime} 1$ & 108.000 \\
\hline $\mathrm{O} 1-\mathrm{C} 8-\mathrm{C} 9$ & $114.3(6)$ & $\mathrm{C} 4-\mathrm{C} 5{ }^{\prime}-\mathrm{H} 5{ }^{\prime} 2$ & 108.000 \\
\hline $\mathrm{O} 1-\mathrm{C} 8-\mathrm{C} 6$ & $109.1(5)$ & $\mathrm{C} 6-\mathrm{C}^{\prime}-\mathrm{H}^{\prime} 2$ & 108.000 \\
\hline $\mathrm{C} 9-\mathrm{C} 8-\mathrm{C} 6$ & $109.5(5)$ & $\mathrm{H}^{\prime} 1-\mathrm{C}^{\prime}-\mathrm{H}^{\prime} 2$ & 107.200 \\
\hline $\mathrm{O} 1-\mathrm{C} 8-\mathrm{H} 8$ & 107.900 & $\mathrm{C} 7-\mathrm{N} 1-\mathrm{C} 1$ & $105.3(5)$ \\
\hline $\mathrm{C} 9-\mathrm{C} 8-\mathrm{H} 8$ & 107.900 & $\mathrm{C} 7-\mathrm{N} 2-\mathrm{C} 2$ & $106.6(5)$ \\
\hline $\mathrm{C} 6-\mathrm{C} 8-\mathrm{H} 8$ & 107.900 & $\mathrm{C} 7-\mathrm{N} 2-\mathrm{C} 3$ & $127.2(5)$ \\
\hline $\mathrm{C} 10-\mathrm{C} 9-\mathrm{C} 8$ & $112.9(6)$ & $\mathrm{C} 2-\mathrm{N} 2-\mathrm{C} 3$ & $126.2(5)$ \\
\hline
\end{tabular}

\begin{tabular}{|c|c|c|c|}
\hline Atoms 1,2,3,4 & Tors. an. 1,2,3,4 [ $\left.{ }^{\circ}\right]$ & Atoms 1,2,3,4 & Tors. an. 1,2,3,4 $\left[^{\circ}\right]$ \\
\hline $\mathrm{N} 1-\mathrm{C} 1-\mathrm{C} 2-\mathrm{N} 2$ & $0.9(9)$ & $\mathrm{C} 12^{\prime}-\mathrm{C} 11-\mathrm{C} 12-\mathrm{C} 6$ & $5-93 .(5)$ \\
\hline $\mathrm{N} 2-\mathrm{C} 3-\mathrm{C} 4-\mathrm{C}^{\prime}$ & $-6 .(3)$ & $\mathrm{C}^{\prime}-\mathrm{C} 4-\mathrm{C} 5-\mathrm{C} 6$ & $58 .(2)$ \\
\hline $\mathrm{N} 2-\mathrm{C} 3-\mathrm{C} 4-\mathrm{C} 5$ & 39.(1) & $\mathrm{C} 3-\mathrm{C} 4-\mathrm{C} 5-\mathrm{C} 6$ & $-59.5(9)$ \\
\hline $\mathrm{C} 12-\mathrm{C} 6-\mathrm{C} 7-\mathrm{N} 1$ & $-74.2(9)$ & $\mathrm{C} 7-\mathrm{C} 6-\mathrm{C} 5-\mathrm{C} 4$ & $47.4(8)$ \\
\hline $\mathrm{C} 5-\mathrm{C} 6-\mathrm{C} 7-\mathrm{N} 1$ & $163.6(7)$ & $\mathrm{C} 12-\mathrm{C} 6-\mathrm{C} 5-\mathrm{C} 4$ & $-72.4(8)$ \\
\hline $\mathrm{C} 12^{\prime}-\mathrm{C} 6-\mathrm{C} 7-\mathrm{N} 1$ & $-59.9(18)$ & $\mathrm{C} 12^{\prime}-\mathrm{C} 6-\mathrm{C} 5-\mathrm{C} 4$ & $-78.6(17)$ \\
\hline $\mathrm{C} 8-\mathrm{C} 6-\mathrm{C} 7-\mathrm{N} 1$ & $46.3(9)$ & $\mathrm{C} 8-\mathrm{C} 6-\mathrm{C} 5-\mathrm{C} 4$ & $165.3(6)$ \\
\hline $\mathrm{C}^{\prime}-\mathrm{C} 6-\mathrm{C} 7-\mathrm{N} 1$ & $-157.1(17)$ & $\mathrm{C}^{\prime}-\mathrm{C} 6-\mathrm{C} 5-\mathrm{C} 4$ & $-49 \cdot(2)$ \\
\hline $\mathrm{C} 12-\mathrm{C} 6-\mathrm{C} 7-\mathrm{N} 2$ & $101.4(7)$ & $\mathrm{C} 10-\mathrm{C} 11-\mathrm{C} 12^{\prime}-\mathrm{C} 6$ & $5-76 .(2)$ \\
\hline $\mathrm{C} 5-\mathrm{C} 6-\mathrm{C} 7-\mathrm{N} 2$ & $-20.8(9)$ & $\mathrm{C} 12-\mathrm{C} 11-\mathrm{C} 12^{\prime}-\mathrm{C} 6$ & $567 .(4)$ \\
\hline $\mathrm{C} 12^{\prime}-\mathrm{C} 6-\mathrm{C} 7-\mathrm{N} 2$ & $115.7(17)$ & $\mathrm{C} 7-\mathrm{C} 6-\mathrm{C} 12^{\prime}-\mathrm{C} 11$ & $-172.1(18)$ \\
\hline $\mathrm{C} 8-\mathrm{C} 6-\mathrm{C} 7-\mathrm{N} 2$ & $-138.1(7)$ & $\mathrm{C} 12-\mathrm{C} 6-\mathrm{C} 12^{\prime}-\mathrm{C} 11$ & $-70 .(4)$ \\
\hline $\mathrm{C}^{\prime}-\mathrm{C} 6-\mathrm{C} 7-\mathrm{N} 2$ & $18.5(17)$ & $\mathrm{C} 5-\mathrm{C} 6-\mathrm{C} 12^{\prime}-\mathrm{C} 11$ & $-45 .(3)$ \\
\hline $\mathrm{C} 7-\mathrm{C} 6-\mathrm{C} 8-\mathrm{O} 1$ & $62.8(7)$ & $\mathrm{C} 8-\mathrm{C} 6-\mathrm{C} 12^{\prime}-\mathrm{C} 11$ & $75 .(2)$ \\
\hline $\mathrm{C} 12-\mathrm{C} 6-\mathrm{C} 8-\mathrm{O} 1$ & $-178.0(6)$ & $\mathrm{C} 5^{\prime}-\mathrm{C} 6-\mathrm{C} 12^{\prime}-\mathrm{C} 11$ & $-63 .(3)$ \\
\hline $\mathrm{C} 5-\mathrm{C} 6-\mathrm{C} 8-\mathrm{O} 1$ & $-54.6(7)$ & $\mathrm{C} 3-\mathrm{C} 4-\mathrm{C}^{\prime}-\mathrm{C} 6$ & $31 .(4)$ \\
\hline $\mathrm{C} 12^{\prime}-\mathrm{C} 6-\mathrm{C} 8-\mathrm{O} 1$ & $173.5(12)$ & $\mathrm{C} 5-\mathrm{C} 4-\mathrm{C} 5^{\prime}-\mathrm{C} 6$ & $-55 .(2)$ \\
\hline $\mathrm{C} 5^{\prime}-\mathrm{C} 6-\mathrm{C} 8-\mathrm{O} 1$ & $-84.0(19)$ & $\mathrm{C} 7-\mathrm{C} 6-\mathrm{C} 5^{\prime}-\mathrm{C} 4$ & $-35 .(4)$ \\
\hline $\mathrm{C} 7-\mathrm{C} 6-\mathrm{C} 8-\mathrm{C} 9$ & $-171.4(6)$ & $\mathrm{C} 12-\mathrm{C} 6-\mathrm{C} 5^{\prime}-\mathrm{C} 4$ & $-141 .(3)$ \\
\hline $\mathrm{C} 12-\mathrm{C} 6-\mathrm{C} 8-\mathrm{C} 9$ & $-52.3(8)$ & $\mathrm{C} 5-\mathrm{C} 6-\mathrm{C} 5^{\prime}-\mathrm{C} 4$ & $62 .(2)$ \\
\hline $\mathrm{C} 5-\mathrm{C} 6-\mathrm{C} 8-\mathrm{C} 9$ & $71.1(7)$ & $\mathrm{C} 12^{\prime}-\mathrm{C} 6-\mathrm{C} 5^{\prime}-\mathrm{C} 4$ & $-142 .(3)$ \\
\hline $\mathrm{C} 12^{\prime}-\mathrm{C} 6-\mathrm{C} 8-\mathrm{C} 9$ & $-60.8(12)$ & $\mathrm{C} 8-\mathrm{C} 6-\mathrm{C} 5^{\prime}-\mathrm{C} 4$ & 112.(3) \\
\hline $\mathrm{C}^{\prime}-\mathrm{C} 6-\mathrm{C} 8-\mathrm{C} 9$ & $41.7(19)$ & $\mathrm{N} 2-\mathrm{C} 7-\mathrm{N} 1-\mathrm{C} 1$ & $2.0(8)$ \\
\hline $\mathrm{O} 1-\mathrm{C} 8-\mathrm{C} 9-\mathrm{C} 10$ & $177.8(6)$ & $\mathrm{C} 6-\mathrm{C} 7-\mathrm{N} 1-\mathrm{C} 1$ & $178.0(6)$ \\
\hline $\mathrm{C} 6-\mathrm{C} 8-\mathrm{C} 9-\mathrm{C} 10$ & $55.1(8)$ & $\mathrm{C} 2-\mathrm{C} 1-\mathrm{N} 1-\mathrm{C} 7$ & $-1.8(8)$ \\
\hline $\mathrm{C} 8-\mathrm{C} 9-\mathrm{C} 10-\mathrm{C} 11$ & $-56.4(8)$ & $\mathrm{N} 1-\mathrm{C} 7-\mathrm{N} 2-\mathrm{C} 2$ & $-1.5(8)$ \\
\hline $\mathrm{C} 9-\mathrm{C} 10-\mathrm{C} 11-\mathrm{C} 12$ & $53.5(9)$ & $\mathrm{C} 6-\mathrm{C} 7-\mathrm{N} 2-\mathrm{C} 2$ & $-177.7(6)$ \\
\hline $\mathrm{C} 9-\mathrm{C} 10-\mathrm{C} 11-\mathrm{C} 12^{\prime}$ & ' $62.6(12)$ & $\mathrm{N} 1-\mathrm{C} 7-\mathrm{N} 2-\mathrm{C} 3$ & $-179.4(7)$ \\
\hline $\mathrm{C} 7-\mathrm{C} 6-\mathrm{C} 12-\mathrm{C} 11$ & $171.9(6)$ & $\mathrm{C} 6-\mathrm{C} 7-\mathrm{N} 2-\mathrm{C} 3$ & $4.4(11)$ \\
\hline $\mathrm{C} 5-\mathrm{C} 6-\mathrm{C} 12-\mathrm{C} 11$ & $-68.5(8)$ & $\mathrm{C} 1-\mathrm{C} 2-\mathrm{N} 2-\mathrm{C} 7$ & $0.3(8)$ \\
\hline $\mathrm{C} 12^{\prime}-\mathrm{C} 6-\mathrm{C} 12-\mathrm{C} 11$ & $90 .(5)$ & $\mathrm{C} 1-\mathrm{C} 2-\mathrm{N} 2-\mathrm{C} 3$ & $178.3(7)$ \\
\hline $\mathrm{C} 8-\mathrm{C} 6-\mathrm{C} 12-\mathrm{C} 11$ & $52.4(9)$ & $\mathrm{C} 4-\mathrm{C} 3-\mathrm{N} 2-\mathrm{C} 7$ & $-13.0(12)$ \\
\hline $\mathrm{C}^{\prime}-\mathrm{C} 6-\mathrm{C} 12-\mathrm{C} 11$ & $-82.8(16)$ & $\mathrm{C} 4-\mathrm{C} 3-\mathrm{N} 2-\mathrm{C} 2$ & $169.4(7)$ \\
\hline $\mathrm{C}_{10}-\mathrm{C}_{11}-\mathrm{C}_{12}-\mathrm{C} 6$ & & & \\
\hline
\end{tabular}




\section{The crystal structure of 5 .}

In the solid state molecules of $\mathbf{5}$ interact with each other by means of formation of intermolecular hydrogen bonds to form a 1D chain. This chain is depicted in Figure S4, selected geometrical parameters are summarized in Table S6. The orientation of the chains along the crystallographic $b$ axes within the crystal lattice is shown in Figure S6 as well as an illustration that the chains to not further interact with each other.

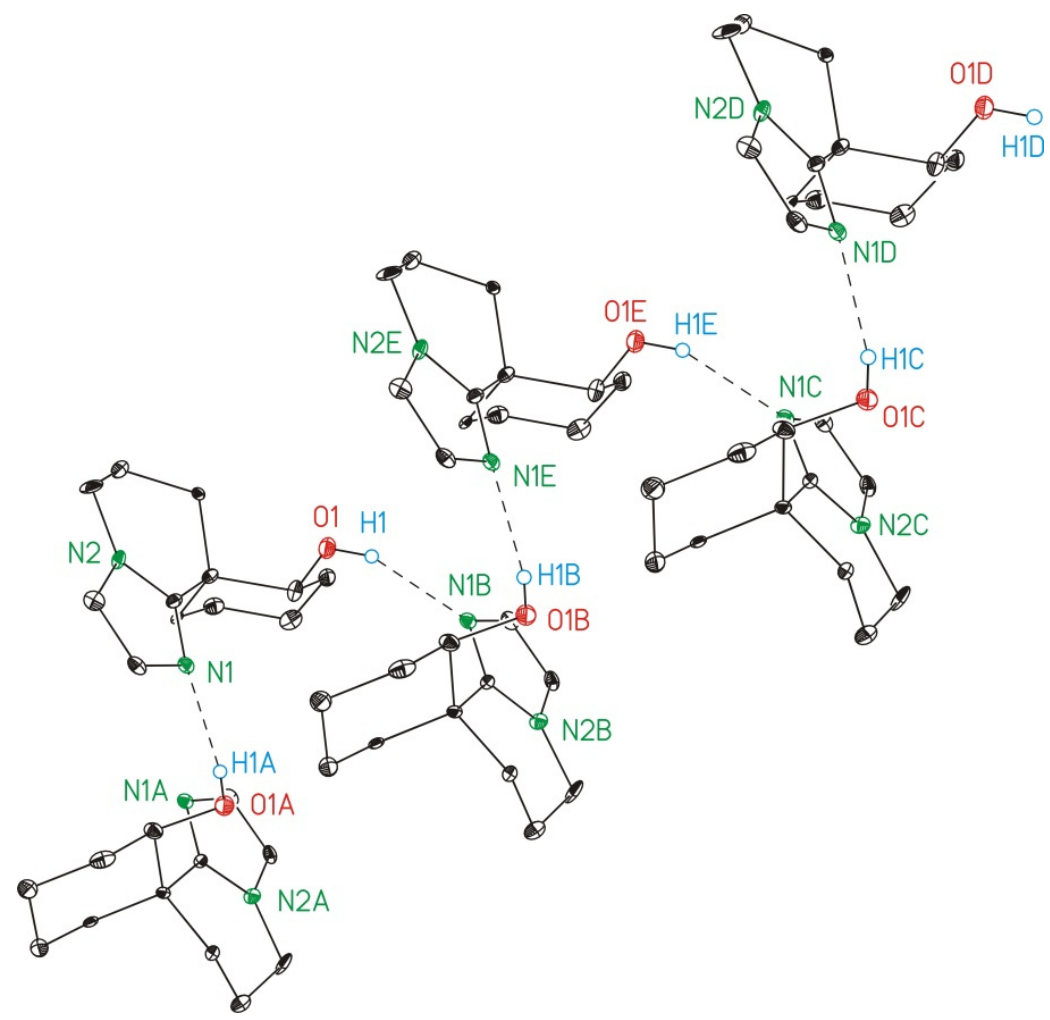

Figure S6 ORTEP diagram (25\% probability ellipsoids) of a selected part of one of the 1D chains formed by 5 in the solid state due to intermolecular hydrogen bond formation, indicated by dotted lines. Disordered atomic positions as well as carbon bonded hydrogen atoms are omitted for clarity. Symmetry operations: "A" $=1-x, 1-y, z+1 / 2$. "B" $=1-x, 1-y, z-1 / 2$. "C" $=1-x, 1-y, z-3 / 2$. "D" $=x, y, \square 2+$ z. "E" = x, $y,-1+z$.

Table S4 Selected bond lengths $(A)$ and angles $\left({ }^{\circ}\right)$ of the intermolecular hydrogen bonds formed by 5 in the solid state.

\begin{tabular}{|l|l|l|l|l|}
\hline$\underline{\mathrm{D}-\mathrm{H} \cdots \mathrm{A}}$ & $\underline{\mathrm{D}-\mathrm{H}}$ & $\underline{\mathrm{H} \cdots \mathrm{A}}$ & $\underline{\mathrm{D} \cdots \mathrm{A}}$ & $\underline{\mathrm{D}-\mathrm{H} \cdots \mathrm{A}}$ \\
\hline $\mathrm{O} 1-\mathrm{H} 1 \cdots \mathrm{N} 1 \mathrm{~B}$ & 0.82 & 2.11 & $2.876(7)$ & 156 \\
\hline \multicolumn{2}{|l}{ Symmetry operation: "B" $=1-x, 1-y, z-1 / 2}$. \\
\hline
\end{tabular}




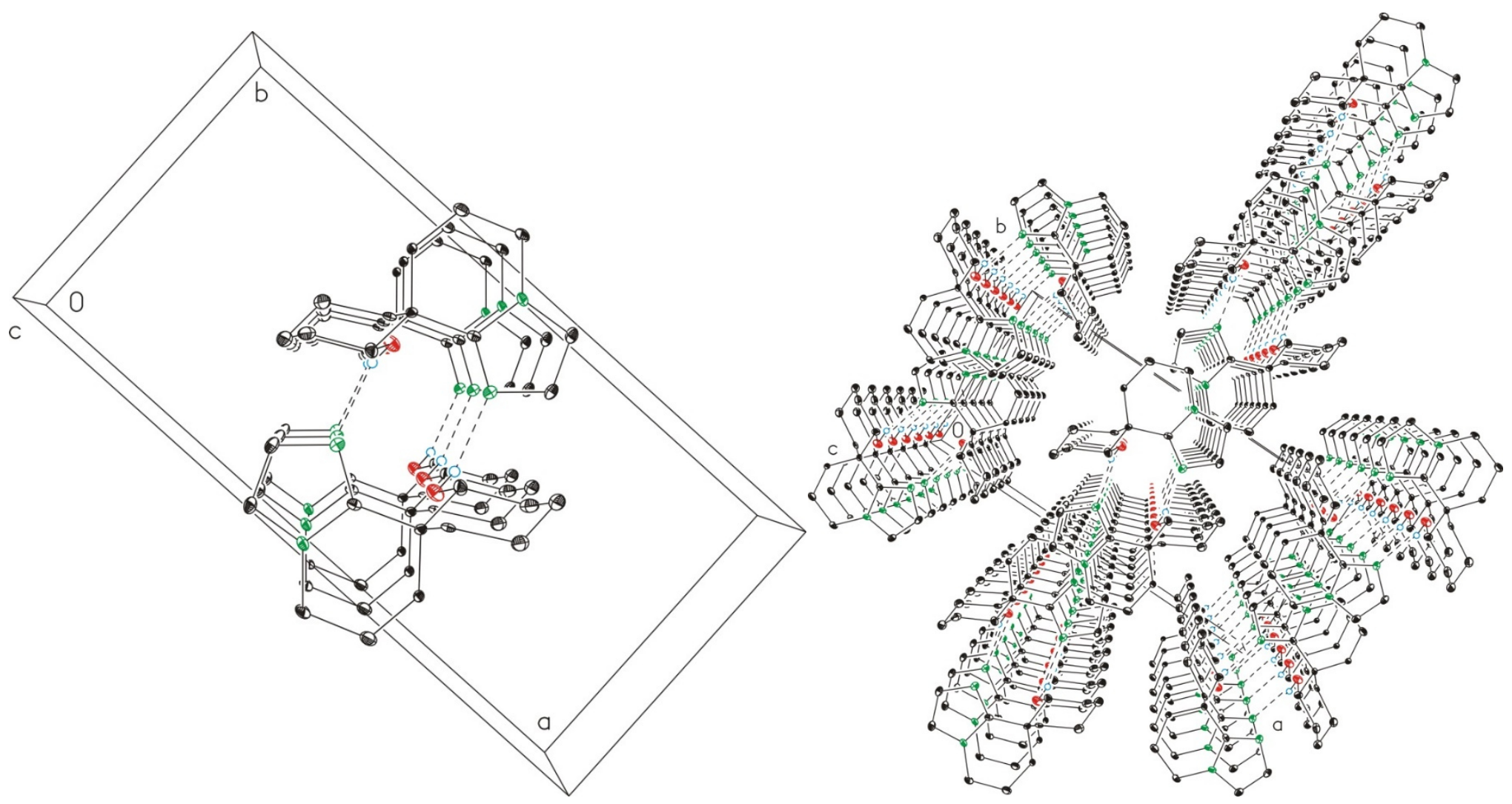

Figure S7 Left: ORTEP diagram (25\% probability ellipsoids) of a selected part of one of 1D chains formed by 5 in the solid state displaying its orientation along the crystallographic $b$ axes. Right: ORTEP diagram ( $25 \%$ probability ellipsoids) of a selected cut-off of the crystal structure of 5 , displaying that $1 \mathrm{D}$ chains do not interact with each other. Disordered atomic positions and carbon bonded hydrogens are omitted for clarity. Dotted lines indicate intermolecular hydrogen bonds. 


\section{Comparison of characterization data for nitrabirine (5)}

Table S5: Comparison table of characterization data for nitrabirine (5)

\begin{tabular}{|c|c|c|c|}
\hline \multicolumn{2}{|c|}{${ }^{1} \mathrm{H}$ NMR $\left(\mathrm{CDCl}_{3}, 250 \mathrm{MHz}\right)$} & \multicolumn{2}{|c|}{${ }^{13} \mathrm{C}\left\{{ }^{1} \mathrm{H}\right\}$ NMR $\left(\mathrm{CDCl}_{3}, 69.9 \mathrm{MHz}\right)$} \\
\hline Isolated $^{3}$ & Synthetic & Isolated $^{3}$ & Synthetic \\
\hline $\begin{array}{l}\delta 6.94\left(\mathrm{~d},{ }^{3} J_{\mathrm{H}, \mathrm{H}}=1.0\right. \\
\mathrm{Hz}, 1 \mathrm{H},-\mathrm{CH}=\mathrm{C} \underline{\mathrm{H}}-\mathrm{N}=),\end{array}$ & $\begin{array}{l}7.01\left(\mathrm{~d},{ }^{3} J_{\mathrm{H}, \mathrm{H}}=1.1\right. \\
\mathrm{Hz}, 1 \mathrm{H},-\mathrm{CH}=\mathrm{C} \underline{-}- \\
\mathrm{N}=) .\end{array}$ & $\delta 150.9(\mathrm{~s},-\mathrm{N}=\underline{\mathrm{C}}-)$ & $150.8(\mathrm{~s},-\mathrm{N}=\underline{\mathrm{C}}-)$ \\
\hline $\begin{array}{l}\delta 6.73\left(\mathrm{~d},{ }^{3} \mathrm{~J}_{\mathrm{H}, \mathrm{H}}=1.0\right. \\
\mathrm{Hz}, 1 \mathrm{H},-\mathrm{N}-\mathrm{C} \underline{\mathrm{H}}=\mathrm{CH}-),\end{array}$ & $\begin{array}{l}6.75\left(\mathrm{~d},{ }^{3} \mathrm{~J}_{\mathrm{H}, \mathrm{H}}=1.2\right. \\
\mathrm{Hz}, 1 \mathrm{H},-\mathrm{N}-\mathrm{C} \underline{\mathrm{H}}=\mathrm{CH}- \\
) .\end{array}$ & $\begin{array}{l}\delta 127.7\left(\mathrm{~d}, \mathrm{C}-2^{\prime},-\right. \\
\mathrm{CH}=\underline{\mathrm{C}} \mathrm{H}-\mathrm{N}=),\end{array}$ & $\begin{array}{l}127.4\left(\mathrm{~d}, \mathrm{C}-2^{\prime},-\right. \\
\mathrm{CH}=\underline{\mathrm{C}} \mathrm{H}-\mathrm{N}=) .\end{array}$ \\
\hline $\begin{array}{l}\delta 4.37\left(\mathrm{dd},{ }^{3} \mathrm{~J}_{\mathrm{H}, \mathrm{H}}=10\right. \\
4.5 \mathrm{~Hz}, 1 \mathrm{H},-\mathrm{CH}_{2}-\mathrm{C} \underline{-}- \\
\mathrm{OH})\end{array}$ & $\begin{array}{l}4.43\left(\mathrm{dd},{ }^{3} \mathrm{~J}_{\mathrm{H}, \mathrm{H}}=\right. \\
11.2,4.3 \mathrm{~Hz}, 1 \mathrm{H},- \\
\left.\mathrm{CH}_{2}-\mathrm{C} \underline{\mathrm{H}}-\mathrm{OH}\right) .\end{array}$ & $\begin{array}{l}\delta 117.9\left(\mathrm{~d}, \mathrm{C}-3^{\prime},-\mathrm{N}-\right. \\
\underline{\mathrm{C}} \mathrm{H}=\mathrm{CH}-),\end{array}$ & $\begin{array}{l}118.1\left(\mathrm{~d}, \mathrm{C}-3^{\prime},-\mathrm{N}-\right. \\
\underline{\mathrm{C}} \mathrm{H}=\mathrm{CH}-) .\end{array}$ \\
\hline $\begin{array}{l}\delta 3.91\left(\mathrm{~m}, 2 \mathrm{H},-\mathrm{CH}_{2^{-}}\right. \\
\left.\text {C}_{2}-\mathrm{N}-\right)\end{array}$ & $\begin{array}{l}3.95\left(\mathrm{~m}, 2 \mathrm{H},-\mathrm{CH}_{2^{-}}\right. \\
\left.\underline{\mathrm{CH}}_{2}-\mathrm{N}-\right) .\end{array}$ & $\delta 74.7(\mathrm{~d},-\mathrm{H} \underline{\mathrm{C}}-\mathrm{OH})$ & $74.8(\mathrm{~d},-\mathrm{H} \underline{\mathrm{C}}-\mathrm{OH})$ \\
\hline$\delta 2.93(\mathrm{~s}, 1 \mathrm{H},-\mathrm{OH})$ & $2.15(\mathrm{~s}, 1 \mathrm{H},-\mathrm{OH})$. & $\begin{array}{l}\delta 44.7\left(\mathrm{t},-\mathrm{CH}_{2}-\underline{\mathrm{C}}_{2-}\right. \\
\mathrm{N}-),\end{array}$ & $44.8\left(\mathrm{t},-\mathrm{CH}_{2}-\underline{\mathrm{CH}}_{2}-\mathrm{N}\right)$ \\
\hline $\begin{array}{l}\delta 1.47-2.00(\mathrm{~m}, 12 \mathrm{H}, \\
\left.-\underline{\mathrm{C}}_{2}{ }^{-}\right)\end{array}$ & $\begin{array}{l}1.48-2.08(\mathrm{~m}, 12 \mathrm{H},- \\
\left.\mathrm{CH}_{2}-\right) .\end{array}$ & $\delta 42.7(\mathrm{~s},-\underline{\mathrm{C}}-\mathrm{C}=\mathrm{N}-)$ & 42.7 (s, - $\underline{\mathrm{C}}-\mathrm{C}=\mathrm{N}-)$. \\
\hline \multirow{6}{*}{\multicolumn{2}{|c|}{$\begin{array}{l}\text { mp. } 184-185^{\circ} \mathrm{C}^{3} \\
\text { mp. } 193-195^{\circ} \mathrm{C} \\
\text { IR (KBr pellet); } v_{\max } 3350-3180,2945,2875 \\
\text { 1670, 1595, 1530, 1490,1250,1090, 935. } \\
\\
\text { IR (ATR); } v_{\max }(\mathrm{cm}-1) 3231,2964,2932 \\
\text { 2863, } 1524,14831441,1353,1311,1266 \\
\text { 1208. } 1128,1070,1021,984,928,903,755 \\
729,651,597 .\end{array}$}} & $\delta 35.4\left(\mathrm{t},-\underline{-} \mathrm{CH}_{2^{-}}\right)$ & $35.2\left(\mathrm{t},-\underline{\mathrm{C}} \mathrm{H}_{2-}-\right)$ \\
\hline & & $\begin{array}{l}\delta 29.1\left(\mathrm{t},-\underline{\mathrm{CH}}_{2}-\mathrm{CH}-\right. \\
\mathrm{OH}),\end{array}$ & $\begin{array}{l}28.9\left(\mathrm{t},-\underline{\mathrm{C}} \mathrm{H}_{2}-\mathrm{CH}-\right. \\
\mathrm{OH}) .\end{array}$ \\
\hline & & $\delta 24.6\left(\mathrm{t},-\underline{\mathrm{C}} \mathrm{H}_{2^{-}}\right)$ & $24.5\left(\mathrm{t},-\underline{\mathrm{C}} \mathrm{H}_{2-}\right)$. \\
\hline & & $\delta 21.6\left(\mathrm{t},-\underline{\mathrm{C}} \mathrm{H}_{2^{-}}\right)$ & $21.3\left(\mathrm{t},-\underline{\mathrm{C}} \mathrm{H}_{2^{-}}\right)$. \\
\hline & & $\delta 20.8\left(\mathrm{t},-\underline{\mathrm{CH}_{2}}{ }^{-}\right)$ & $20.7\left(\mathrm{t},-\underline{\mathrm{C}} \mathrm{H}_{2^{-}}\right)$. \\
\hline & & $\delta 19.7\left(\mathrm{t},-\underline{\mathrm{C}} \mathrm{H}_{2^{-}}\right)$ & $19.6\left(\mathrm{t},-\underline{\mathrm{C}} \mathrm{H}_{2^{-}}\right)$. \\
\hline
\end{tabular}




\section{Evaluation of the biological activity Description of the MIC assay ${ }^{4}$}

Serial dilutions of compounds were prepared as triplicates in sterile U-bottom shaped 96-well plates (Corning ${ }^{\mathrm{TM}}$, USA). Mueller-Hinton broth (MHB) media was used for bacteria and YMG media was used for filamentous fungi and yeasts. The selected organisms represent a broad spectrum of pathogens of clinical interest, as well as sensitive indicator strains (Gram-positive bacteria: Bacillus subtilis, Staphylococcus aureus, Mycolicibacterium smegmatis; Gramnegative bacteria: Acinetobacter baumannii, Chromobacterium violaceum, Escherichia coli, Pseudomonas aeruginosa; filamentous fungi: Mucor hiemalis; yeasts: Candida albicans, Pichia anomala, Rhodotorula glutinis, Schizosaccharomyces pombe). The compounds were dissolved in $\mathrm{MeOH}(1 \mathrm{mg} / \mathrm{mL})$, added to the bacterial suspension and diluted to the final concentrations. The plate was incubated at $37^{\circ} \mathrm{C}$ in static conditions. Growth inhibition was assessed after $24 \mathrm{~h}$. $\mathrm{MeOH}$ was used as negative control. Kanamycin $(1.0 \mathrm{mg} / \mathrm{mL} ; 2 \mu \mathrm{L}[\mathrm{M}$. smegmatis]), gentamycin (1.0 mg/mL; $2 \mu \mathrm{L}$ [P. aeruginosa]), ciprobay $(2.54 \mathrm{mg} / \mathrm{ml} ; 2 \mu \mathrm{L}[A$. baumannii]), nystatin $(1.0 \mathrm{mg} / \mathrm{mL} ; 20 \mu \mathrm{L}$ [S. pombe, P. anomala, M. hiemalis, C. albicans, $R$. glutinis), and oxytetracycline (1.0 mg/mL; $2 \mu \mathrm{L}$ [C. violaceum, E. coli, S. aureus] and $20 \mu \mathrm{L}$ [B. subtilis]) were used as positive controls. 
Table S6: MIC $[\mu \mathrm{M}]$ assay data

\begin{tabular}{|c|c|c|c|c|c|c|c|c|c|c|c|}
\hline Organisms tested & 21 & 5 & $5^{\prime}$ & 22 & $25^{\prime}$ & 25 & $26 a$ & 26b & $26 c$ & 26d & $\begin{array}{l}\text { Reference } \\
\text { compounds }\end{array}$ \\
\hline $\begin{array}{c}\text { Schizosaccharomyces } \\
\text { pombe DSM } 70572\end{array}$ & n.i. & n.i. & n.i. & n.i. & n.i. & n.i. & n.i. & n.i. & 213.6 & 66.6 & 4.5 Nystatin \\
\hline $\begin{array}{c}\text { Pichia anomala } \\
\text { DSM } 6766\end{array}$ & n.i. & n.i. & n.i. & n.i. & n.i. & n.i. & n.i. & n.i. & n.i. & n.i. & 4.5 Nystatin \\
\hline $\begin{array}{l}\text { Mucor hiemalis } \\
\text { DSM } 2656\end{array}$ & n.i. & n.i. & n.i. & n.i. & n.i. & n.i. & n.i. & n.i. & 213.6 & 66.6 & 4.5 Nystatin \\
\hline $\begin{array}{l}\text { Candida albicans } \\
\text { DSM } 1665\end{array}$ & n.i. & n.i. & n.i. & n.i. & n.i. & n.i. & n.i. & n.i. & n.i. & n.i. & 8.9 Nystatin \\
\hline $\begin{array}{c}\text { Rhodotorula glutinis } \\
\text { DSM } 10134\end{array}$ & n.i. & n.i. & n.i. & n.i. & n.i. & n.i. & n.i. & n.i. & 213.6 & 186.9 & 1.1 Nystatin \\
\hline $\begin{array}{c}\text { Acinetobacter } \\
\text { baumannii DSM } 30008\end{array}$ & n.i. & n.i. & n.i. & n.i. & n.i. & n.i. & n.i. & n.i. & n.i. & n.i. & 0.78 Ciprobay \\
\hline $\begin{array}{c}\text { Escherichia coli } \\
\text { DSM } 1116\end{array}$ & n.i. & n.i. & n.i. & n.i. & n.i. & n.i. & n.i. & n.i. & n.i. & n.i. & $\begin{array}{c}7.2 \\
\text { Oxytetracyclin }\end{array}$ \\
\hline $\begin{array}{c}\text { Bacillus subtilis } \\
\text { DSM } 10\end{array}$ & n.i. & n.i. & n.i. & n.i. & 268.2 & n.i. & 240.1 & n.i. & 53.2 & 186.9 & $\begin{array}{c}36.1 \\
\text { Oxytetracyclin }\end{array}$ \\
\hline 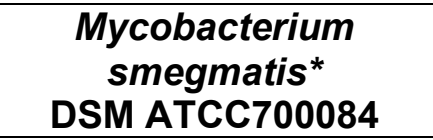 & n.i. & n.i. & n.i. & n.i. & n.i. & n.i. & n.i. & n.i. & 213.6 & 186.9 & 1.7 Kanamycin \\
\hline $\begin{array}{l}\text { Staphylococcus } \\
\text { aureus DSM } 346\end{array}$ & n.i. & n.i. & n.i. & n.i. & n.i. & n.i. & n.i. & n.i. & 100.8 & 93.5 & $\begin{array}{c}0.2 \\
\text { Oxytetracyclin }\end{array}$ \\
\hline $\begin{array}{c}\text { Pseudomonas } \\
\text { aeruginosa DSM PA14 }\end{array}$ & n.i. & n.i. & n.i. & n.i. & n.i. & n.i. & n.i. & n.i. & n.i. & n.i. & $\begin{array}{c}0.88 \\
\text { Gentamycin }\end{array}$ \\
\hline $\begin{array}{c}\text { Chromobacterium } \\
\text { violaceum DSM } 30191\end{array}$ & n.i. & n.i. & n.i. & n.i. & n.i. & n.i. & n.i. & n.i. & 213.6 & n.i. & $\begin{array}{c}0.91 \\
\text { Oxytetracycline }\end{array}$ \\
\hline
\end{tabular}

n.i. = no inhibition 


\section{Description of the biofilm assays $\mathbf{s}^{5,6}$}

Staphylococcus aureus DSM 1104 was taken from $-20{ }^{\circ} \mathrm{C}$ stock and cultured in $25 \mathrm{~mL}$ CASO (casein-peptone soymeal-peptone) medium in a $250 \mathrm{~mL}$ flask at $100 \mathrm{rpm}$ at $37^{\circ} \mathrm{C}$ for $20 \mathrm{~h}$. The $\mathrm{OD}_{600}$ of the culture solution was measured and adjusted to $0.001 \mathrm{McF}$ arland standard. The serial compounds (250-2 $\mu \mathrm{g} / \mathrm{mL}$ ) were diluted in CASO with $4 \%$ glucose broth to $150 \mu \mathrm{L}$ and incubated in 96 well microtiter plates (TPP tissue culture ref.no 92196) for $18 \mathrm{~h}$ at $37^{\circ} \mathrm{C}$. The biofilm inhibition was assessed by using $150 \mu \mathrm{L} 0.1 \%$ crystal violet (CV) (Thermo Fisher, Waltham, USA). The bacterial solution of 96 well plate was discarded and wells were washed by using PBS (phosphate-buffered saline) buffer. In the next step, the biofilms were stained by $0.1 \% \mathrm{CV}$ at room temperature for $15 \mathrm{~min}$ and then washed three times by using PBS buffer. The biofilm was dissolved in $150 \mu \mathrm{L}$ ethanol (95\%), and the absorbance was finally quantified using a plate reader (Synergy 2, BioTek, Santa Clara, USA) at $530 \mathrm{~nm}$. Methanol (2.5\%) and microporenic acid A (250-2 $\mathrm{gg} / \mathrm{mL})$ were used as a negative control and a positive control, respectively. Standard deviations (SD) of two repeats with duplicates each were $10 \%$ or less.

For the preformed biofilm assay, the cultured bacterial suspension of S. aureus DSM 1104 was adjusted to $0.001 \mathrm{McF}$ arland standard at $\mathrm{OD}_{600}$ and incubated in 96-well tissue microtiter plates for $18 \mathrm{~h}$ in $150 \mu \mathrm{L}$ CASO with $4 \%$ glucose broth. The supernatant of 96 well plate was removed and washed with $150 \mu \mathrm{L}$ PBS buffer. Serially compounds were diluted in $150 \mu \mathrm{L}$ of the fresh media (CASO with $4 \%$ glucose broth) at the concentration $(250-2 \mu \mathrm{g} / \mathrm{mL}$ ) and added into the plates. The plates were incubated for $24 \mathrm{~h}$ at $37^{\circ} \mathrm{C}$. Staining of the preformed biofilm and controls was carried out as mentioned above. Methanol $(2.5 \%)$ and microporenic acid A (250-2 $\mu \mathrm{g} / \mathrm{mL}$ ) were used as a negative control and a positive control, respectively. SD of two repeats with duplicates each were $15 \%$ or less. All experiments were accomplished in duplicates with two repetitions.

Candida albicans DSM 11225 was cultured in 25 mL YPED (Yeast extract Peptone Dextrose) medium in a $250 \mathrm{~mL}$ flask at $30^{\circ} \mathrm{C}$ at $100 \mathrm{rpm}$ for $18 \mathrm{~h}$. The $\mathrm{OD}_{600}$ of the bacterial suspension was measured and adjusted to 0.05 McFarland standard in RPMI 1640 medium. The $150 \mu \mathrm{L}$ bacterial solution was added in 96 well non-tissue microtiter plates (Falcon non-tissue plate ref.no 351172 ) at $37^{\circ} \mathrm{C}$ at $150 \mathrm{rpm}$. After $90 \mathrm{~min}$ the supernatant was removed and washed two times by using PBS buffer. Serially compounds were diluted in $150 \mu \mathrm{L}$ of the fresh media (RPMI 1640) at the concentration (250-2 $\mu \mathrm{g} / \mathrm{mL})$ and added into the wells. Methanol $(2.5 \%)$ and farnesol (250-2 $\mu \mathrm{g} / \mathrm{mL})$ were separately used as a negative control and positive control, respectively. The plates were further incubated at $37^{\circ} \mathrm{C}$ at $150 \mathrm{rpm}$ for $24 \mathrm{~h}$. Then, the supernatant was discarded and biofilms were stained by $150 \mu \mathrm{L} 0.1 \% \mathrm{CV}$ at room temperature 
for 25 min after once washed by PBS buffer. Afterwards, the plates were washed four times by using PBS buffer. The biofilms were dissolved in $150 \mu \mathrm{L}$ ethanol (95\%) and the absorbance was finally quantified using a plate reader (Synergy 2, BioTek, Santa Clara, USA) at $610 \mathrm{~nm}$. SD of two repeats with duplicates each were $10 \%$ or less.

P. aeruginosa (PA 14) DSM 19882 was cultured in $25 \mathrm{~mL}$ LB medium (Luria-Bertani Broth) in a $250 \mathrm{~mL}$ flask at $37^{\circ} \mathrm{C}$ at $100 \mathrm{rpm}$ for $18 \mathrm{~h}$. The $O D_{600}$ of the culture solution was measured and adjusted to $0.05 \mathrm{McF}$ arland standard in LB medium. The compounds were added into 100 $\mu \mathrm{L}$ bacterial solution at the concentration $(250-2 \mu \mathrm{g} / \mathrm{mL})$ then the solution was added in 96 well the MBEC Innovatech incubator (MBEC Assay®, Canada). The plates were incubated at $37{ }^{\circ} \mathrm{C}$ at $150 \mathrm{rpm}$ for $24 \mathrm{~h}$. The biofilms were established on the pegs under the growth conditions. The pegs and plates were rinsed once by using PBS buffer, the biofilms on pegs were stained by $150 \mu \mathrm{L} 0.1 \% \mathrm{CV}$ at room temperature for $15 \mathrm{~min}$ and then rinsed two times by using PBS buffer. The pegs were transferred into a new plate filled with $150 \mu \mathrm{L}$ ethanol (95\%). The absorbance was quantified using a plate reader (Synergy 2, BioTek, Santa Clara, USA) at $550 \mathrm{~nm}$. Methanol (2.5\%) and myxovalargin A and were used as negative control and positive control, respectively. 
Table S7: Biofilms and preformed biofilm inhibition of $S$. aureus and biofilm inhibition of C. albicans.

\begin{tabular}{|c|c|c|c|}
\hline Compounds & $\begin{array}{l}\text { Biofilm inhibition of } \\
\text { S. aureus [\%] }\end{array}$ & $\begin{array}{l}\text { Biofilm dispersion of } \\
\text { S. aureus [\%] }\end{array}$ & $\begin{array}{l}\text { Biofilm dispersion of } \\
\text { C. albicans [\%ะ SD] }\end{array}$ \\
\hline 21 & - & - & - \\
\hline 5 & - & - & $40 \pm 9(1.21 \mathrm{mM})$ \\
\hline 5 & - & - & $47 \pm 9(1.21 \mathrm{mM})$ \\
\hline 22 & - & - & $29 \pm 6(1.05 \mathrm{mM})$ \\
\hline 25 & - & - & - \\
\hline 25 & - & - & $42 \pm 7(1.01 \mathrm{mM})$ \\
\hline \multirow{4}{*}{$26 a$} & \multirow{4}{*}{$90(901 \mu \mathrm{M})$} & \multirow{4}{*}{$51(901 \mu \mathrm{M})$} & $83 \pm 4(901 \mu \mathrm{M})$ \\
\hline & & & $64 \pm 9(225 \mu \mathrm{M})$ \\
\hline & & & $26 \pm 9(112 \mu \mathrm{M})$ \\
\hline & & & $13 \pm 8(56 \mu \mathrm{M})$ \\
\hline 26b & - & - & $73 \pm 2(846 \mu \mathrm{M})$ \\
\hline \multirow{4}{*}{$26 c$} & \multirow{4}{*}{ n.t } & \multirow{4}{*}{ n.t } & $79 \pm 1(801 \mu \mathrm{M})$ \\
\hline & & & $70 \pm 6(200 \mu \mathrm{M})$ \\
\hline & & & $47 \pm 10(100 \mu \mathrm{M})$ \\
\hline & & & $17 \pm 5(50 \mu \mathrm{M})$ \\
\hline \multirow{4}{*}{ 26d } & \multirow{4}{*}{ n.t } & \multirow{4}{*}{ n.t } & $79 \pm 2(701 \mu \mathrm{M})$ \\
\hline & & & $73 \pm 6(175 \mu \mathrm{M})$ \\
\hline & & & $60 \pm 10(67 \mu \mathrm{M})$ \\
\hline & & & $39 \pm 1(43 \mu \mathrm{M})$ \\
\hline \multirow{3}{*}{ MAA } & $83 \pm 3(538 \mu \mathrm{M})$ & $69 \pm 5(538 \mu \mathrm{M})$ & \\
\hline & $77 \pm 6(16.0 \mu \mathrm{M})$ & $49 \pm 6(67.1 \mu \mathrm{M})$ & n.t \\
\hline & $49 \pm 9(8.4 \mu \mathrm{M})$ & & \\
\hline \multirow{3}{*}{ Farnesol } & \multirow{3}{*}{ n.t } & \multirow{3}{*}{ n.t } & $85 \pm 4(1.124 \mathrm{mM})$ \\
\hline & & & $83 \pm 1(141 \mu \mathrm{M})$ \\
\hline & & & $37 \pm 6(70 \mu \mathrm{M})$ \\
\hline & & ivity, n.t: not tested & \\
\hline
\end{tabular}




\section{Description of the cell proliferation assay ${ }^{4}$}

The corresponding cells were cultivated at $37{ }^{\circ} \mathrm{C}$ and $10 \% \mathrm{CO}_{2}$ in the medium given in Table S8. $60 \mu \mathrm{L}$ of serial dilutions of the test compound were given to $120 \mu \mathrm{L}$ of suspended cells $(50.000 / \mathrm{mL})$ in wells of 96 -well plates. After 5 days of incubation growth inhibition $\left(\mathrm{IC}_{50}\right)$ was determined using an MTT assay. ${ }^{7}$ The compounds were dissolved in $\mathrm{MeOH}(1 \mathrm{mg} / \mathrm{mL})$, $\mathrm{MeOH}$ itself was used as negative control, epothilone $(1 \mathrm{mg} / \mathrm{mL})$ was used as positive control.

Table S8: Medium conditions for different cell types.

\begin{tabular}{|c|c|c|}
\hline Cell type & Medium & Additives \\
\hline L-929 (DSMZ ACC 2) & $\begin{array}{l}\text { DME medium (high glucose) } \\
\text { (Gibco) }\end{array}$ & $10 \%$ fetal calf serum (Gibco) \\
\hline $\begin{array}{l}\text { SKOV-3 DSMZ ATCC } \\
\text { HTB 77) }\end{array}$ & Mc Coys-Medium (Gibco) & $10 \%$ fetal calf serum (Gibco) \\
\hline MCF-7 (DSMZ ACC & RPMI-Medium (Gibco) & $10 \%$ fetal calf serum (Gibco), $1 \%$ \\
\hline 115) & & $\begin{array}{l}\text { MEM NEAA, } 0,25 \% \text { Human } \\
\text { Insulin (Gibco) }\end{array}$ \\
\hline $\begin{array}{l}\text { A549 (DSMZ ACC } \\
107)\end{array}$ & $\begin{array}{l}\text { DME medium (high glucose) } \\
\text { (Gibco) }\end{array}$ & $10 \%$ fetal calf serum (Gibco) \\
\hline A431(DSMZ ACC 91) & $\begin{array}{l}\text { DME medium (high glucose) } \\
\text { (Gibco) }\end{array}$ & $10 \%$ fetal calf serum (Gibco) \\
\hline $\begin{array}{l}\text { KB3.1 (DSMZ ACC } \\
158)\end{array}$ & $\begin{array}{l}\text { DME medium (high glucose) } \\
\text { (Gibco) }\end{array}$ & $10 \%$ fetal calf serum (Gibco) \\
\hline
\end{tabular}


Table S9: Cytotoxicity assay data $[\mu \mathrm{M}]$

\begin{tabular}{|c|c|c|c|c|c|c|c|}
\hline Compound & $I_{50} L 929$ & $\mathrm{IC}_{50} \mathrm{KB3.1}$ & $\mathrm{IC}_{50} \mathrm{A549}$ & $\mathrm{IC}_{50} \mathrm{~A} 431$ & $\mathrm{IC}_{50} \mathrm{PC}-3$ & $I^{\prime C} C_{50}$ SCOV-3 & $\mathrm{IC}_{50} \mathrm{MCF}-7$ \\
\hline 21 & * & * & n.t. & n.t. & n.t. & n.t. & n.t. \\
\hline 5 & * & * & n.t. & n.t. & n.t. & n.t. & n.t. \\
\hline 5 & * & * & n.t. & n.t. & n.t. & n.t. & n.t. \\
\hline 22 & * & * & n.t. & n.t. & n.t. & n.t. & n.t. \\
\hline 25 & ** & 64 & n.t. & n.t. & n.t. & n.t. & n.t. \\
\hline 25 & * & * & n.t. & n.t. & n.t. & n.t. & n.t. \\
\hline $26 a$ & ** & $* *$ & n.t. & n.t. & n.t. & n.t. & n.t. \\
\hline $26 b$ & ** & ** & n.t. & n.t. & n.t. & n.t. & n.t. \\
\hline $26 c$ & 19.6 & 7.7 & 25.0 & 34.5 & 13.7 & 25.6 & 23.4 \\
\hline 26d & 23.9 & 6.5 & 39.3 & 50.5 & 12.1 & 25.5 & 39.3 \\
\hline Epothilone B & 0.00082 & 0.000053 & 0.000055 & 0.000082 & 0.00029 & 0.00023 & 0.00007 \\
\hline
\end{tabular}

${ }^{*}$ Cells unchanged, no antiproliferative activity. ${ }^{* *}$ Cells unchanged, but weak antiproliferative activity. n.t. $=$ not tested. 


\section{References}

(1) Sheldrick, G. M. A Short History of SHELX. Acta Crystallogr. Sect. A Found. Crystallogr. 2008, 64 (1), 112-122. https://doi.org/10.1107/S0108767307043930.

(2) Farrugia, L. J. WinGX and ORTEP for Windows : An Update. J. Appl. Crystallogr. 2012, 45 (4), 849-854. https://doi.org/10.1107/S0021889812029111.

(3) Ibragimov, A. A.; Osmanov, Z.; Yagudaev, M. R.; Yunusov, S. Y. Alkaloids of Nitraria Sibirica: Structure of Nitrabirine. Khim. Prir. Soedin. 1983, 213-216.

(4) Becker, K.; Wessel, A.; Luangsa-ard, J. J.; Stadler, M. Viridistratins A-C, Antimicrobial and Cytotoxic Benzo[j]Fluoranthenes from Stromata of Annulohypoxylon Viridistratum (Hypoxylaceae, Ascomycota). Biomolecules 2020, $10 \quad$ (5), 805. https://doi.org/10.3390/biom10050805.

(5) Chepkirui, C.; Yuyama, K. T.; Wanga, L. A.; Decock, C.; Matasyoh, J. C.; Abraham, W. R.; Stadler, M. Microporenic Acids A-G, Biofilm Inhibitors, and Antimicrobial Agents from the Basidiomycete Microporus Species. J. Nat. Prod. 2018, 81 (4), 778-784. https://doi.org/10.1021/acs.jnatprod.7b00764.

(6) Schriefer, M. G.; Schrey, H.; Zeng, H.; Stadler, M.; Schobert, R. Synthesis of the Fungal Macrolide Berkeleylactone A and Its Inhibition of Microbial Biofilm Formation. Org. Biomol. Chem. 2021, 19 (21), 4743-4751. https://doi.org/10.1039/d1ob00717c.

(7) Mosmann, T. Rapid Colorimetric Assay for Cellular Growth and Survival: Application to Proliferation and Cytotoxicity Assays. J. Immunol. Methods 1983, 65 (1-2), 55-63. https://doi.org/10.1016/0022-1759(83)90303-4.

\section{Appendix}

HRMS, NMR and IR spectra of $21,5,5^{\prime}, 24,24^{\prime}, 25,25^{\prime}, 26 a, 26 b, 26 c$, and $26 d$. 
HRMS, NMR, and IR spectra for 21

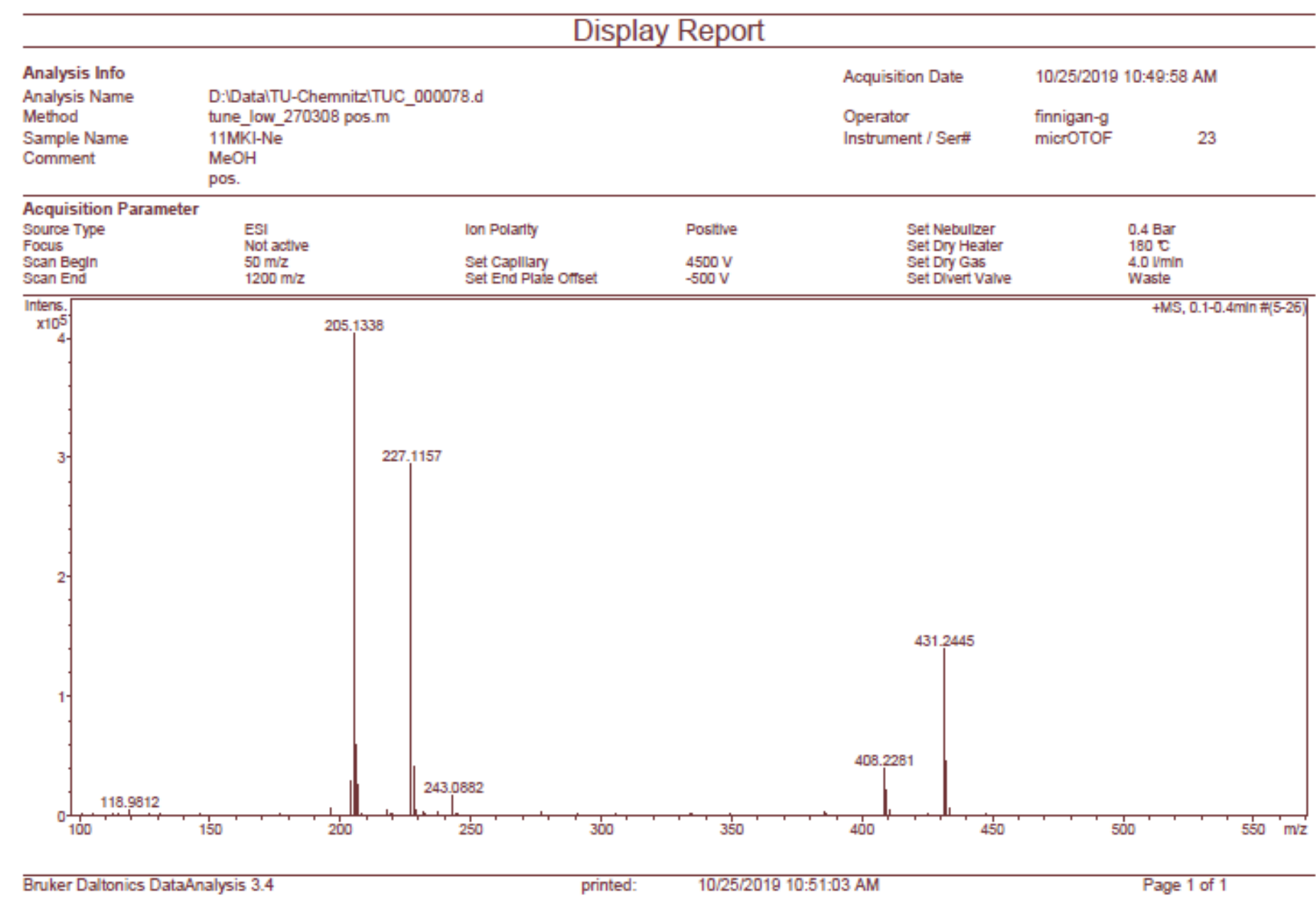

Figure S8: HRMS for 21 

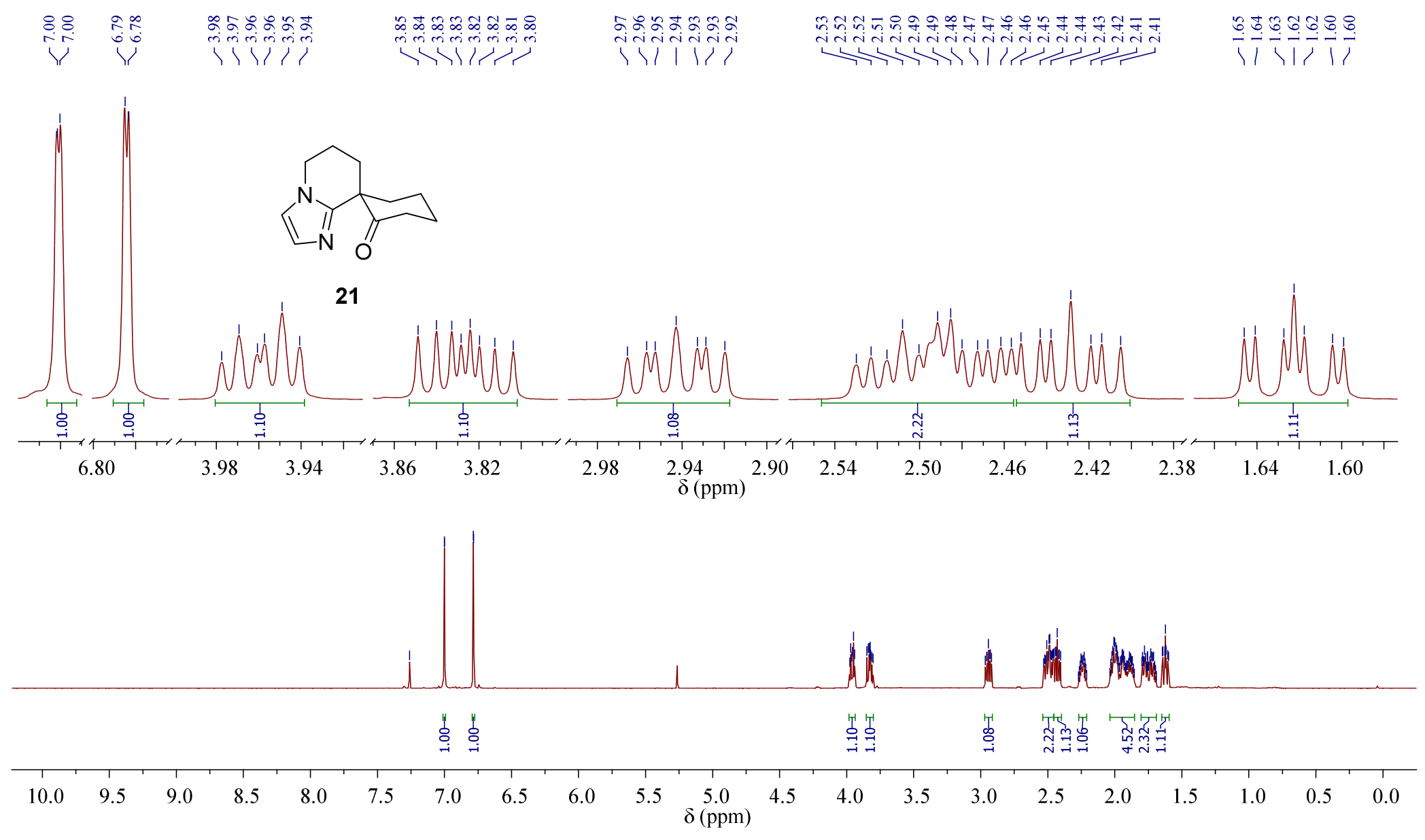

Figure S9: ${ }^{1} \mathrm{H}$ NMR $\left(\mathrm{CDCl}_{3}, 600 \mathrm{MHz}\right)$ spectrum for 21 


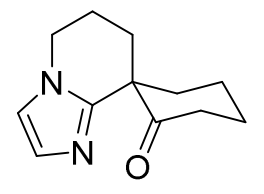

21

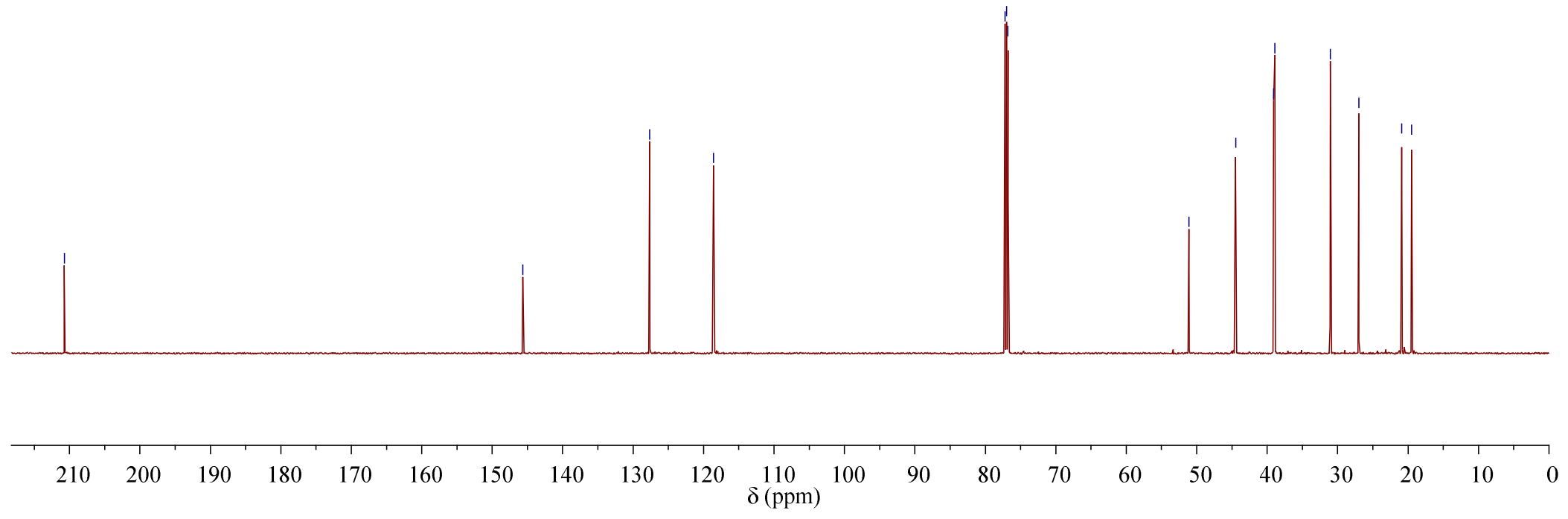

Figure S10: ${ }^{13} \mathrm{C}\left\{{ }^{1} \mathrm{H}\right\}$ NMR $\left(\mathrm{CDCl}_{3}, 150.9 \mathrm{MHz}\right)$ spectrum for 21 


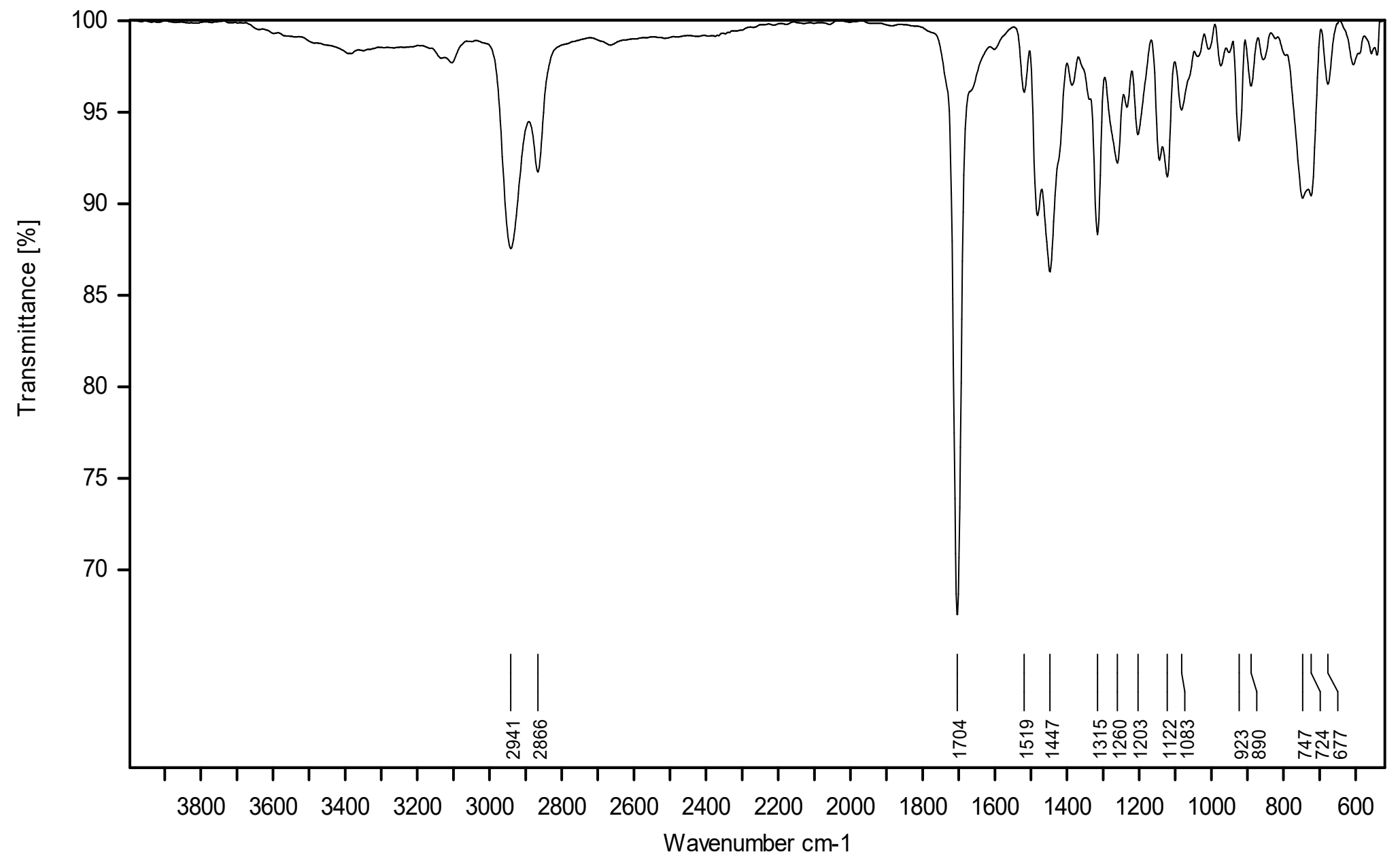

Figure S11: IR spectrum for 21 
HRMS, NMR, and IR spectra for 5

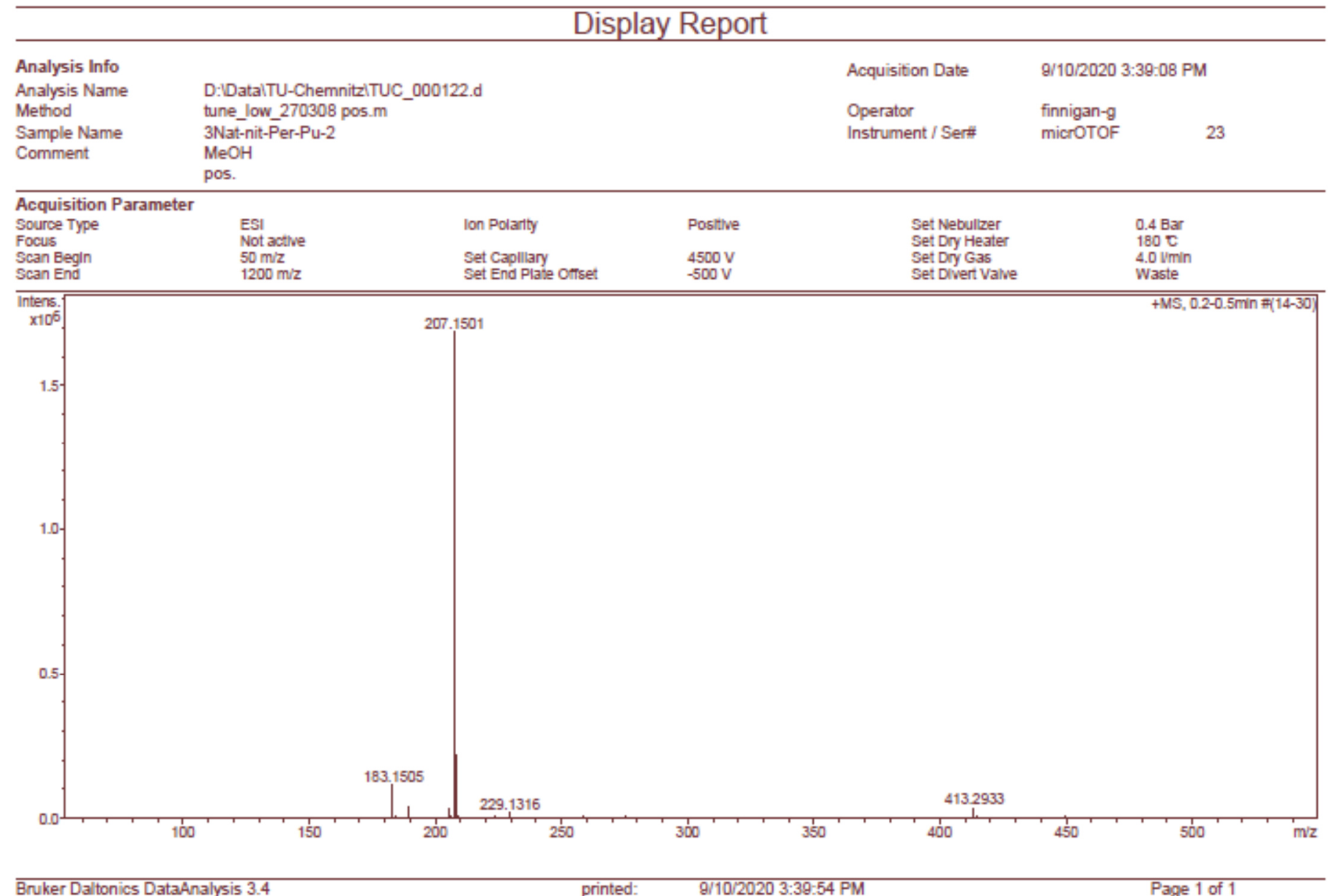

Figure S12: HRMS for 5 

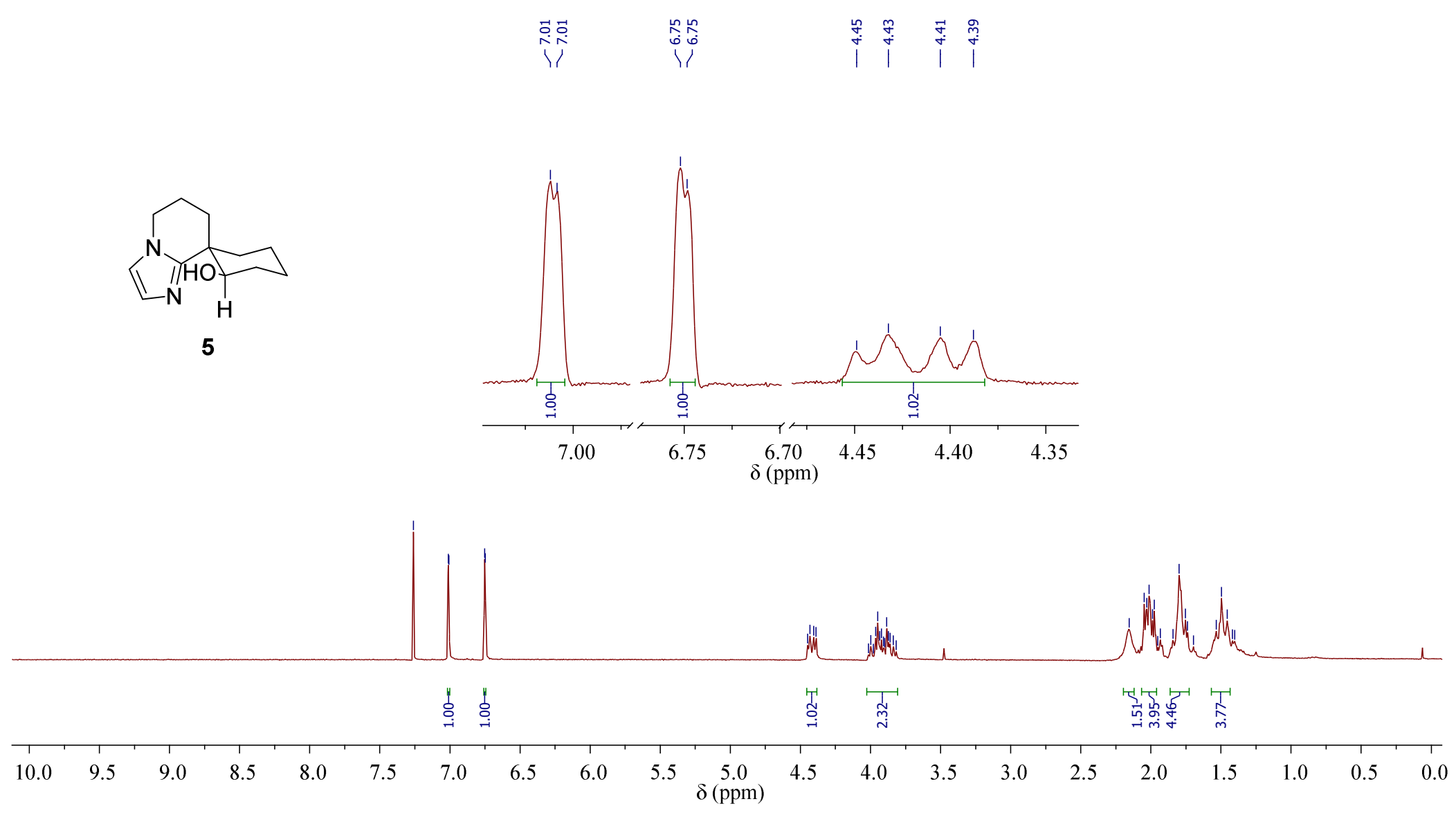

Figure S13: ${ }^{1} \mathrm{H} \mathrm{NMR}\left(\mathrm{CDCl}_{3}, 250 \mathrm{MHz}\right)$ spectrum for 5 


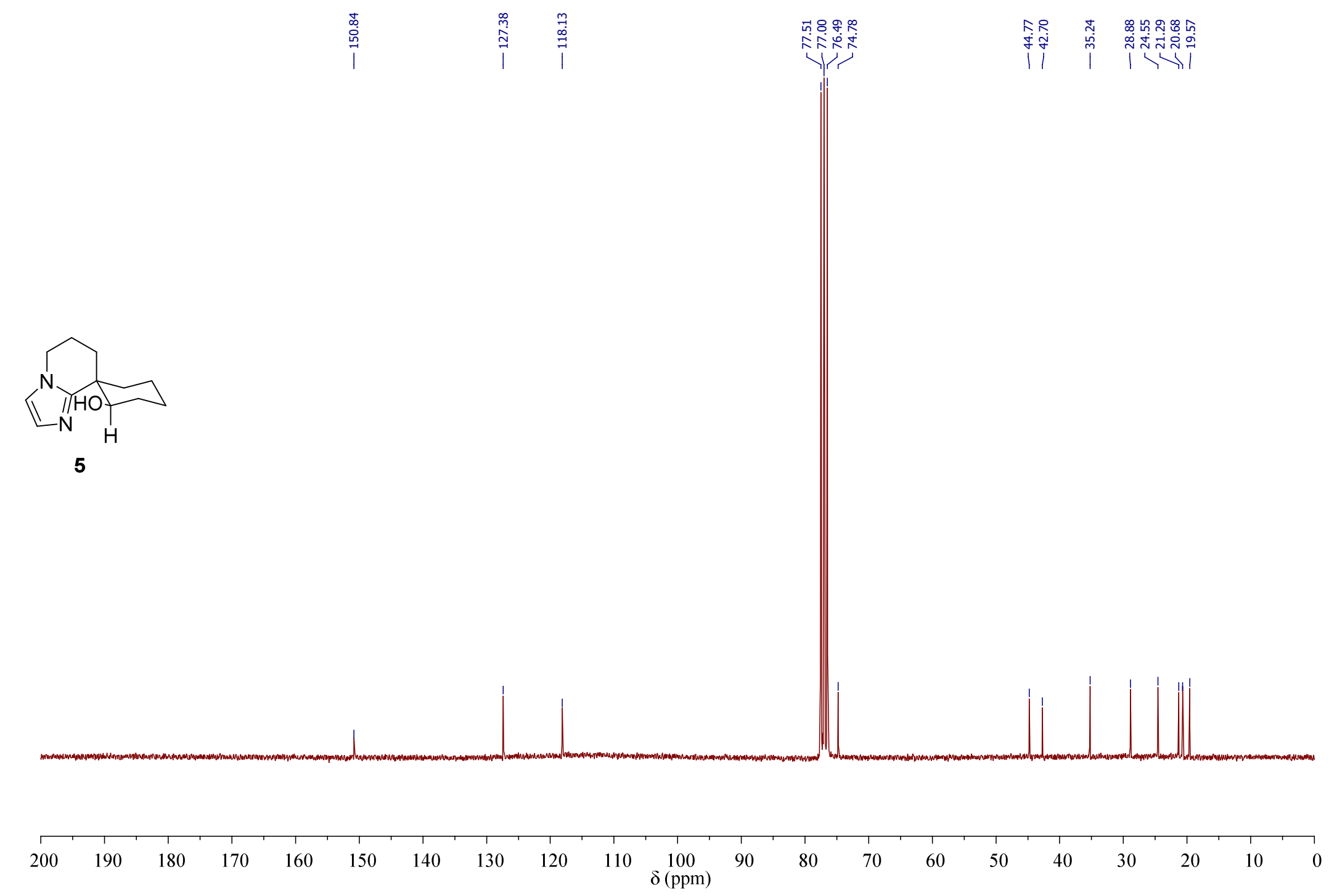

Figure S14: ${ }^{13} \mathrm{C}\left\{{ }^{1} \mathrm{H}\right\} \mathrm{NMR}\left(\mathrm{CDCl}_{3}, 69.9 \mathrm{MHz}\right)$ spectrum for 5 

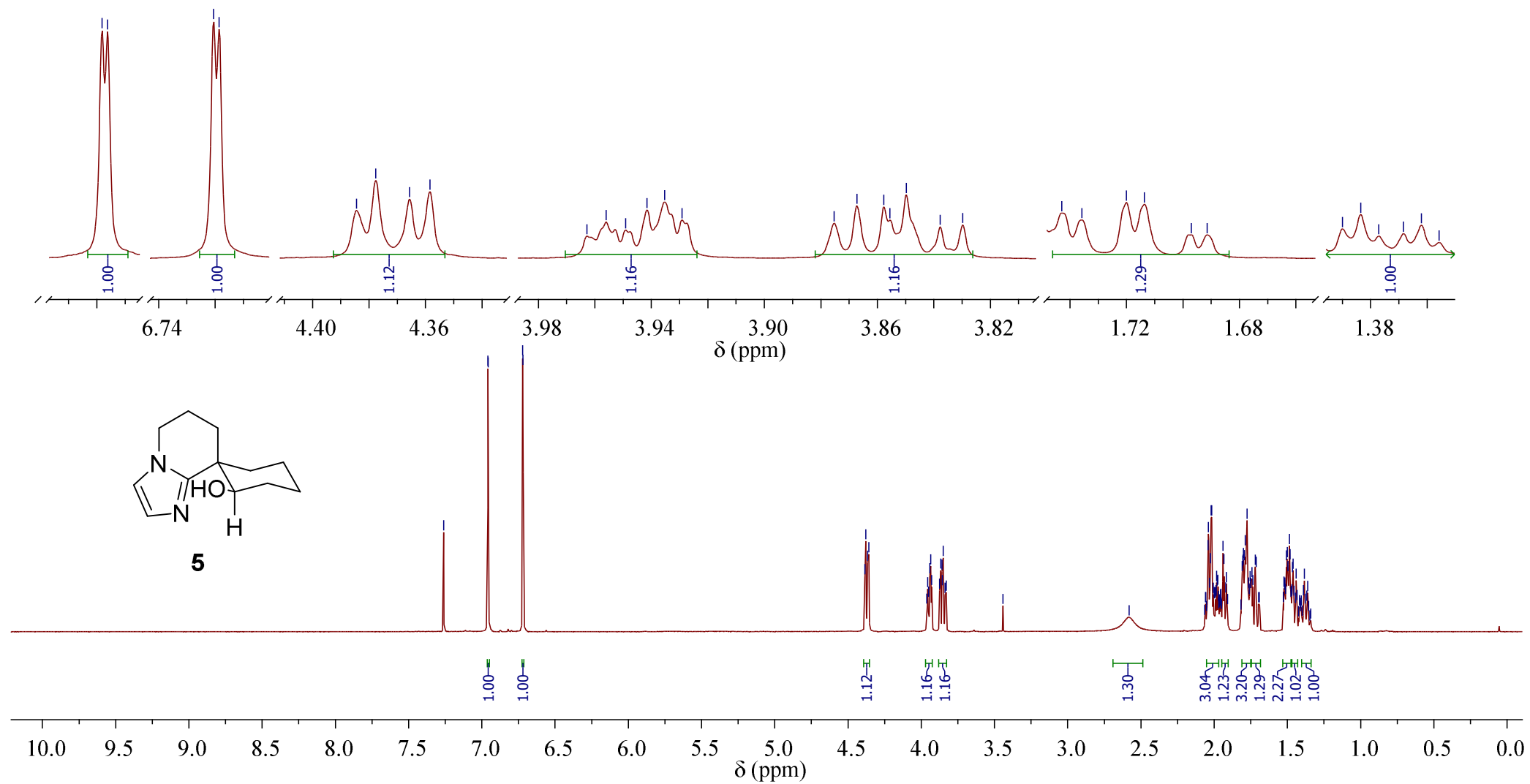

Figure S15: ${ }^{1} \mathrm{H}$ NMR $\left(\mathrm{CDCl}_{3}, 600 \mathrm{MHz}\right)$ spectrum for 5 


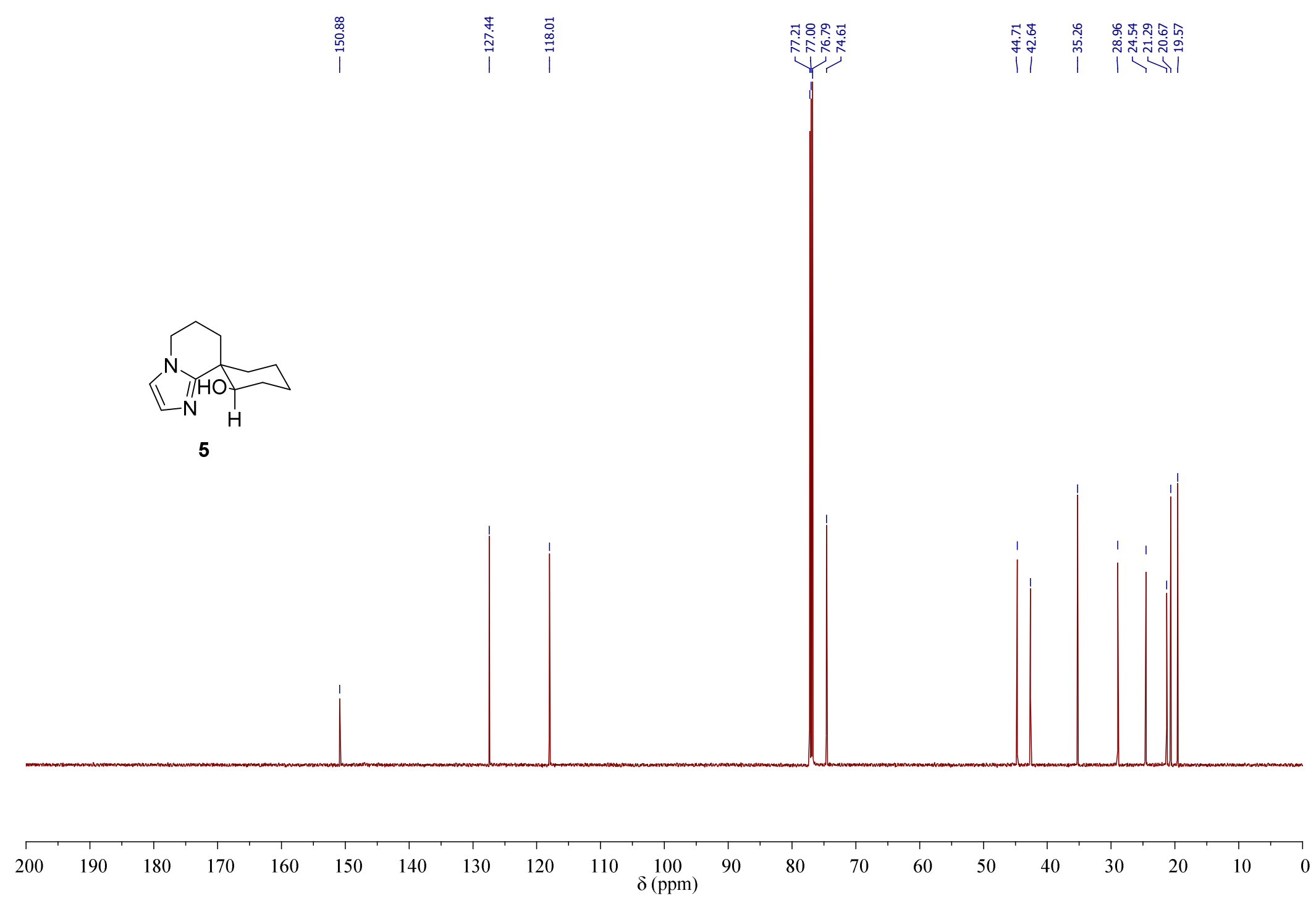

Figure S16: ${ }^{13} \mathrm{C}\left\{{ }^{1} \mathrm{H}\right\}$ NMR $\left(\mathrm{CDCl}_{3}, 150.9 \mathrm{MHz}\right)$ spectrum for 5 


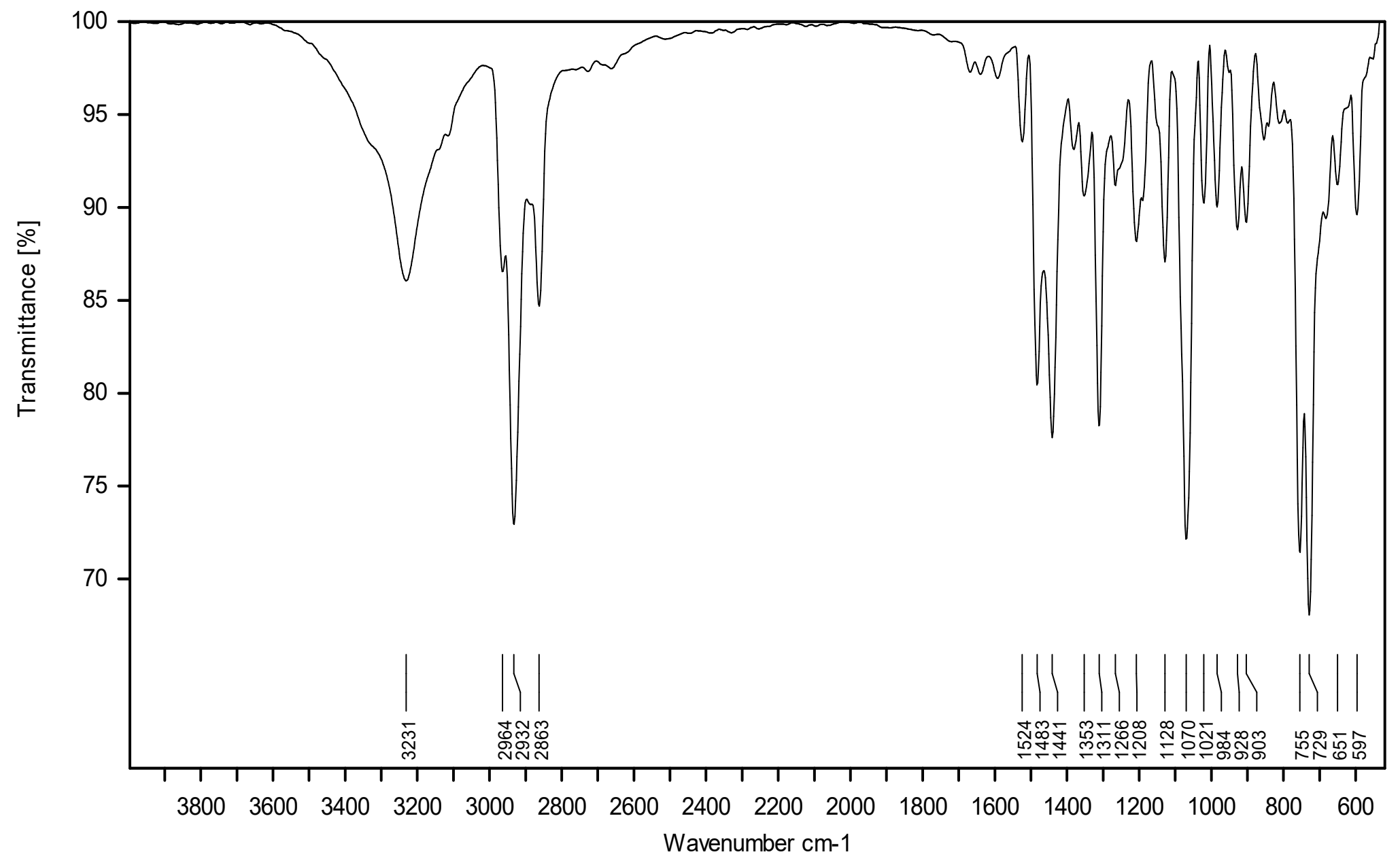

Figure S17: IR spectrum for 5 
HRMS, NMR, and IR spectra for 5'

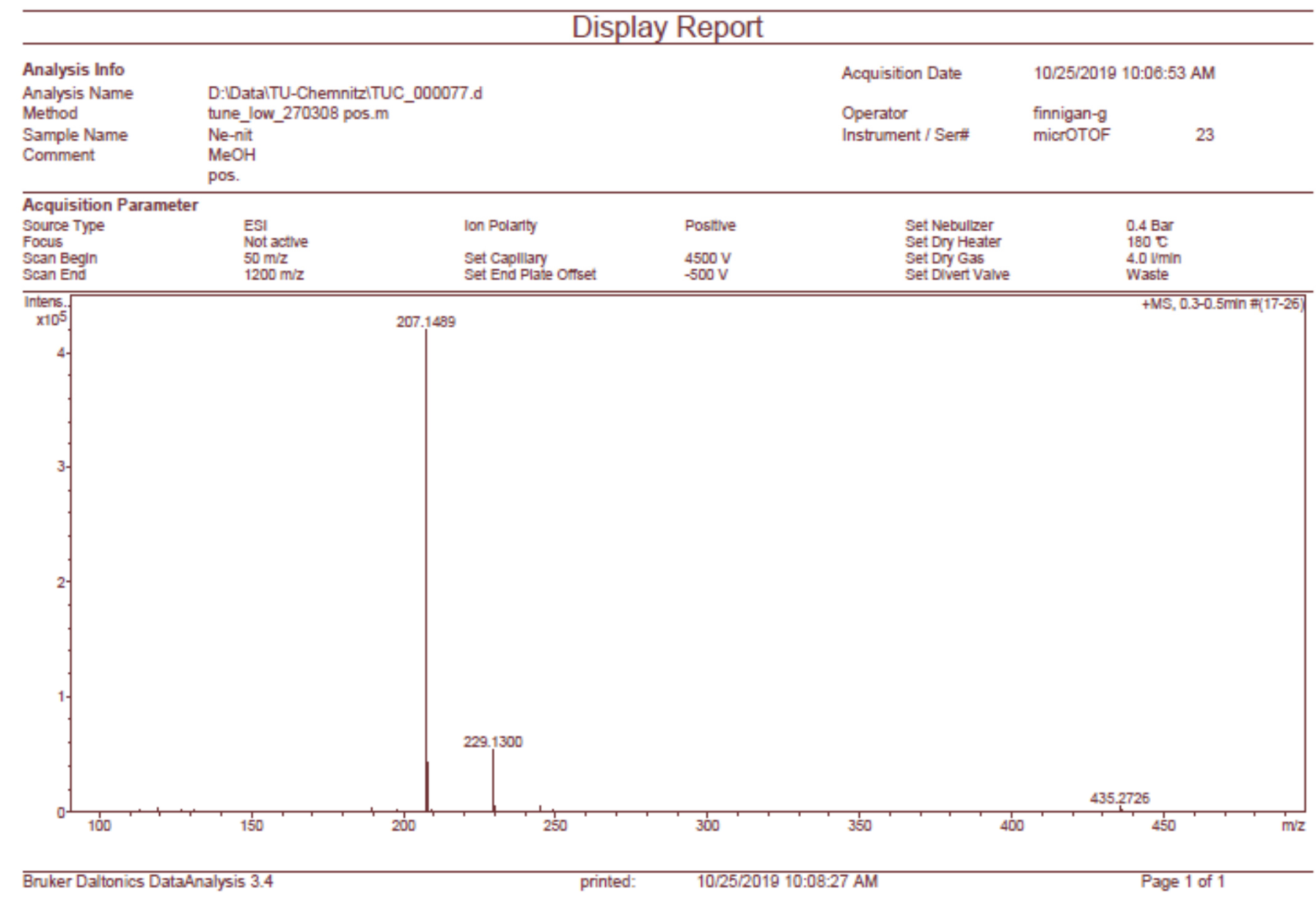

Figure S18: HRMS for 5 

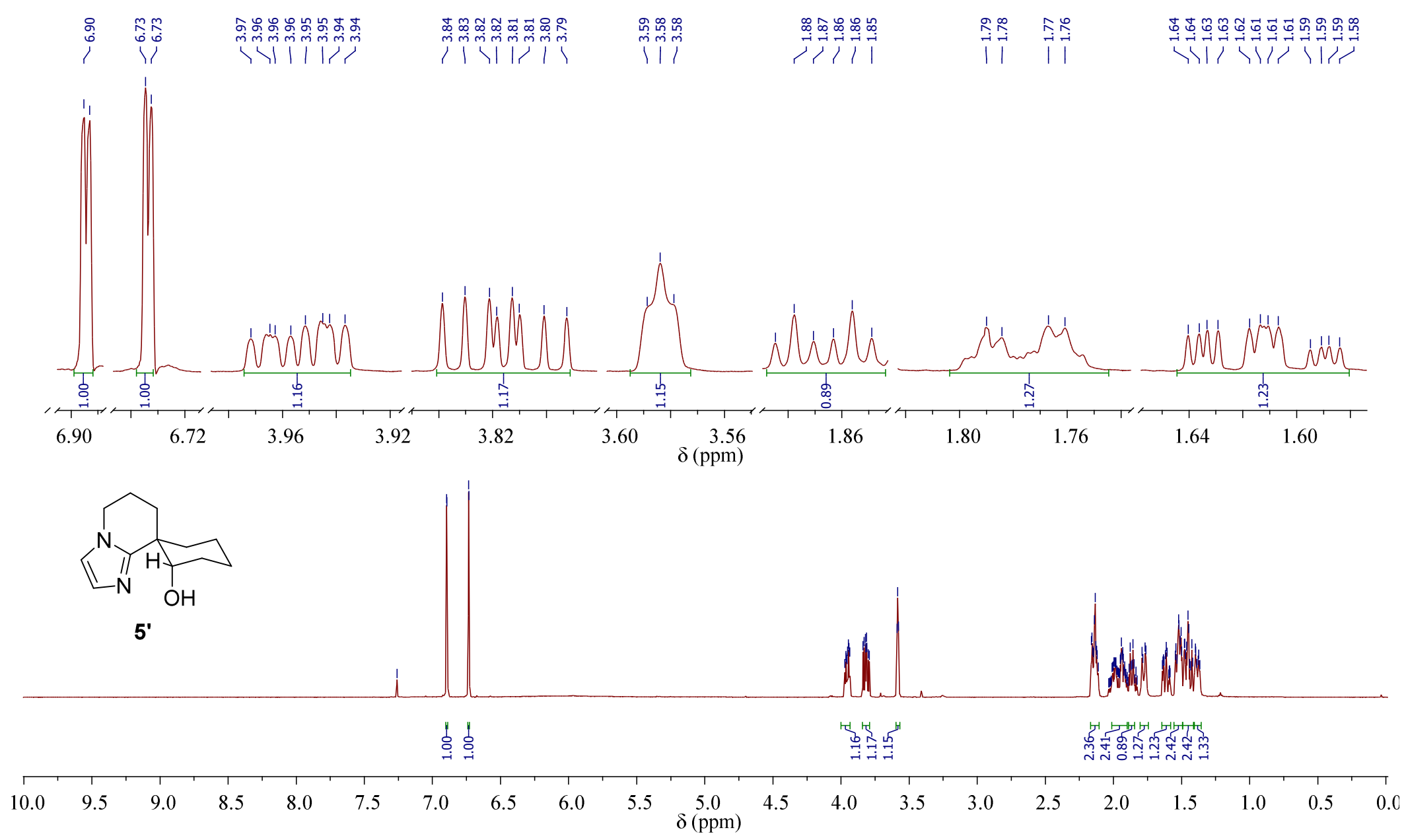

Figure S19: ${ }^{1} \mathrm{H} \mathrm{NMR}\left(\mathrm{CDCl}_{3}, 600 \mathrm{MHz}\right)$ spectrum for 5' 


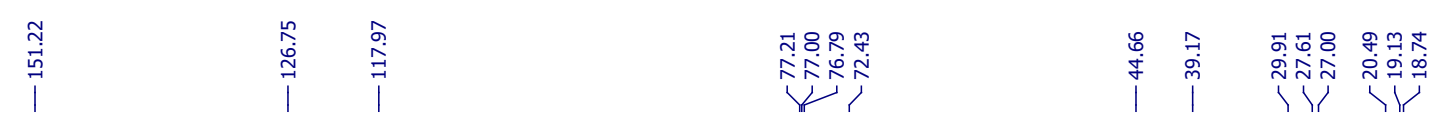
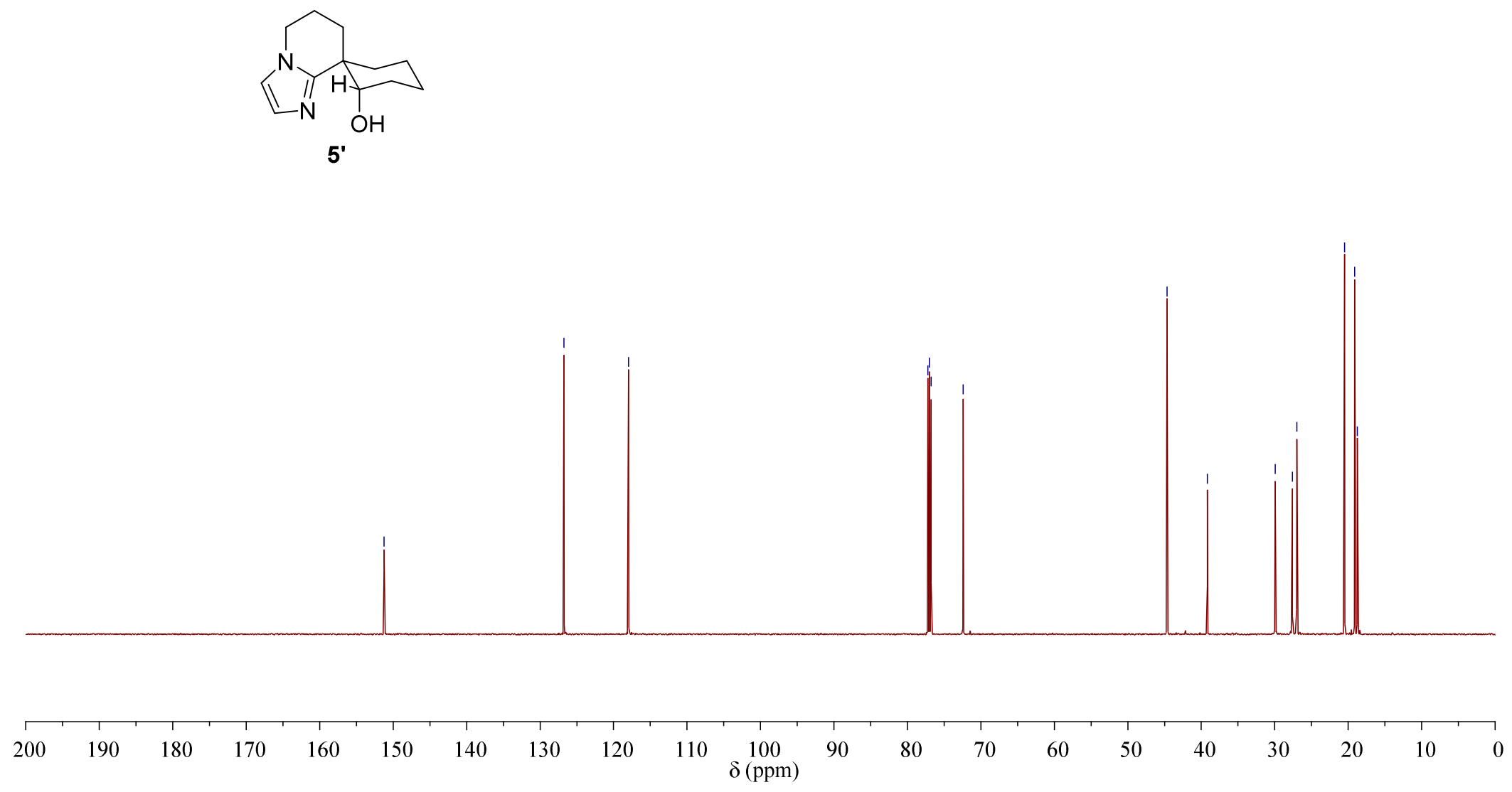

Figure S20: ${ }^{13} \mathrm{C}\left\{{ }^{1} \mathrm{H}\right\} \mathrm{NMR}\left(\mathrm{CDCl}_{3}, 150.9 \mathrm{MHz}\right)$ spectrum for $5^{\prime}$ 


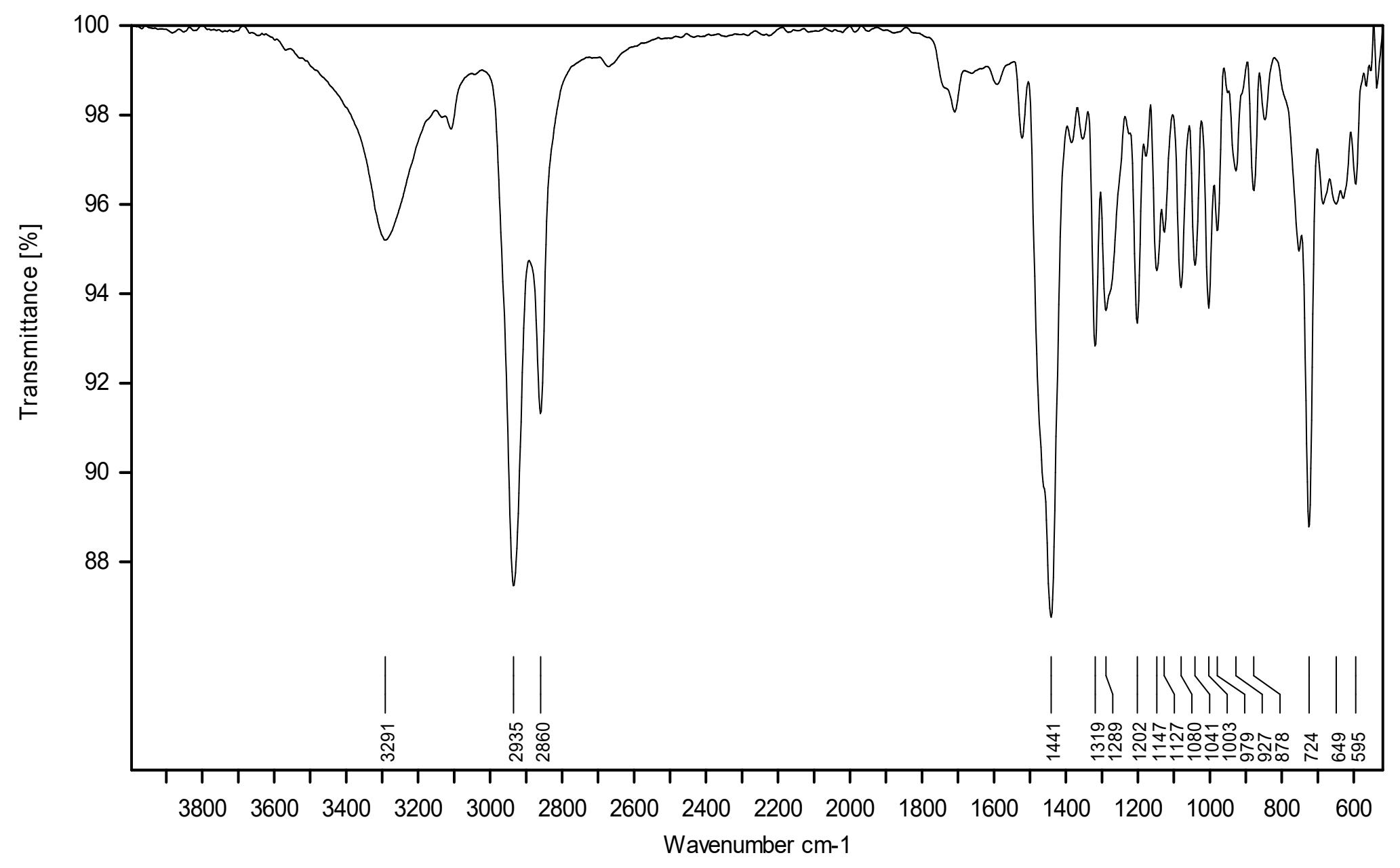

Figure S21: IR spectrum for 5' 
HRMS, NMR, and IR spectra for 22

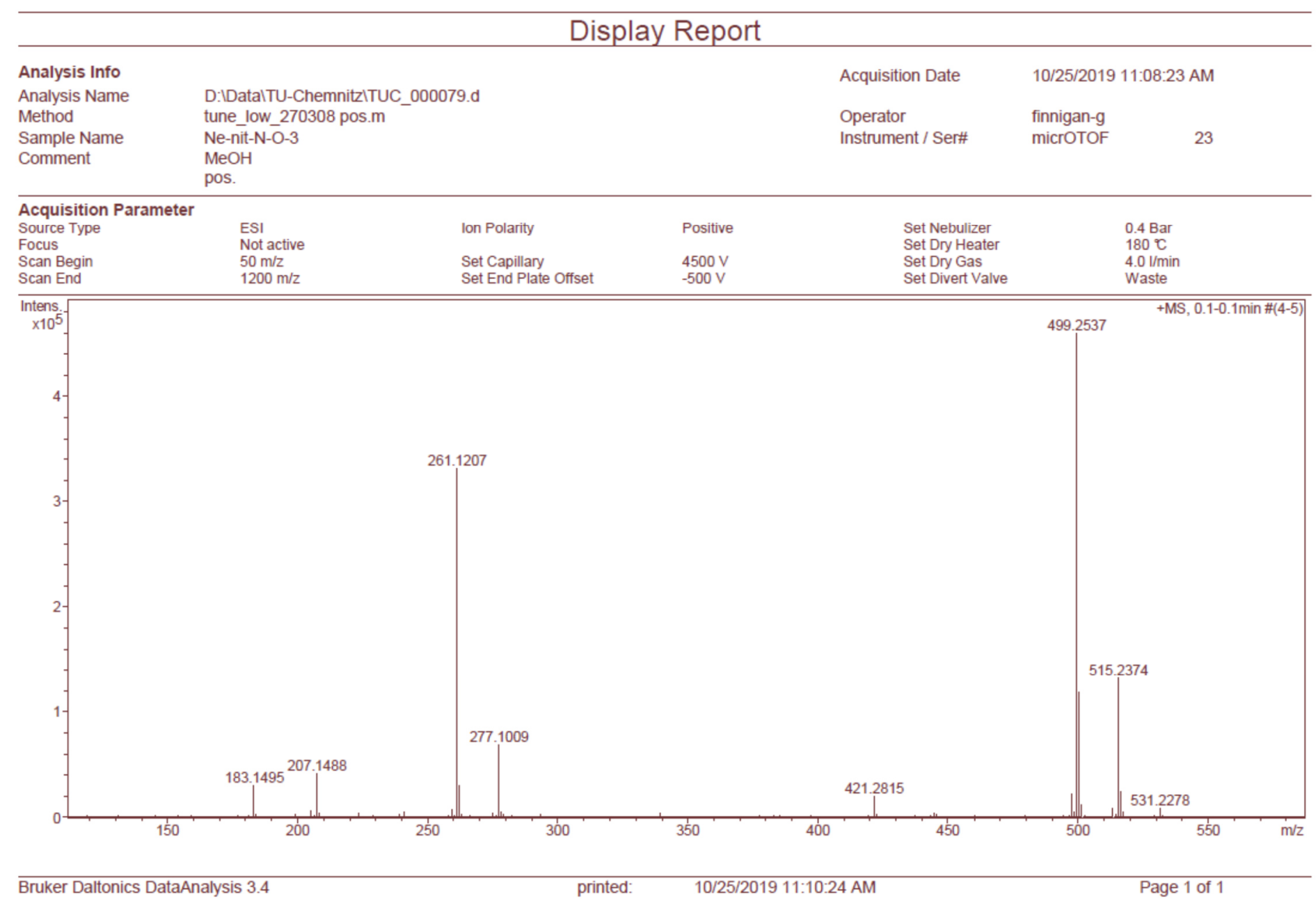

Figure S22: HRMS for 22 


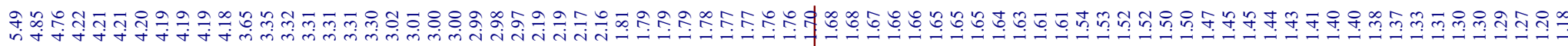

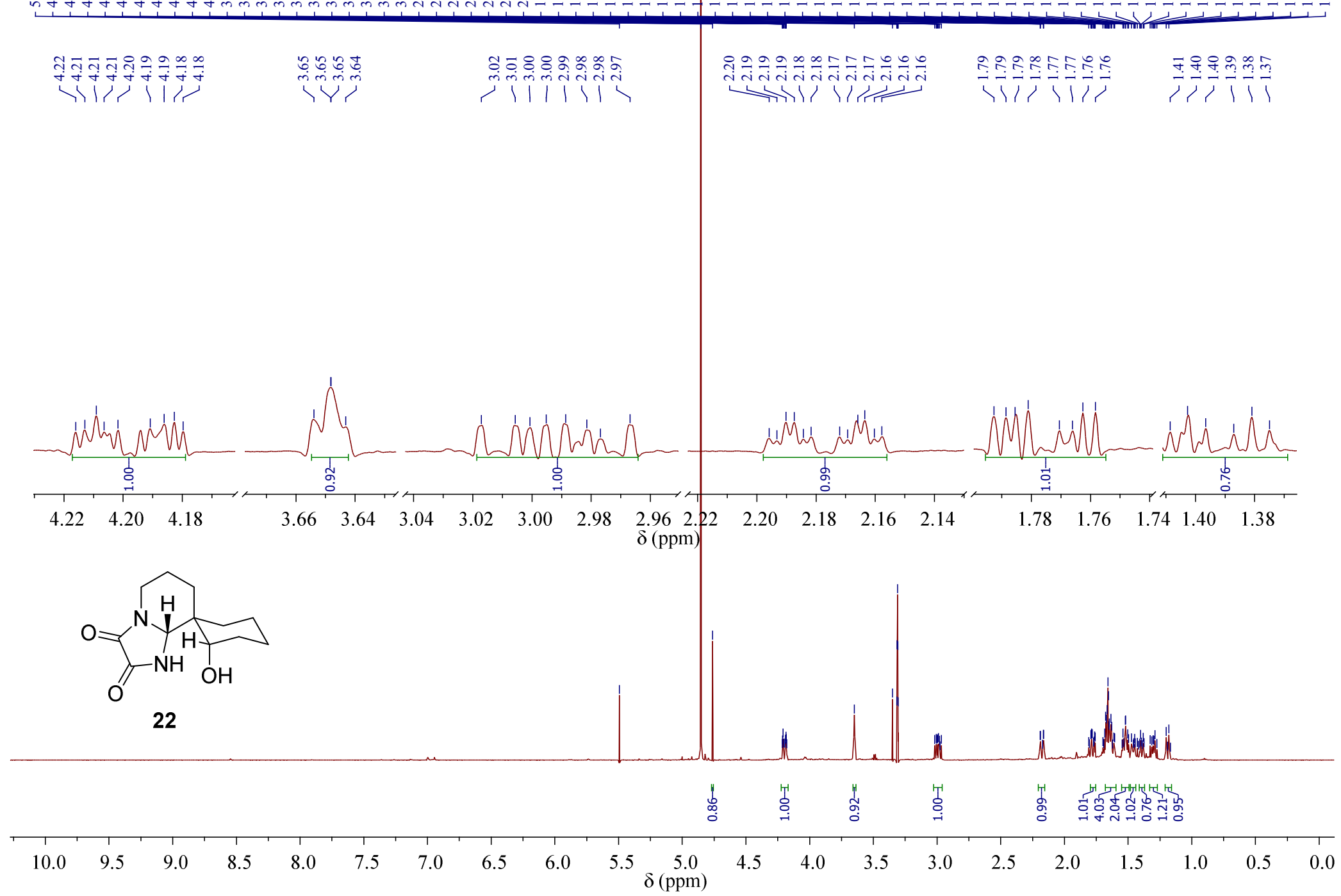

Figure S23: ${ }^{1} \mathrm{H}$ NMR $\left(\mathrm{CD}_{3} \mathrm{OD}, 600 \mathrm{MHz}\right)$ spectrum for 22 


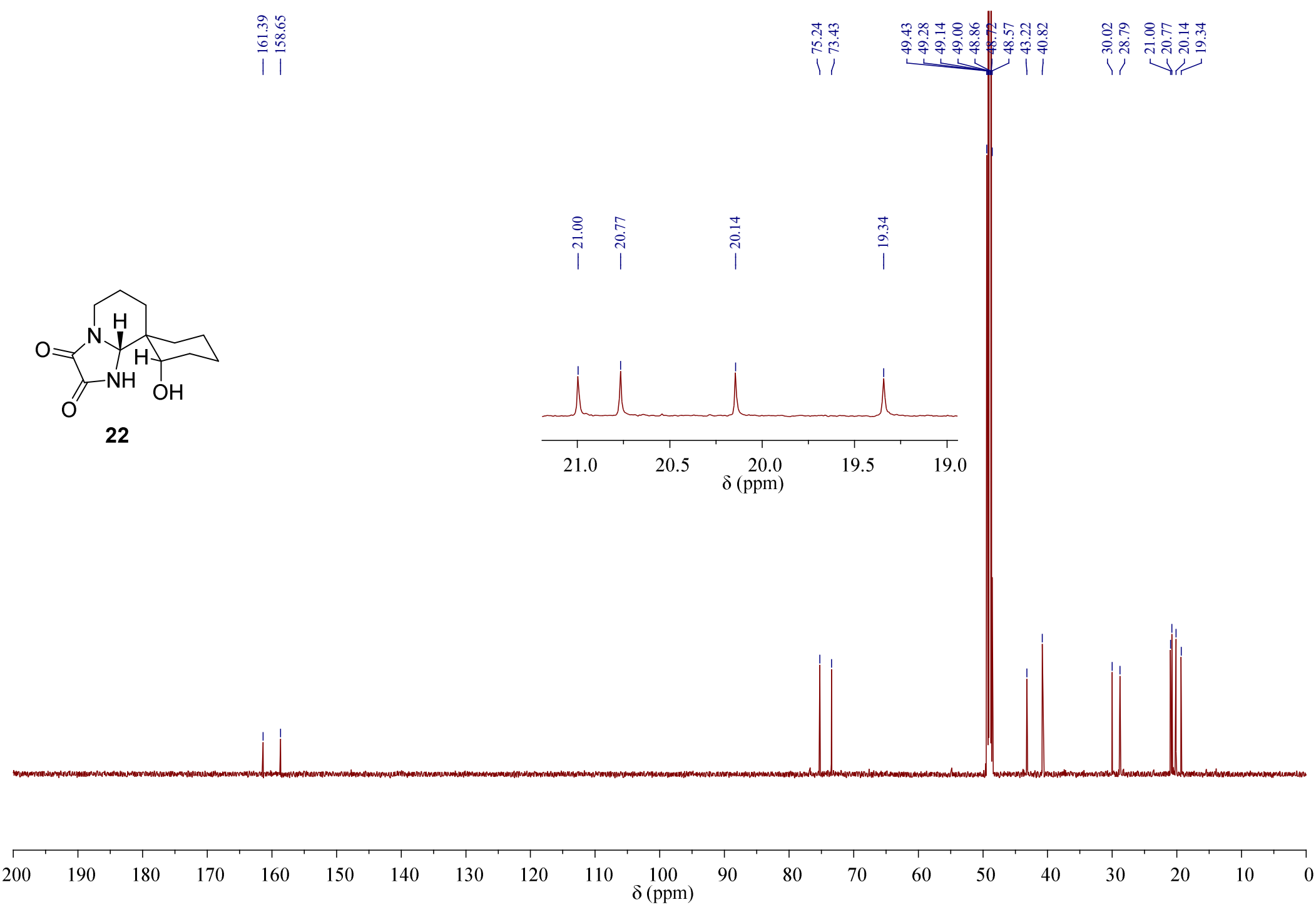

Figure S24: ${ }^{13} \mathrm{C}\left\{{ }^{1} \mathrm{H}\right\} \mathrm{NMR}\left(\mathrm{CD}_{3} \mathrm{OD}, 150.9 \mathrm{MHz}\right)$ spectrum for 22 


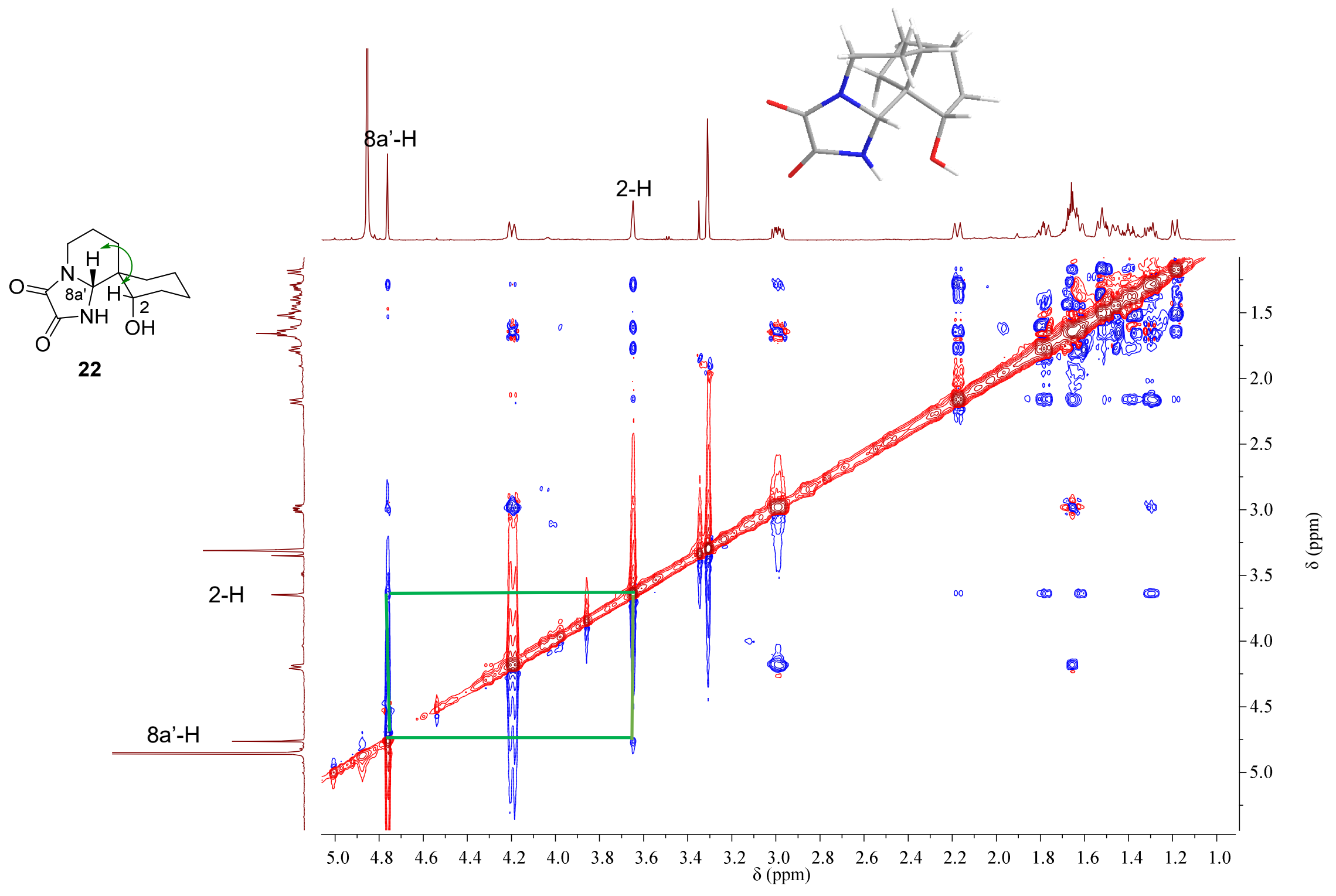

Figure S25: NOESY $\left(C_{3} \mathrm{OD}, 600 \mathrm{MHz}\right)$ spectrum for 22 


$$
4
$$


HRMS, NMR, and IR spectra for 24

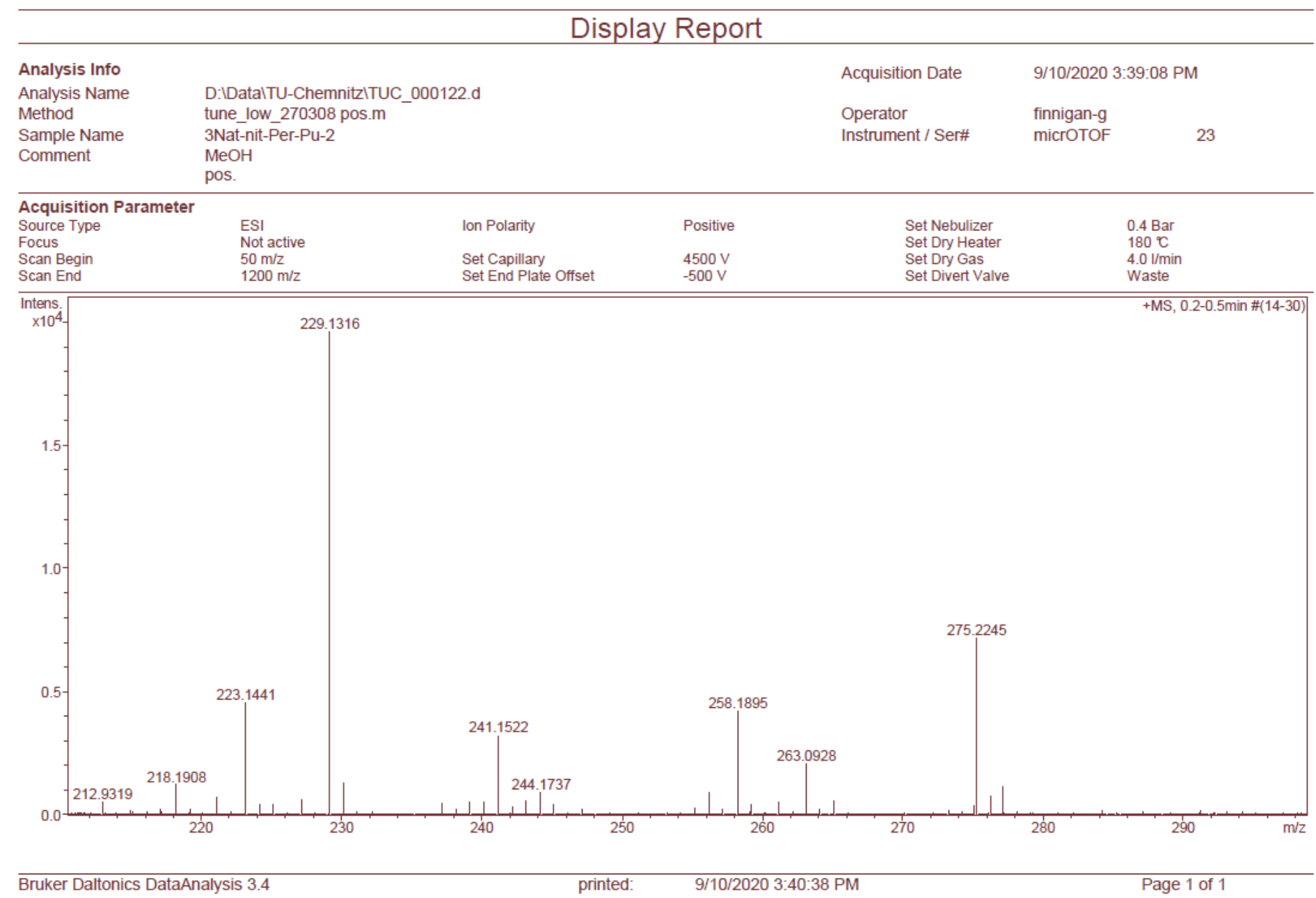

Figure S27: HRMS for 24 


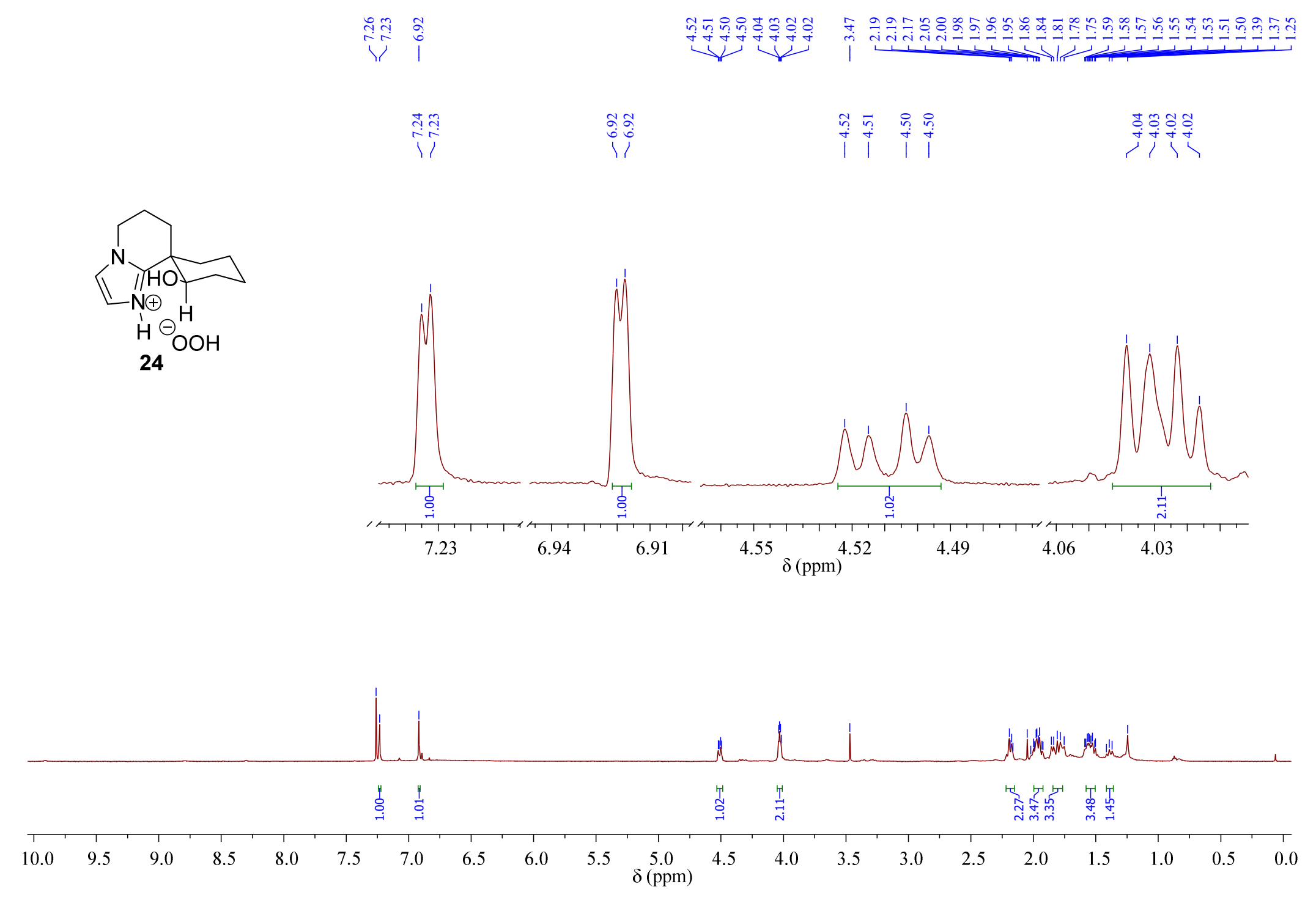

Figure S28: ${ }^{1} \mathrm{H}$ NMR $\left(\mathrm{CDCl}_{3}, 600 \mathrm{MHz}\right)$ spectrum for 24 

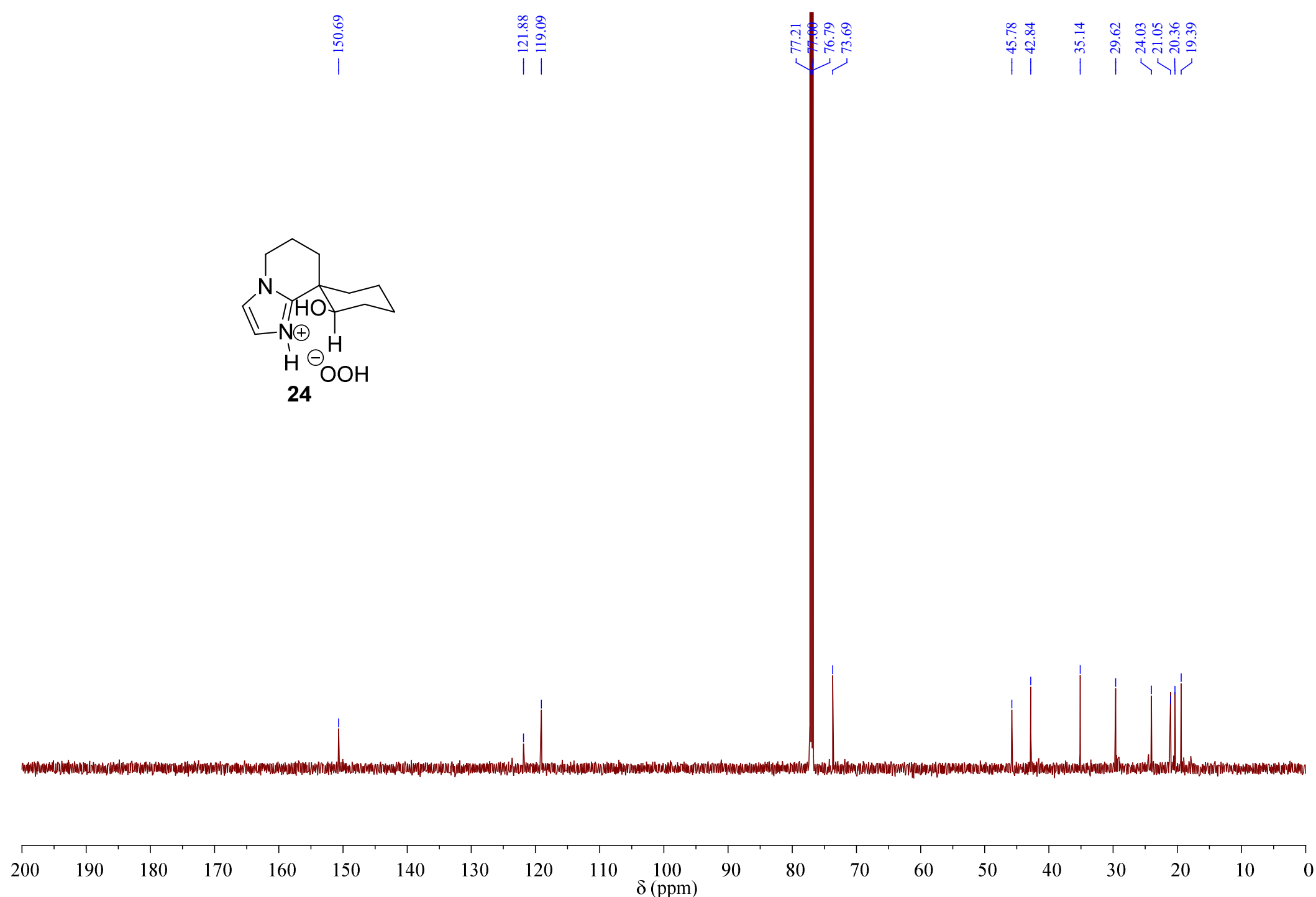

Figure S29: ${ }^{13} \mathrm{C}\left\{{ }^{1} \mathrm{H}\right\} \mathrm{NMR}\left(\mathrm{CDCl}_{3}, 150.9 \mathrm{MHz}\right)$ spectrum for 24 


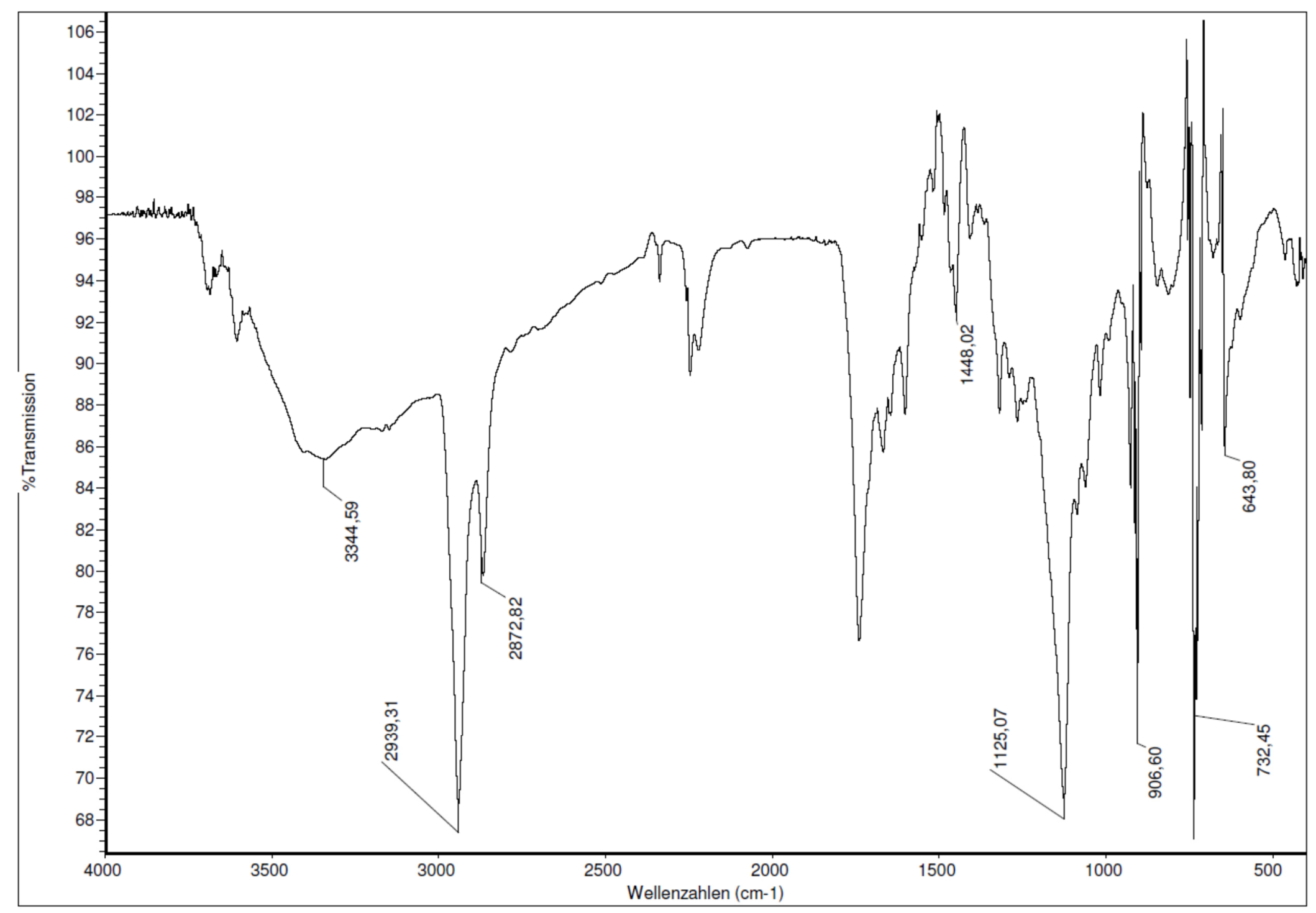

Figure S30: IR spectrum for 24 
HRMS, NMR, and IR spectra for 24'

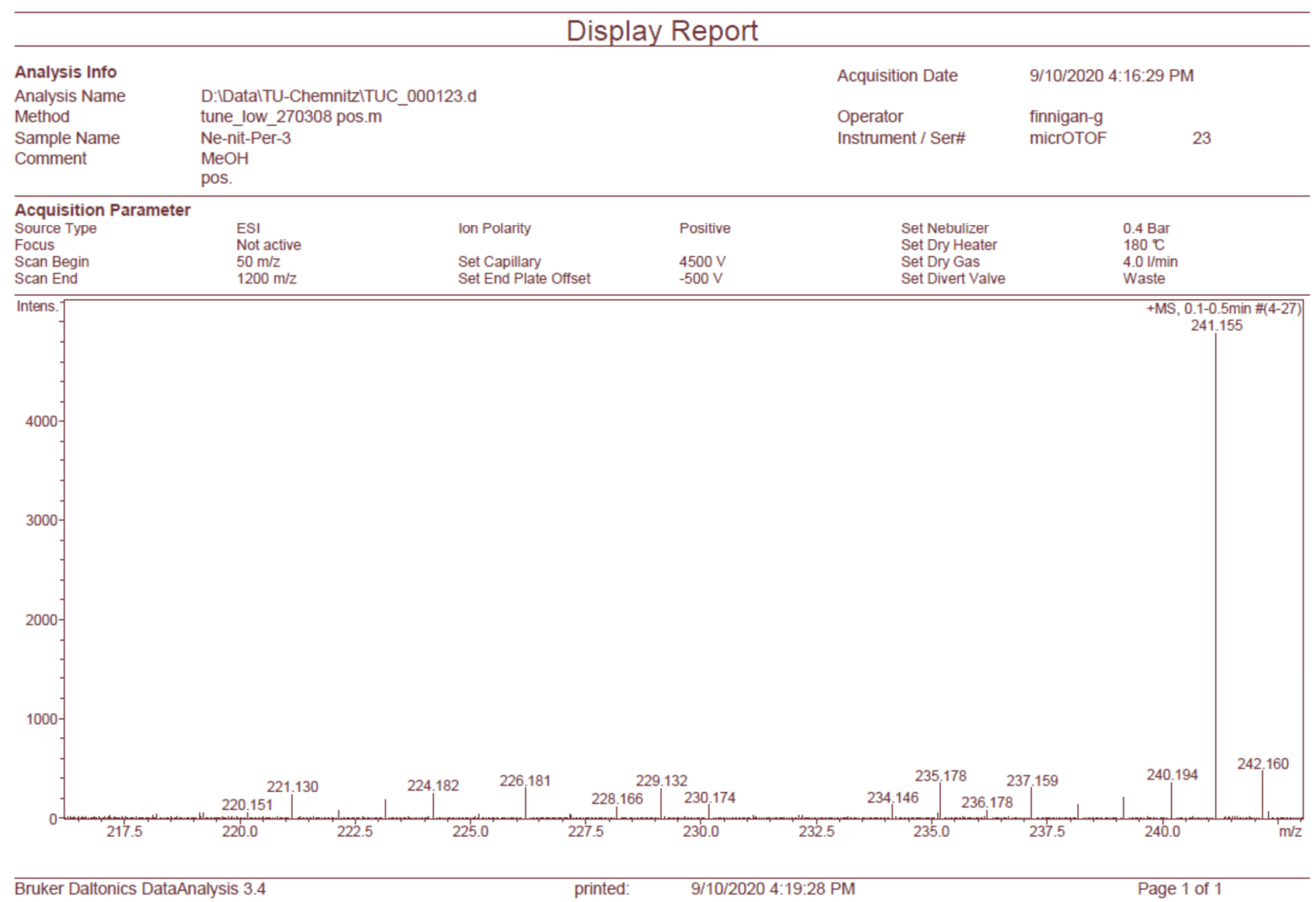

Figure S31: HRMS for 24' 

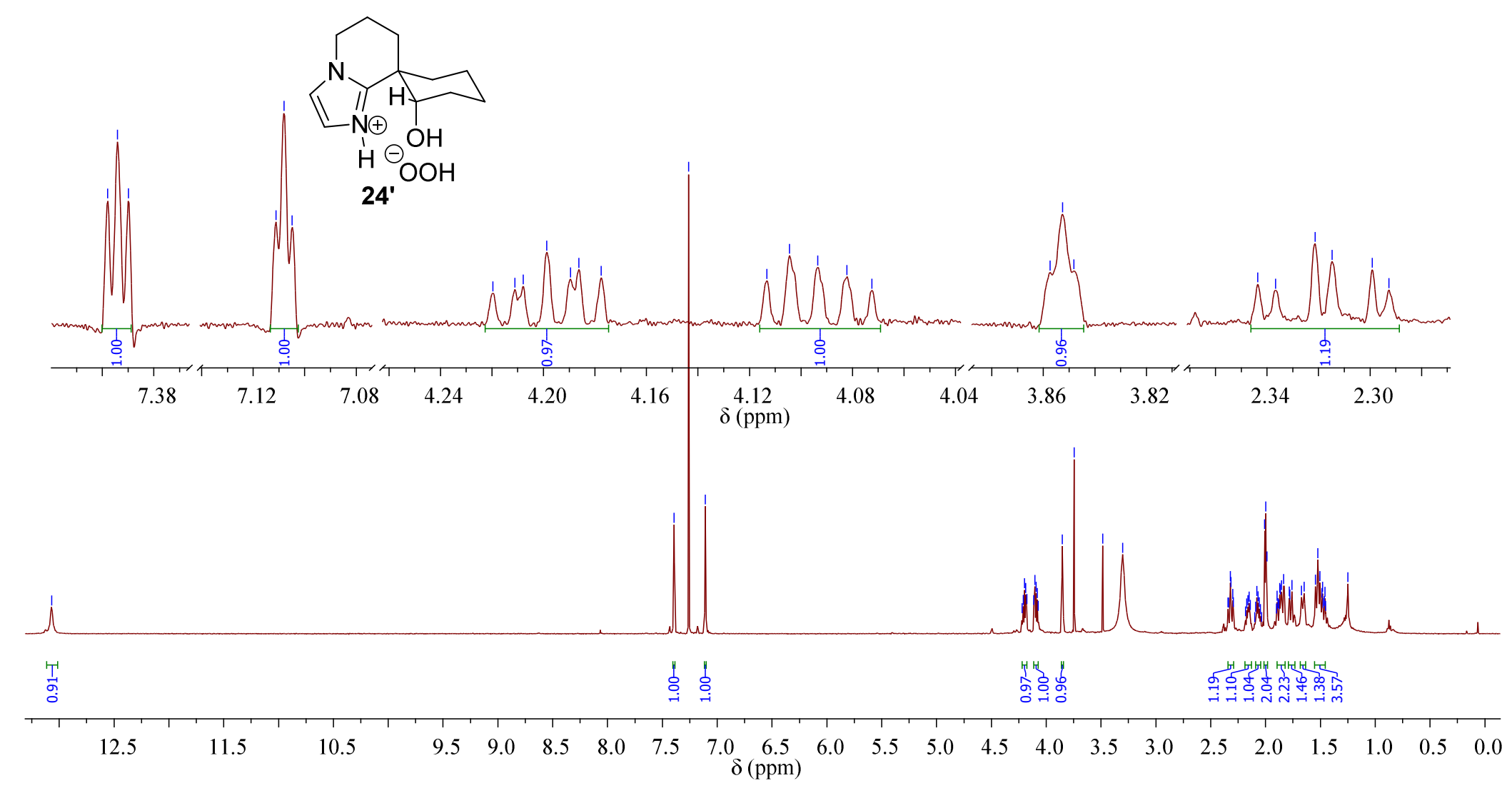

Figure S32: ' $\mathrm{H} \mathrm{NMR}\left(\mathrm{CDCl}_{3}, 600 \mathrm{MHz}\right)$ spectrum for 24 ' 

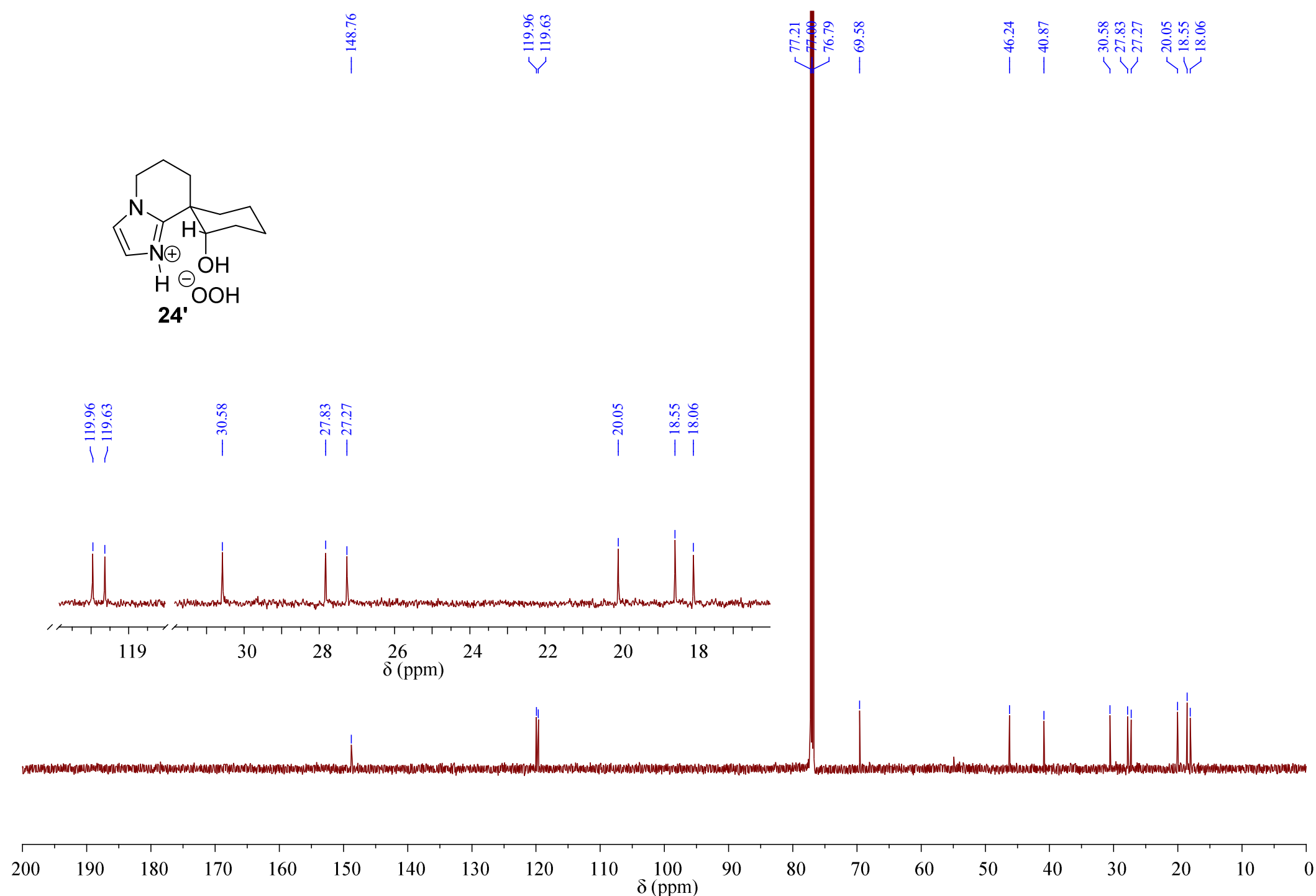

Figure S33: ${ }^{13} \mathrm{C}\left\{{ }^{1} \mathrm{H}\right\}$ NMR $\left(\mathrm{CDCl}_{3}, 150.9 \mathrm{MHz}\right)$ spectrum for $25^{\prime}$ 


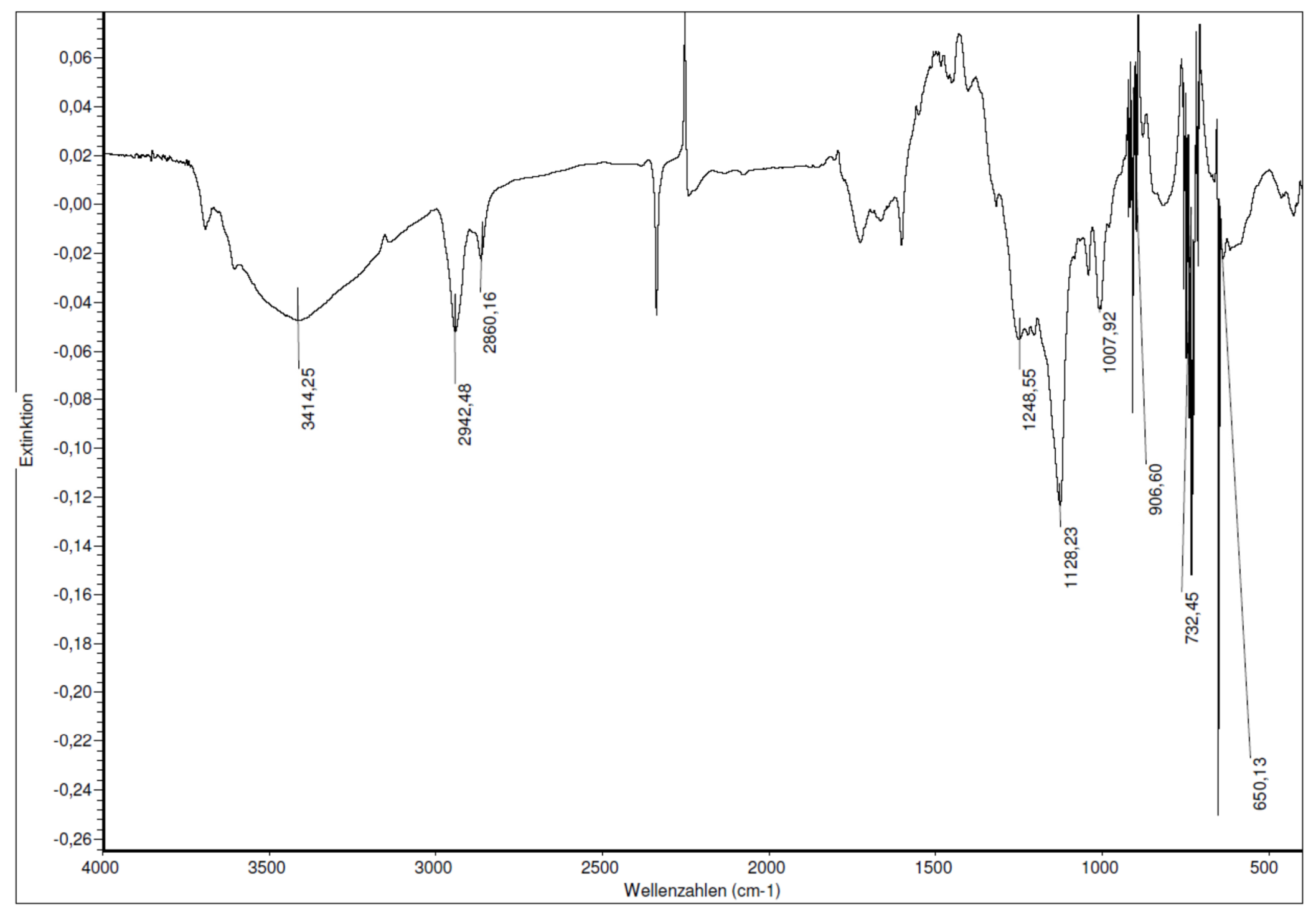

Figure S34: IR spectrum for 24' 
HRMS, NMR, and IR spectra for 25

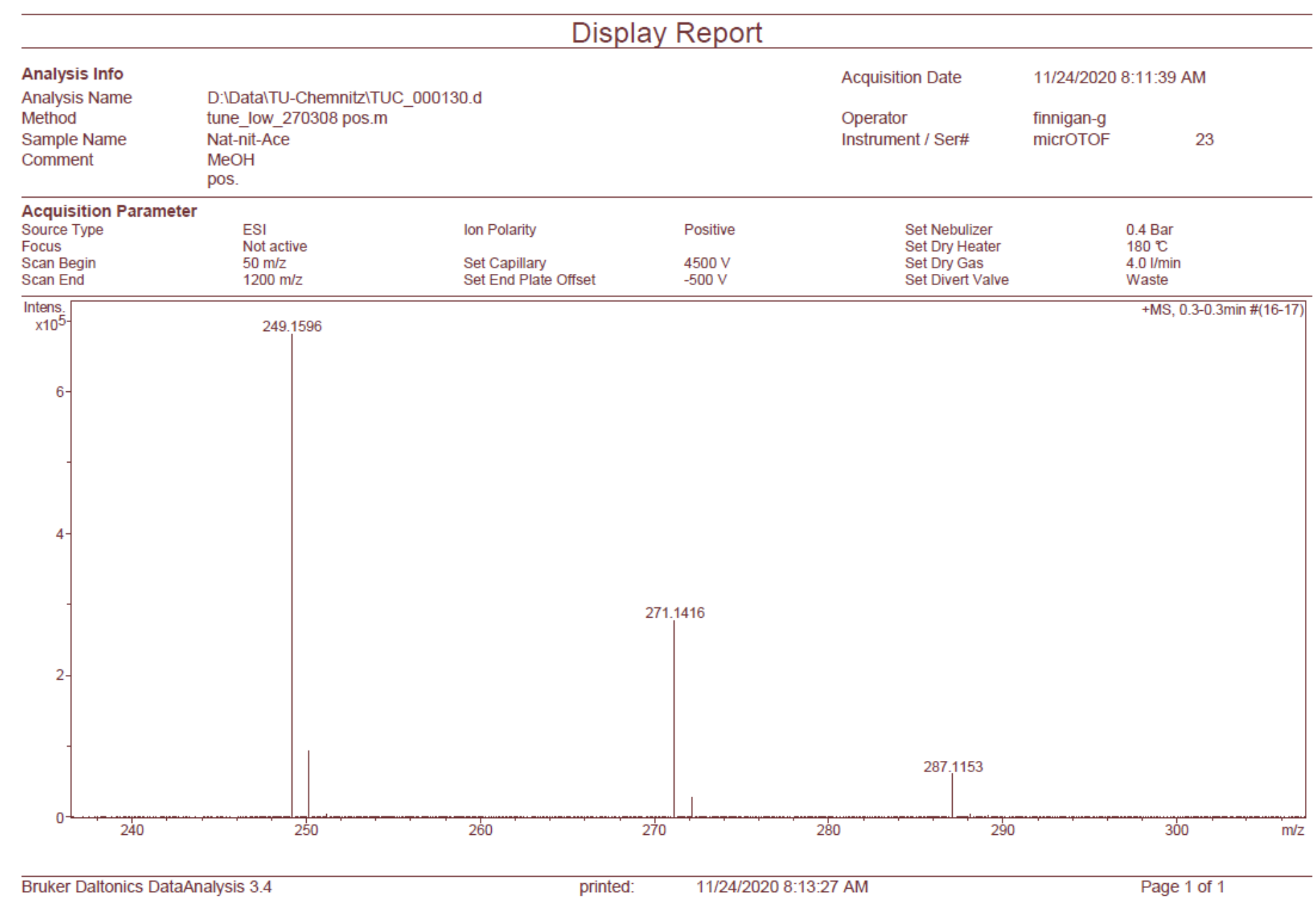

Figure S35: HRMS for 25 

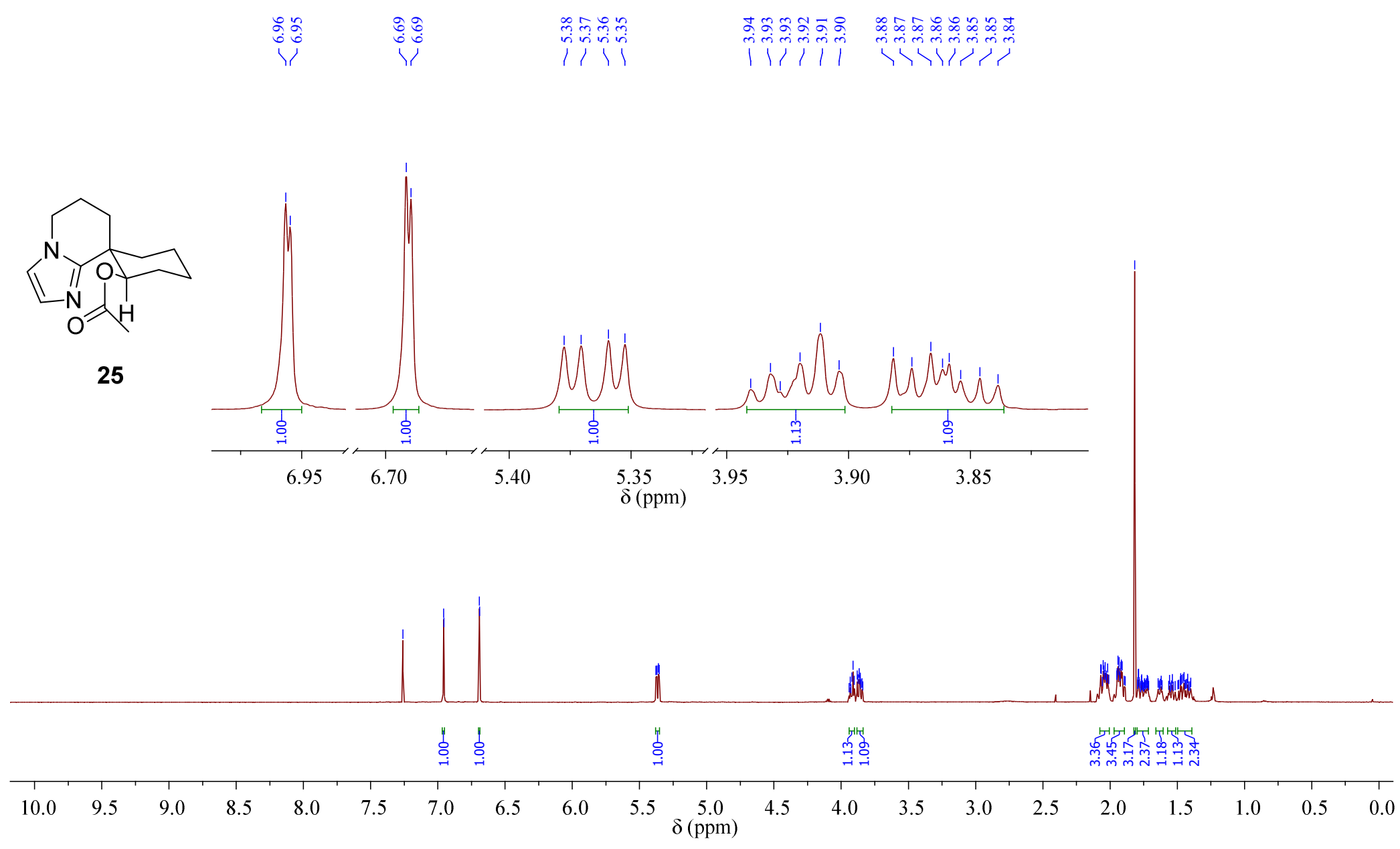

Figure S36: ${ }^{1} \mathrm{H}$ NMR $\left(\mathrm{CDCl}_{3}, 600 \mathrm{MHz}\right)$ spectrum for 25 


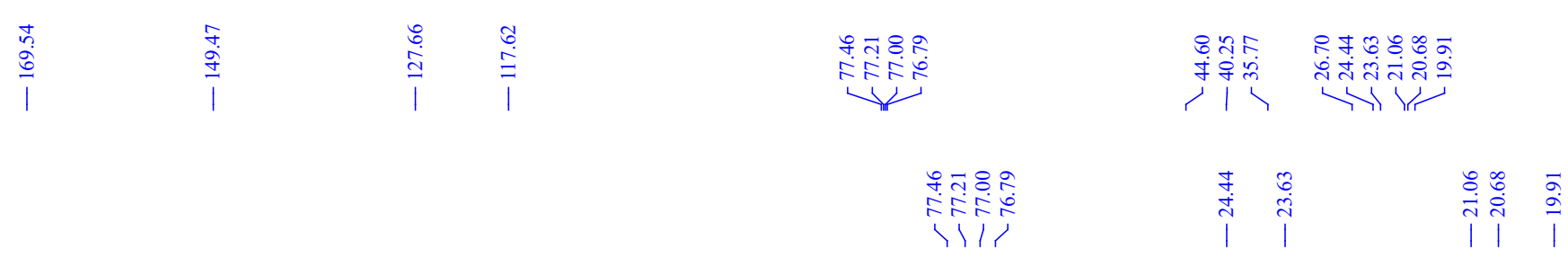

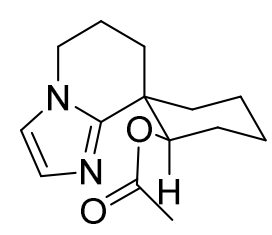

25
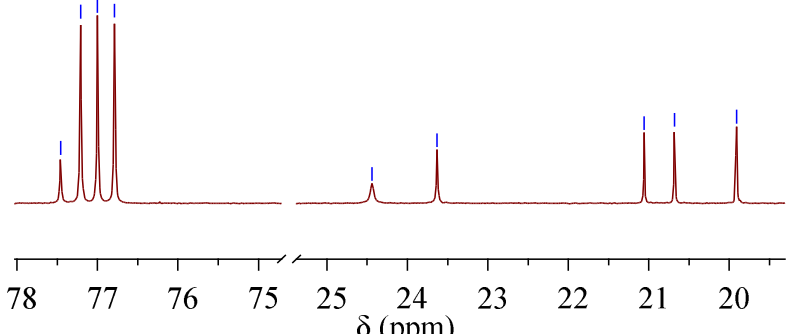
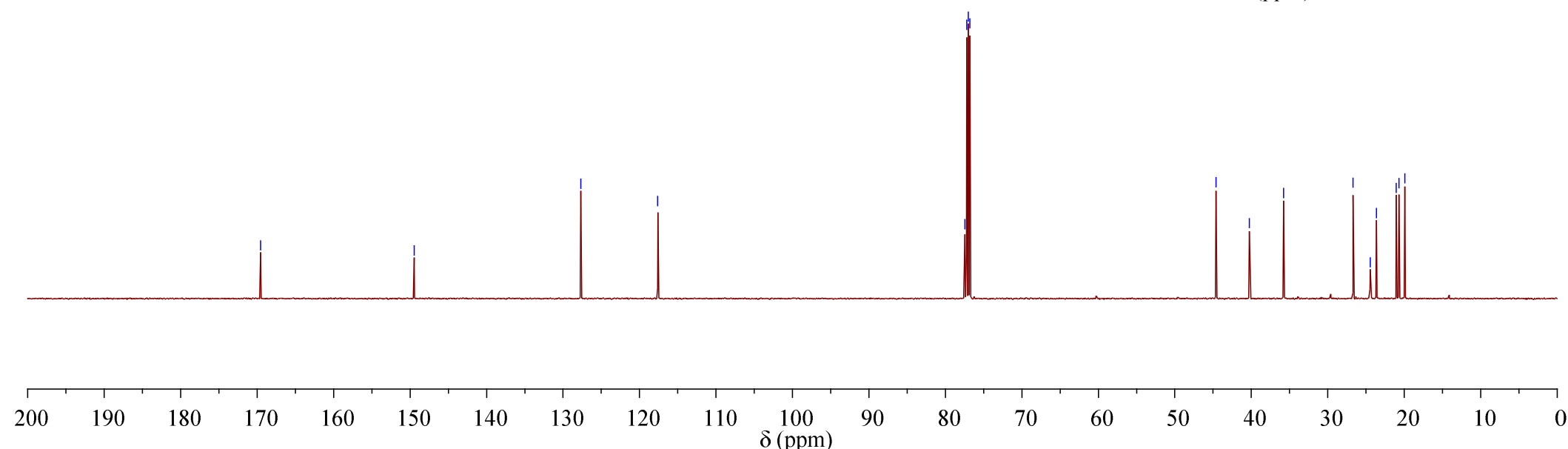

Figure S37: ${ }^{13} \mathrm{C}\left\{{ }^{1} \mathrm{H}\right\} \mathrm{NMR}\left(\mathrm{CDCl}_{3}, 150.9 \mathrm{MHz}\right)$ spectrum 25 


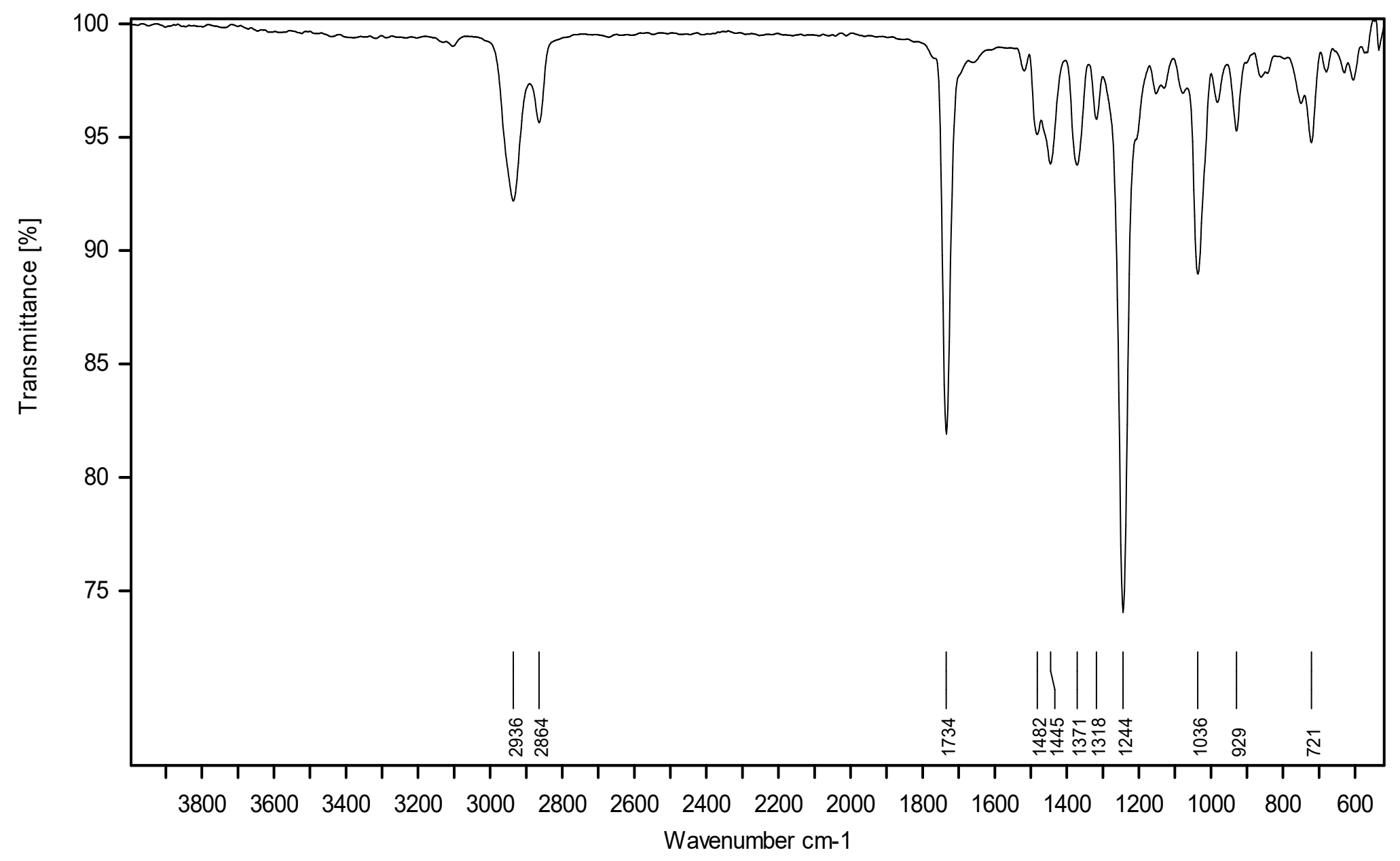

Figure S38: IR spectrum 28 
HRMS, NMR, and IR spectra for $\mathbf{2 5}^{\prime}$

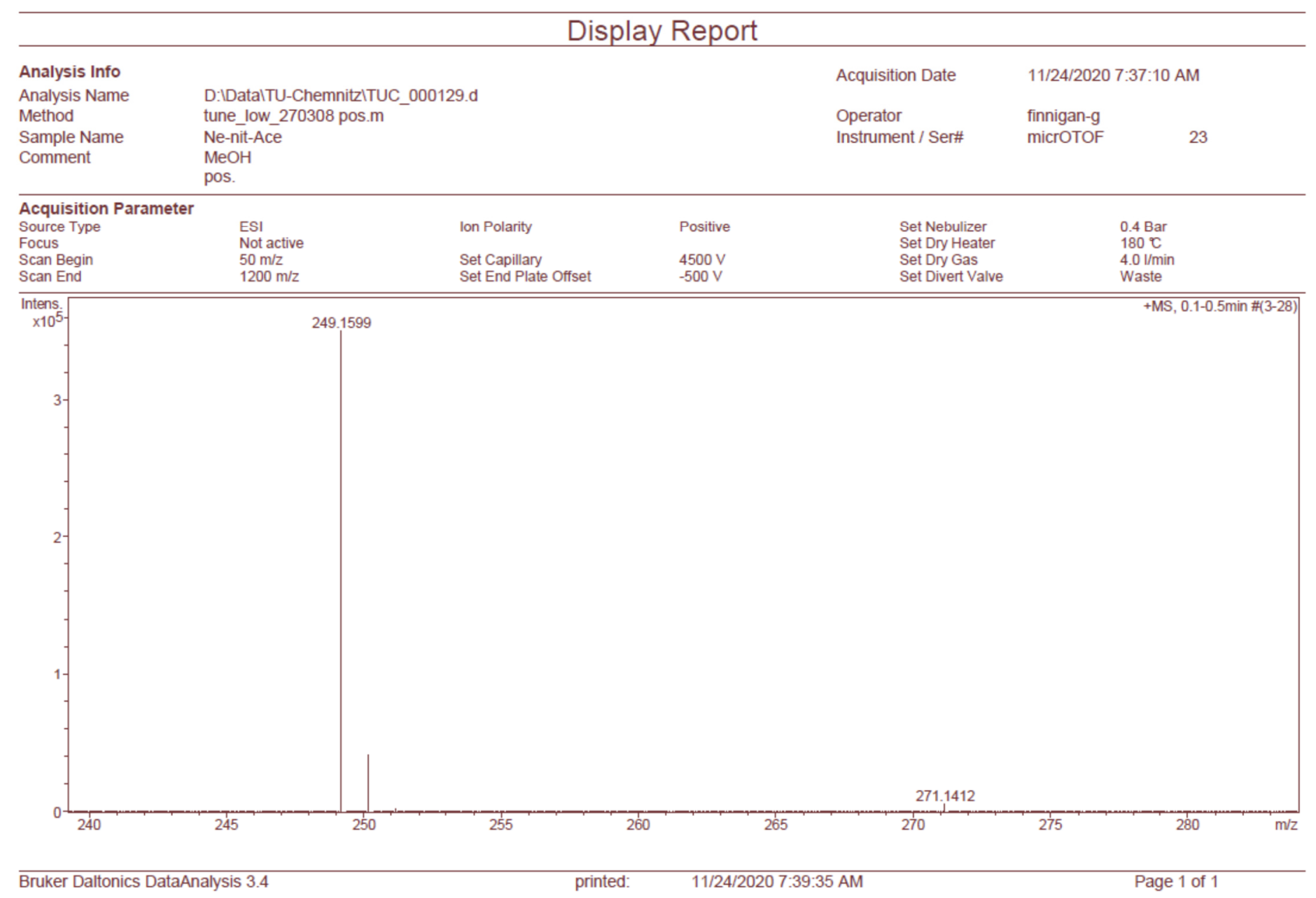

Figure S39: HRMS for 25' 

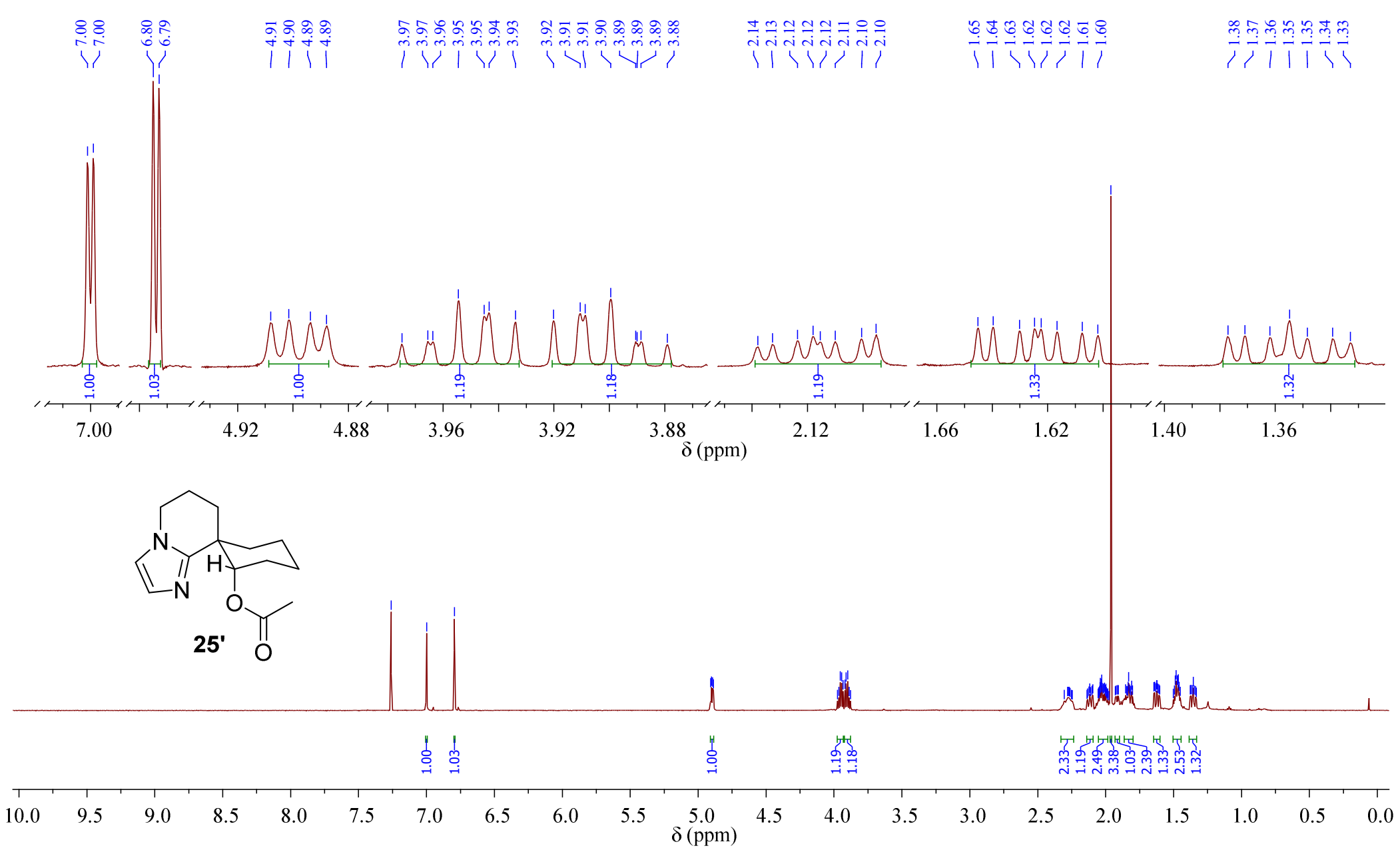

Figure S40: ${ }^{1} \mathrm{H} \mathrm{NMR}\left(\mathrm{CDCl}_{3}, 600 \mathrm{MHz}\right)$ spectrum for 25 ' 

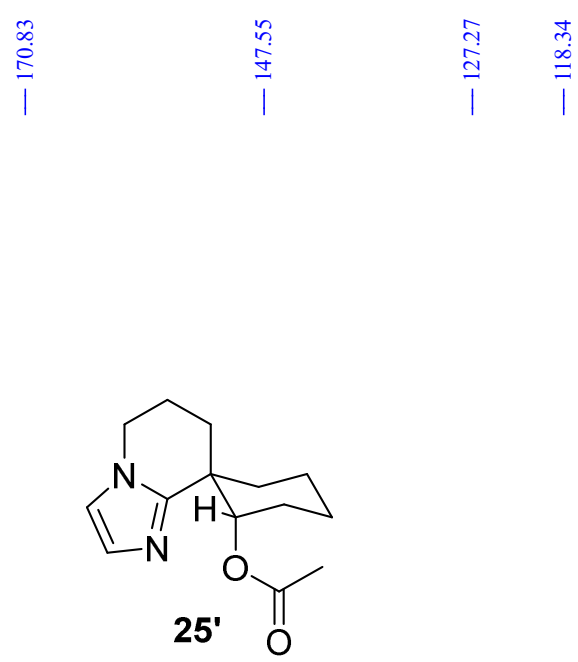

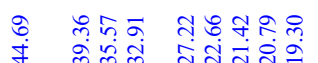

गे

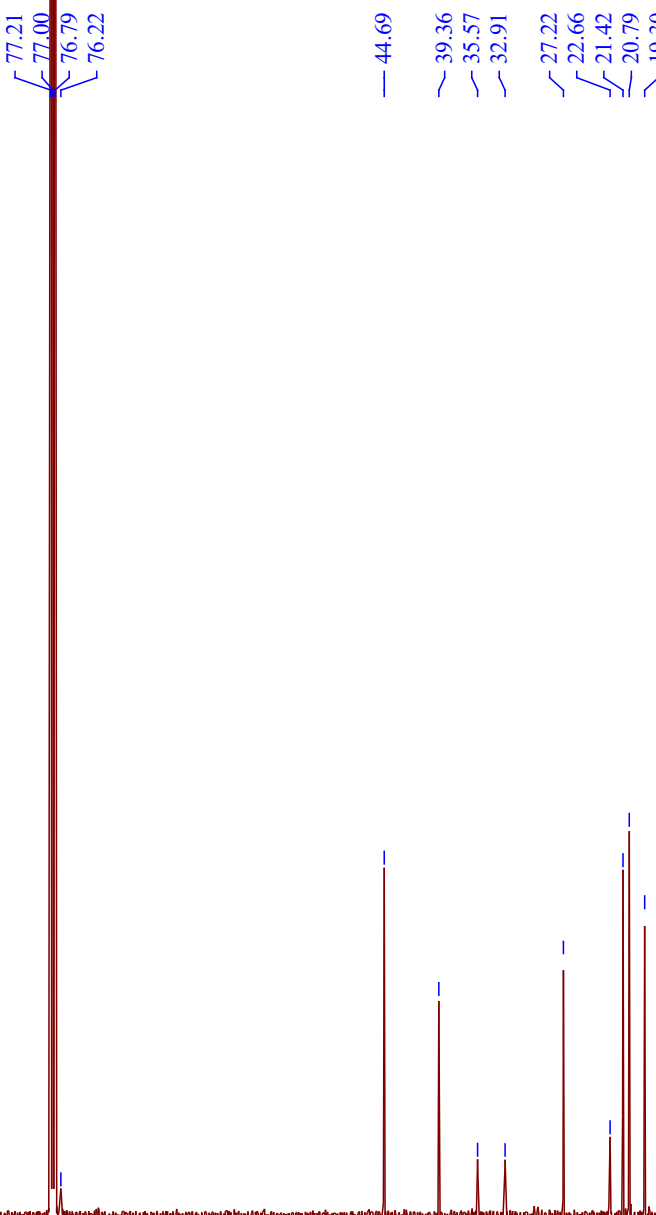

$\begin{array}{rrrrrr} & 1 & & & & 1 \\ 200 & 190 & 180 & 170 & 160 & 150\end{array}$

Figure S41: ${ }^{13} \mathrm{C}\left\{{ }^{1} \mathrm{H}\right\} \mathrm{NMR} \mathrm{CDCl}_{3}, 150.9 \mathrm{MHz}$ ) spectrum for $25^{\prime}$ 


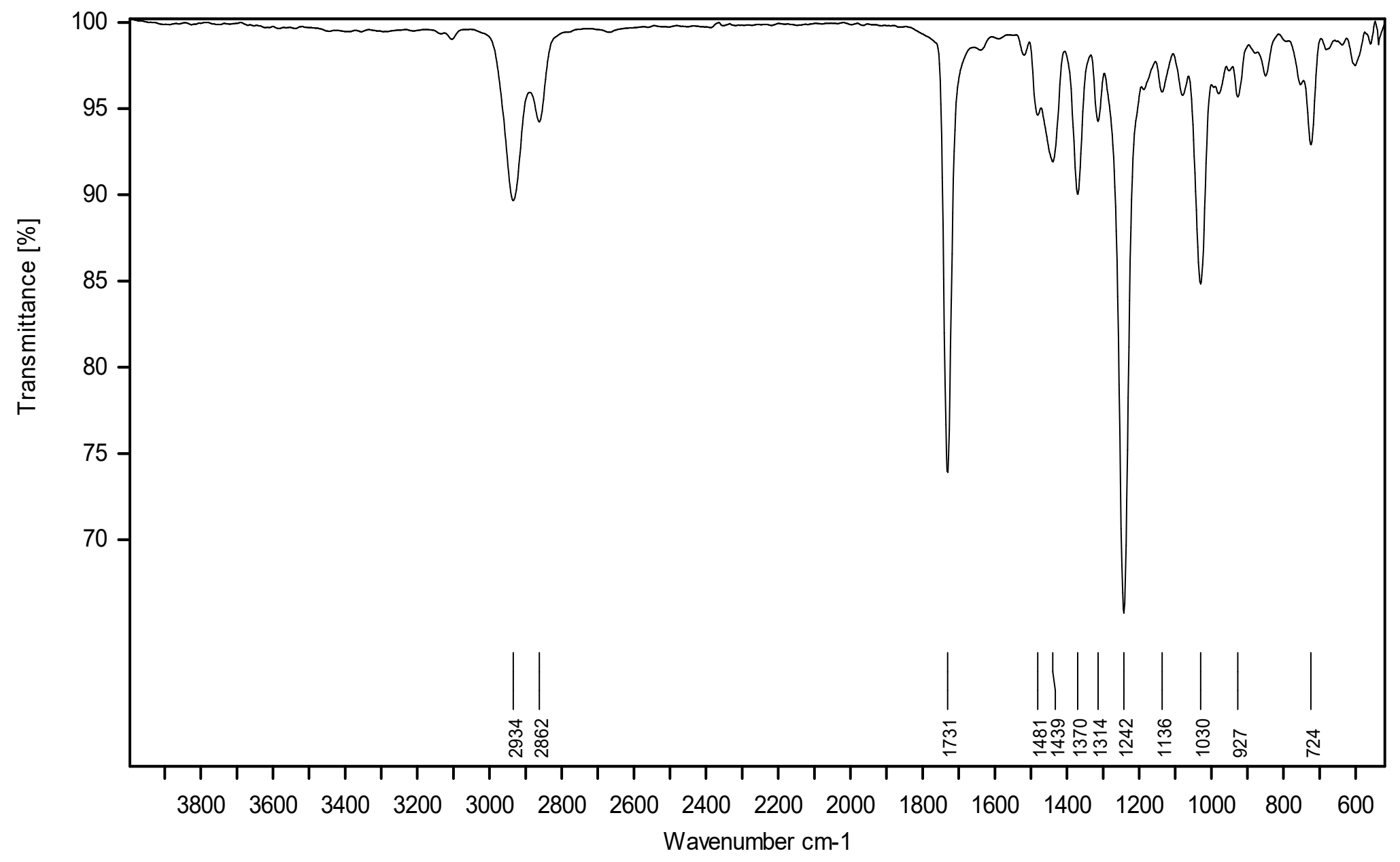

Figure S42: IR spectrum for $25^{\prime}$ 
HRMS, NMR, and IR spectra for $26 a$

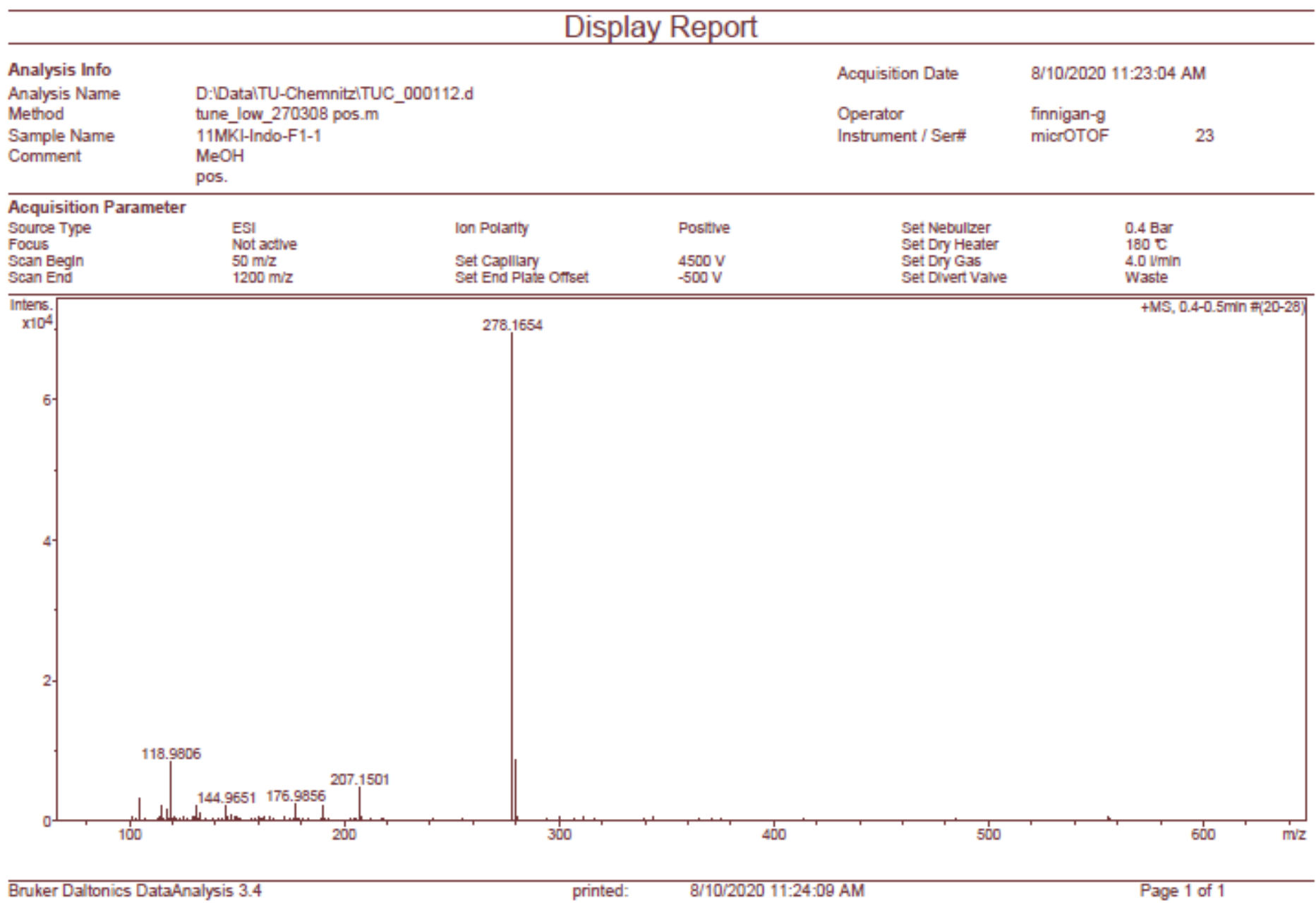

Figure S43: HRMS for 26a 


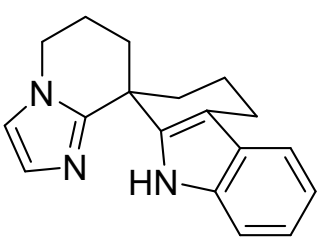

26a
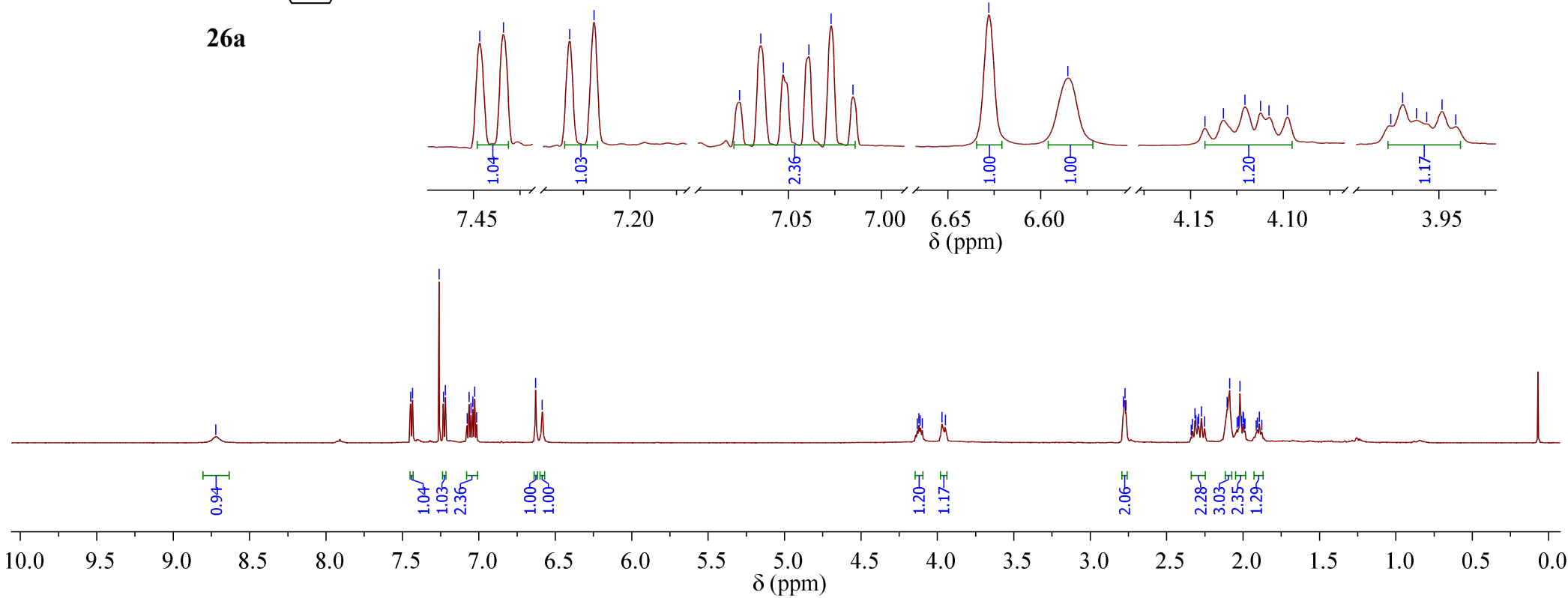

Figure S44: ${ }^{1} \mathrm{H}$ NMR $\left(\mathrm{CDCl}_{3}, 600 \mathrm{MHz}\right)$ spectrum for $26 \mathrm{a}$ 


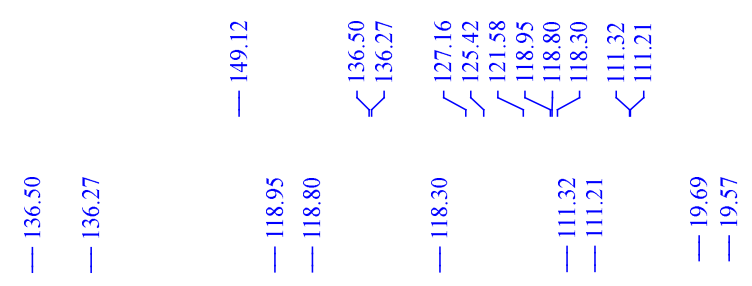
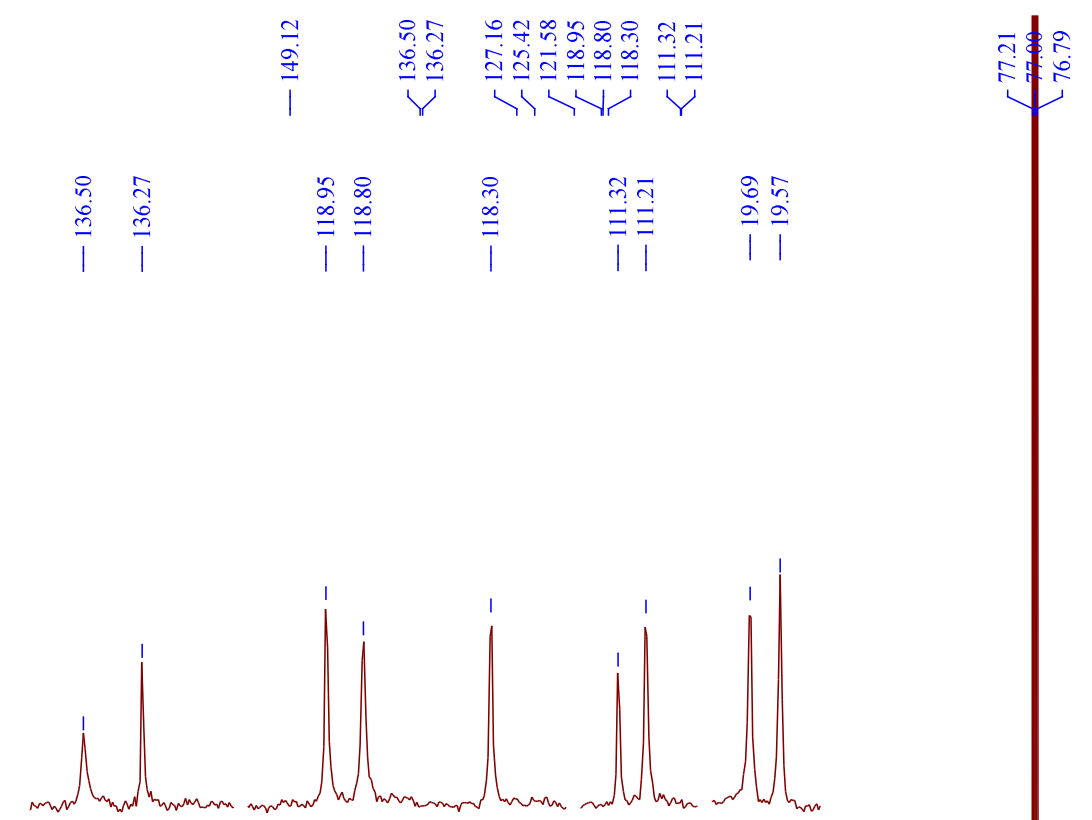

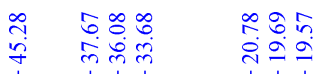

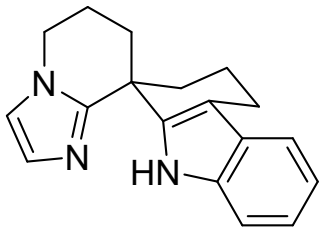

26a

$$
136.5
$$$$
\begin{array}{lll}
136.0 & 119.0 & \begin{array}{c}
118.5 \\
\delta(\mathrm{ppm})
\end{array}
\end{array}
$$

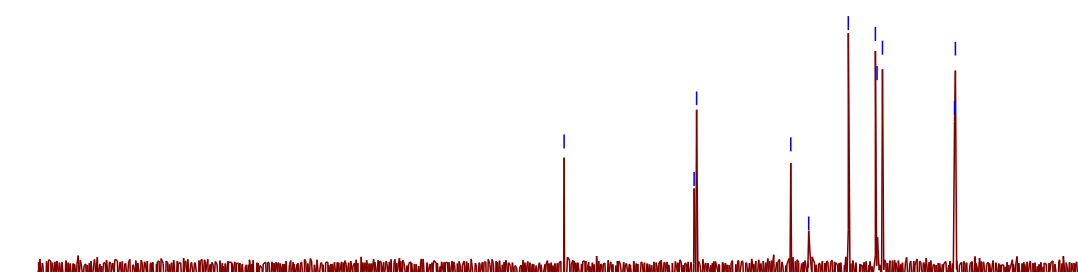

$\begin{array}{rrrrr} & & & & \\ 200 & 190 & 180 & 170 & 160\end{array}$

150

$140 \quad 130$

120

110

$\delta(\mathrm{ppm})$

$80 \quad 70$

60

50

40

30

20

$10 \quad 0$

Figure S45: ${ }^{13} \mathrm{C}\left\{{ }^{1} \mathrm{H}\right\} \mathrm{NMR}\left(\mathrm{CDCl}_{3}, 150.9 \mathrm{MHz}\right)$ spectrum for $26 \mathrm{a}$ 


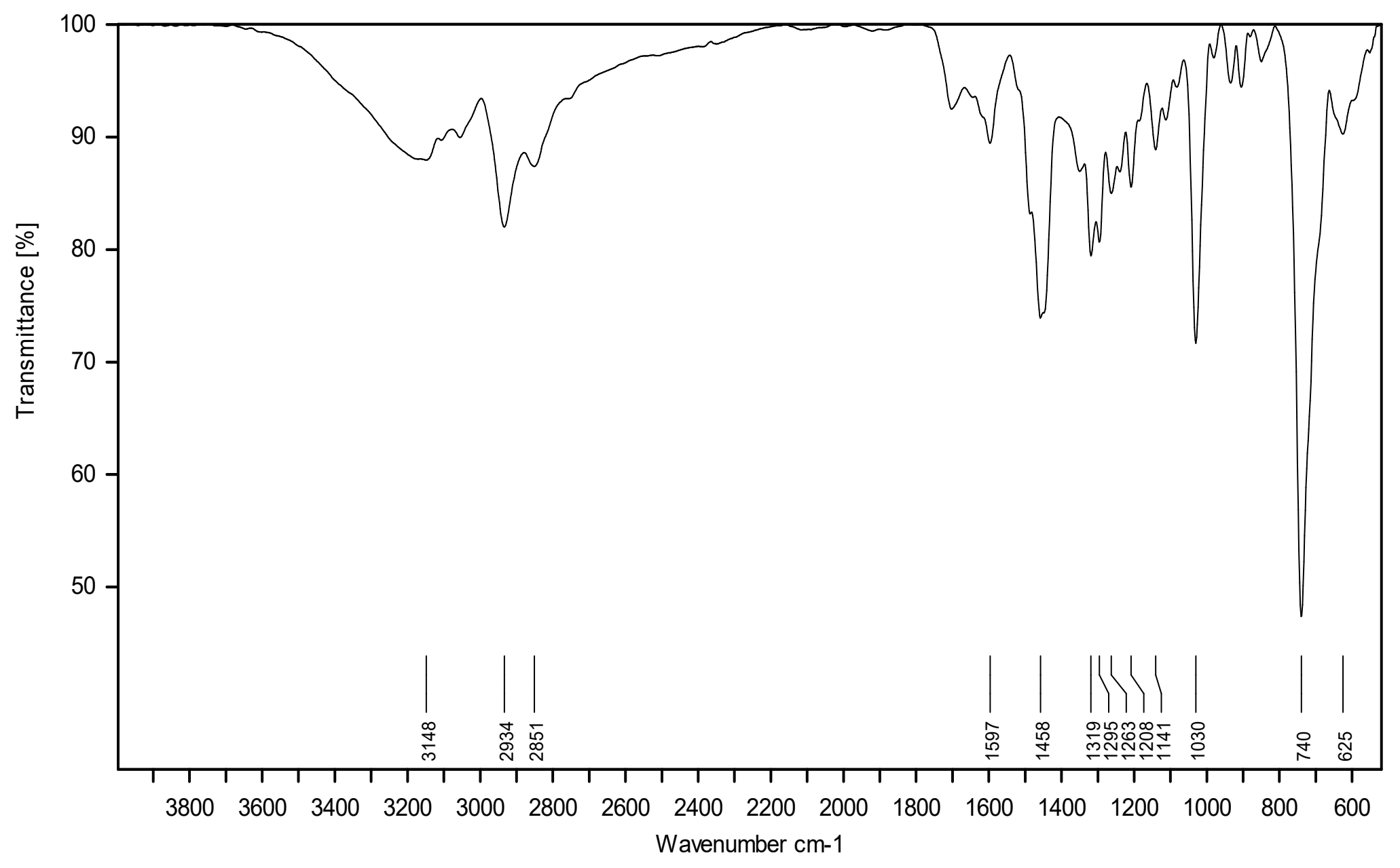

Figure S46: IR spectrum for $26 a$ 
HRMS, NMR, and IR spectra for 26b

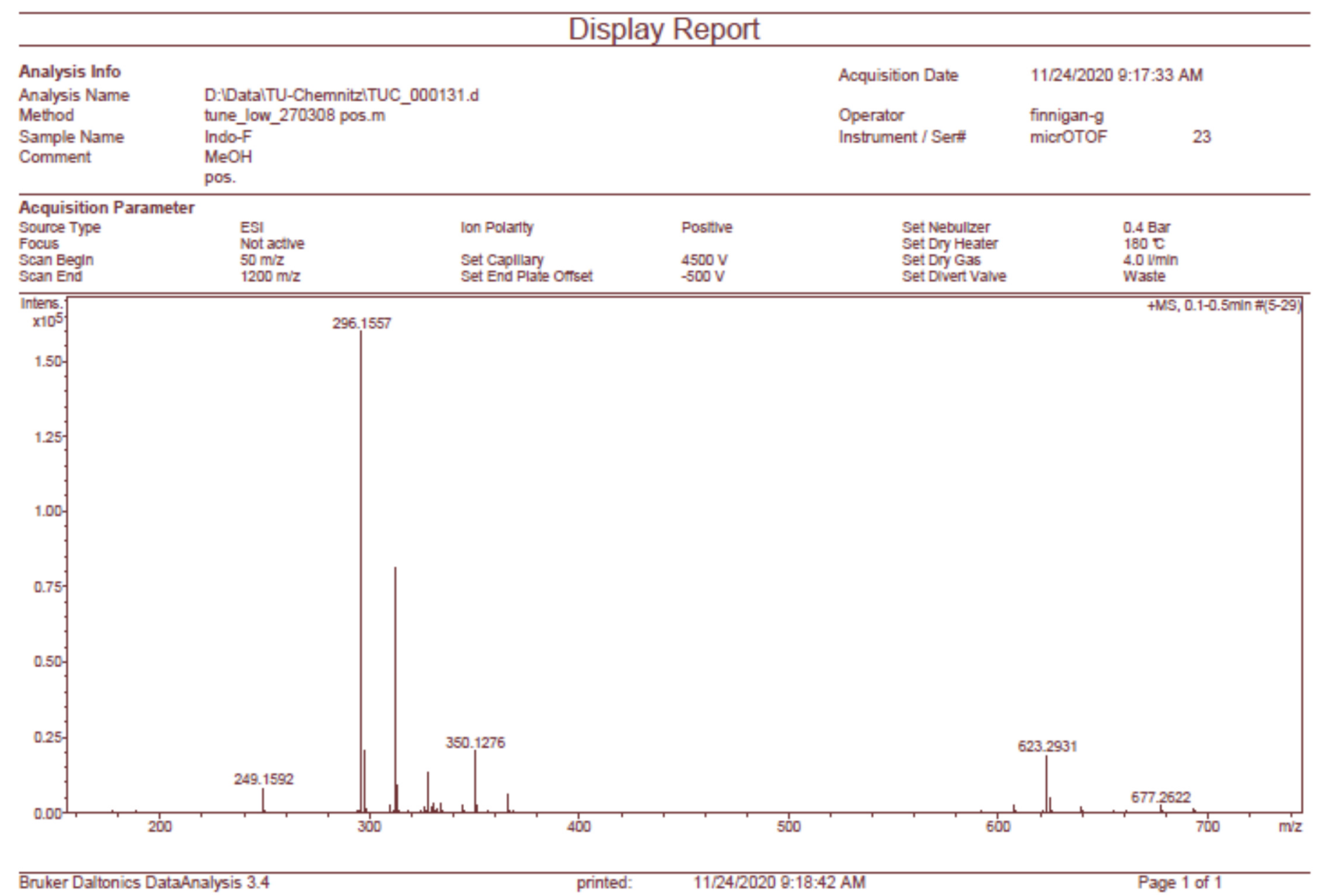

Figure S47: HRMS for 26b 


\section{on}

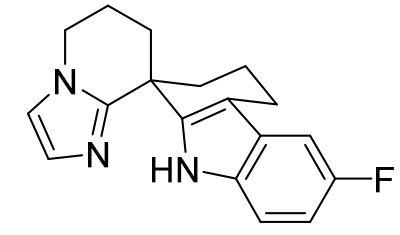

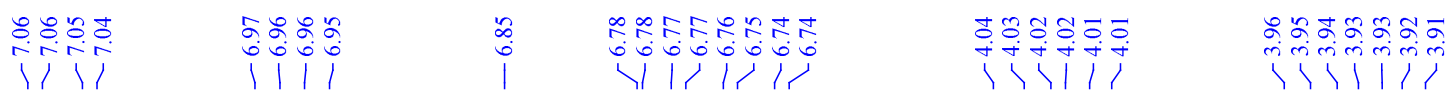

26b
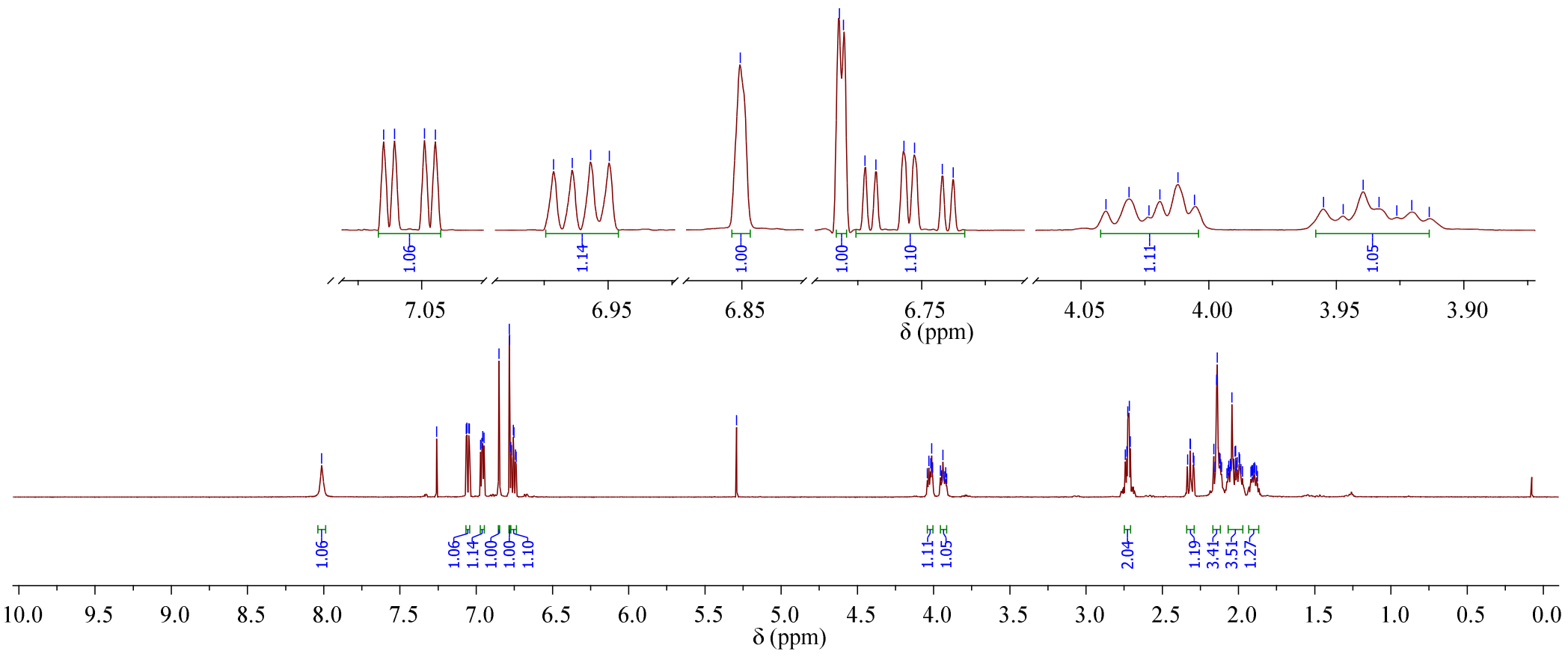

Figure S48: ${ }^{1} \mathrm{H}$ NMR $\left(\mathrm{CDCl}_{3}, 600 \mathrm{MHz}\right)$ spectrum for $26 \mathrm{~b}$ 


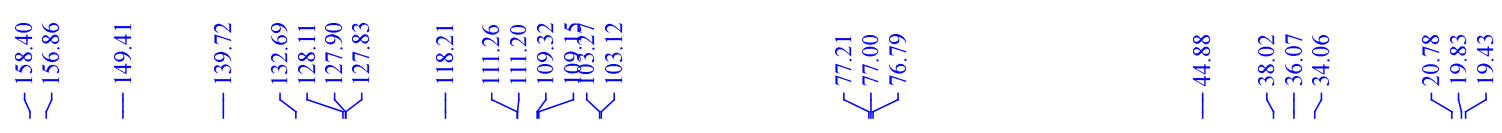

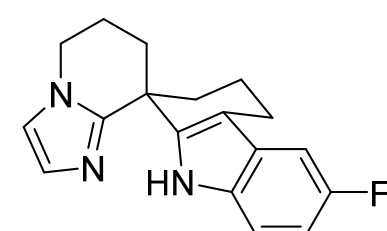

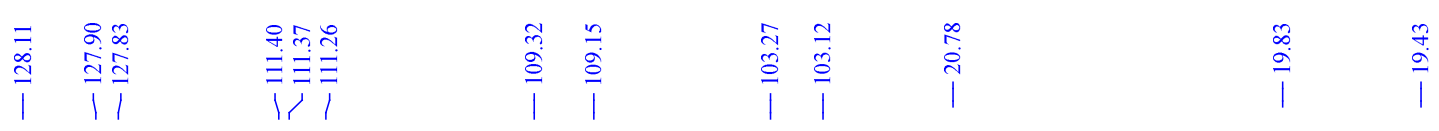

$26 b$

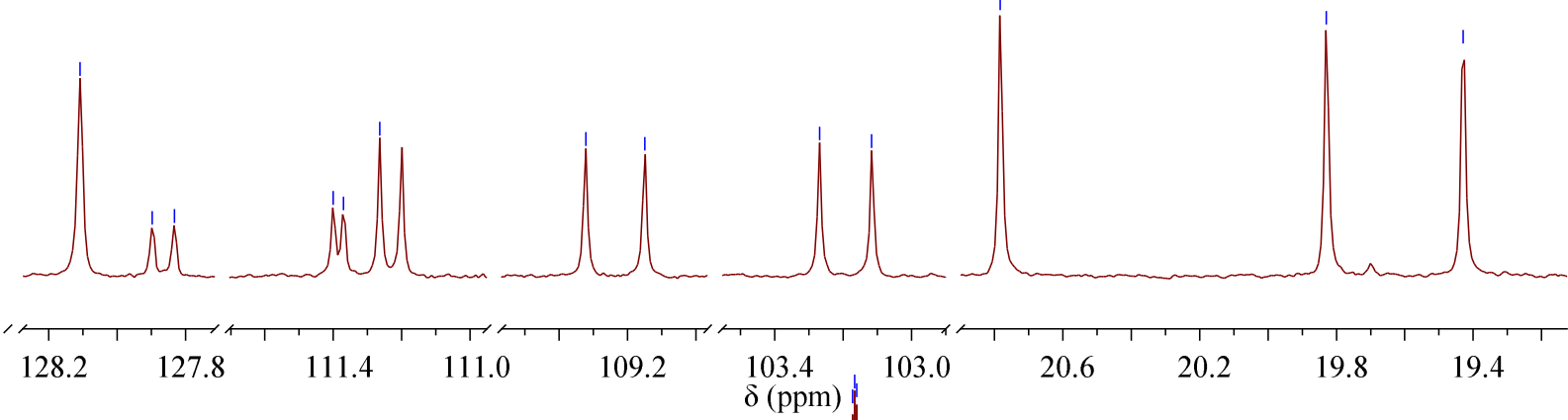

$\begin{array}{lllll}200 & 190 & 180 & 170 & 160\end{array}$

$140 \quad 130 \quad 120$

$110 \quad 100$

$80 \quad 70$

60

50

$40 \quad 30$

$20 \quad 10 \quad 0$

Figure S49: ${ }^{13} \mathrm{C}\left\{{ }^{1} \mathrm{H}\right\} \mathrm{NMR}\left(\mathrm{CDCl}_{3}, 150.9 \mathrm{MHz}\right)$ spectrum for $26 \mathrm{~b}$ 


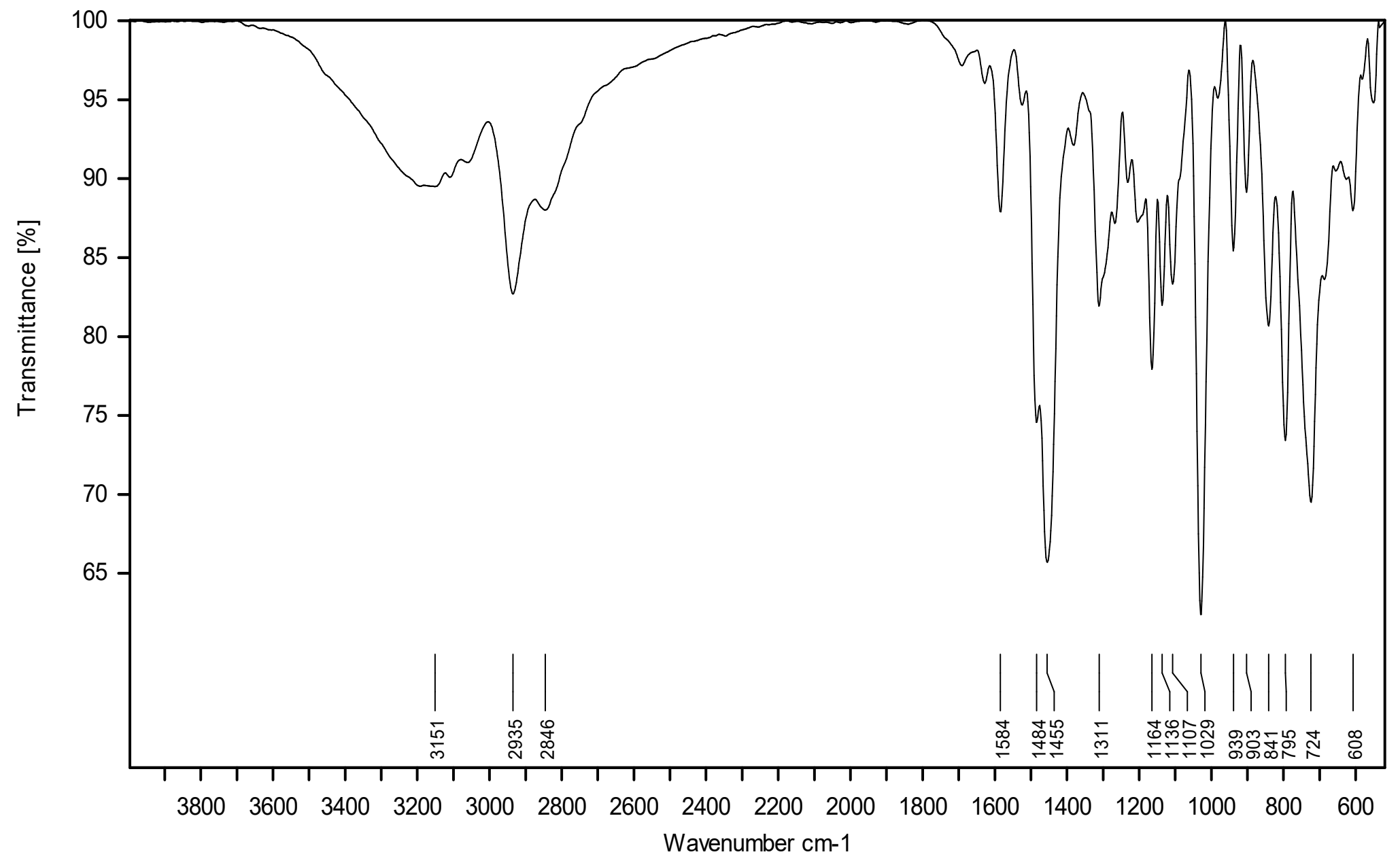

Figure S50: IR spectrum for $26 \mathrm{~b}$ 
HRMS, NMR, and IR spectra for 26c

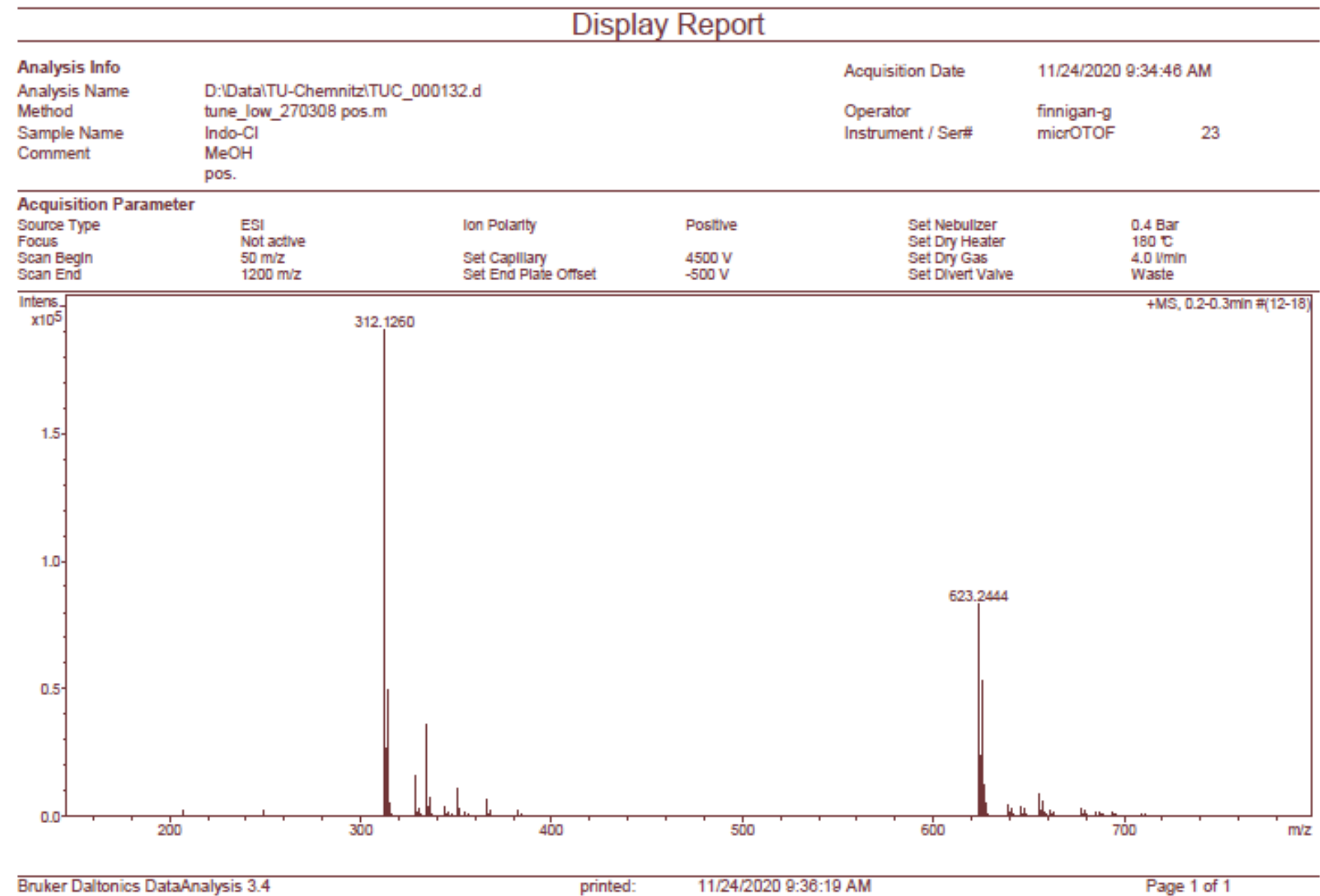

Figure S51: HRMS for 26c 


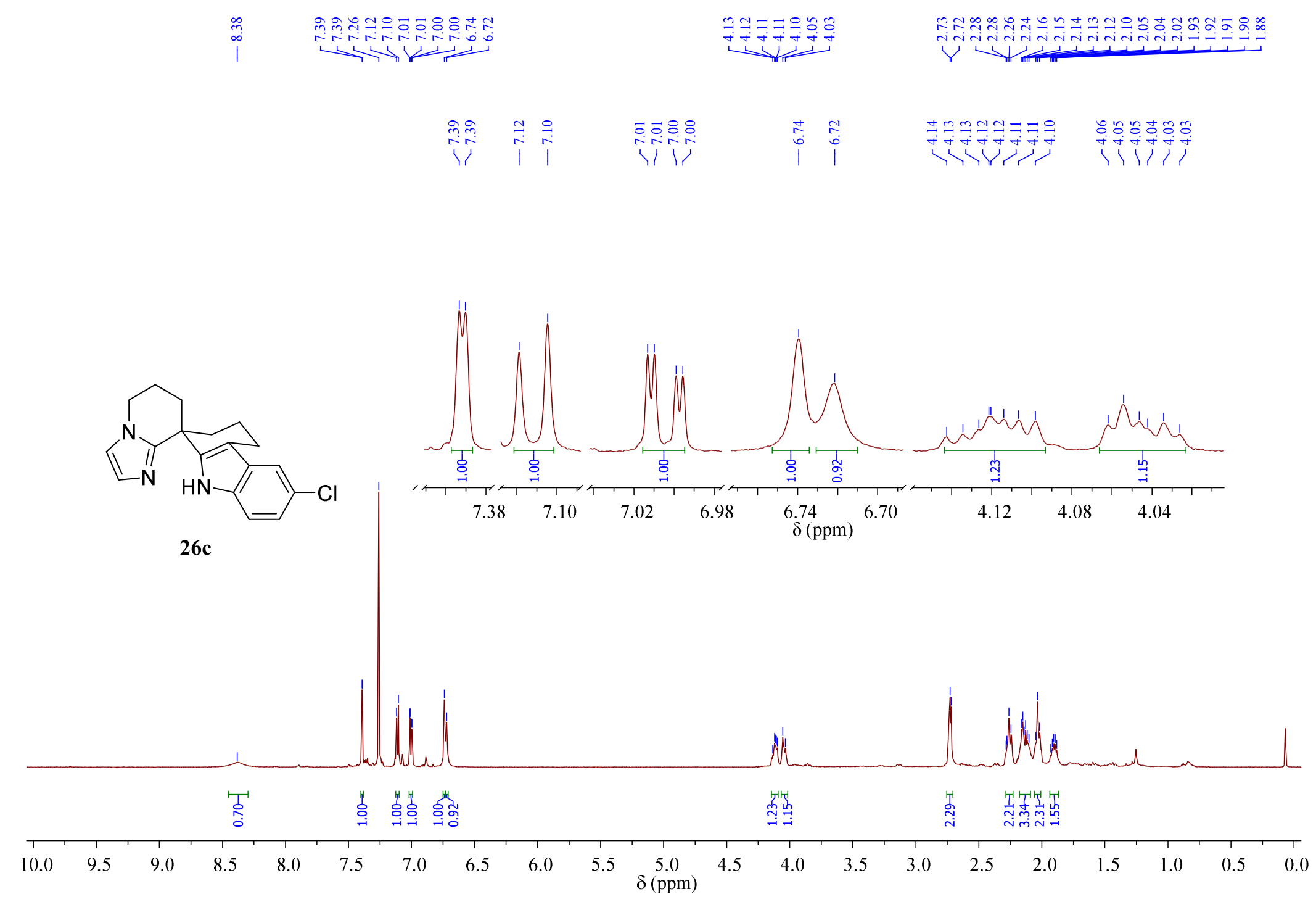

Figure S52: ${ }^{1} \mathrm{H}$ NMR $\left(\mathrm{CDCl}_{3}, 600 \mathrm{MHz}\right)$ spectrum for $26 \mathrm{c}$ 


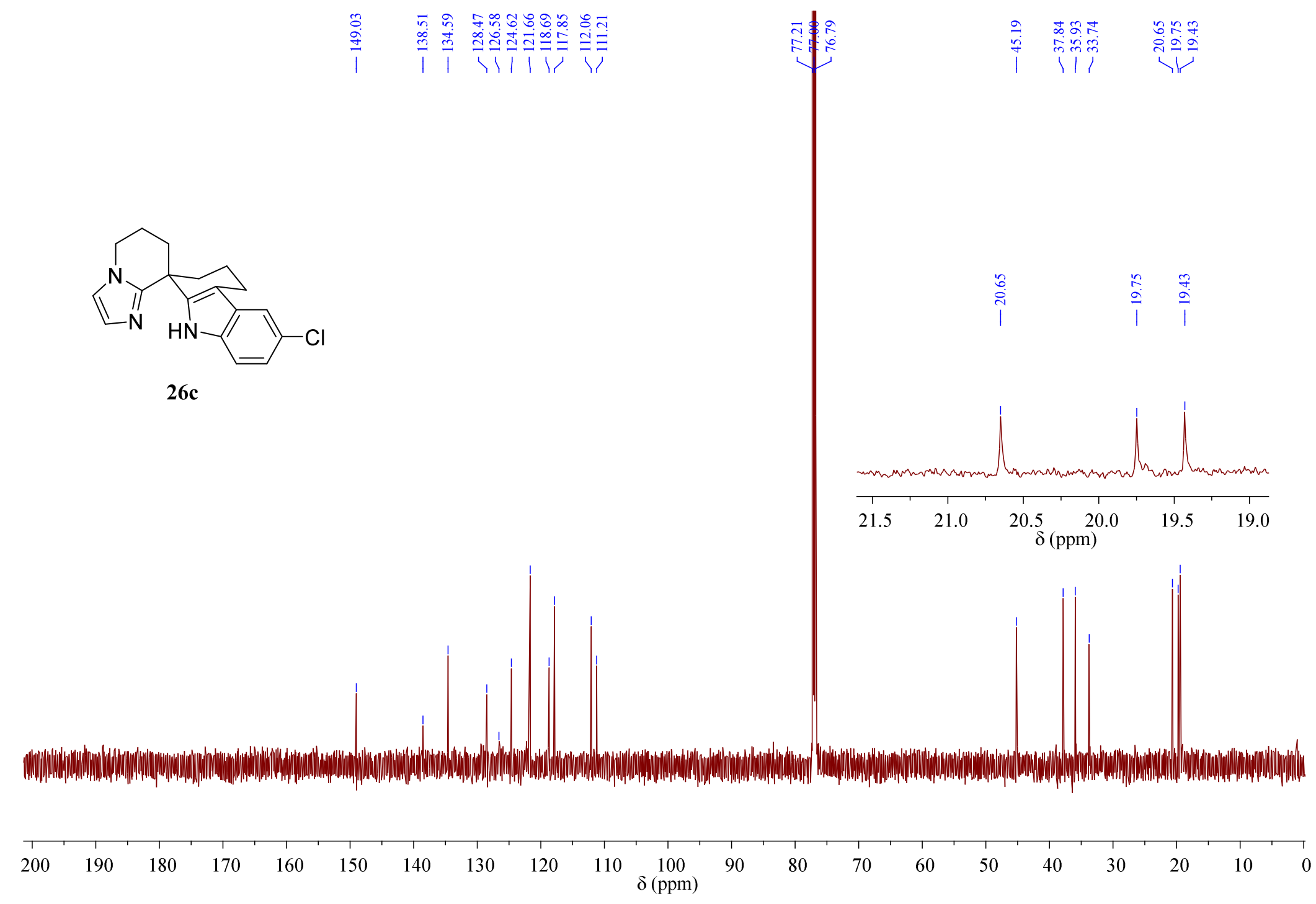

Figure S53: ${ }^{13} \mathrm{C}\left\{{ }^{1} \mathrm{H}\right\} \mathrm{NMR}\left(\mathrm{CDCl}_{3}, 150.9 \mathrm{MHz}\right)$ spectrum $26 \mathrm{C}$ 


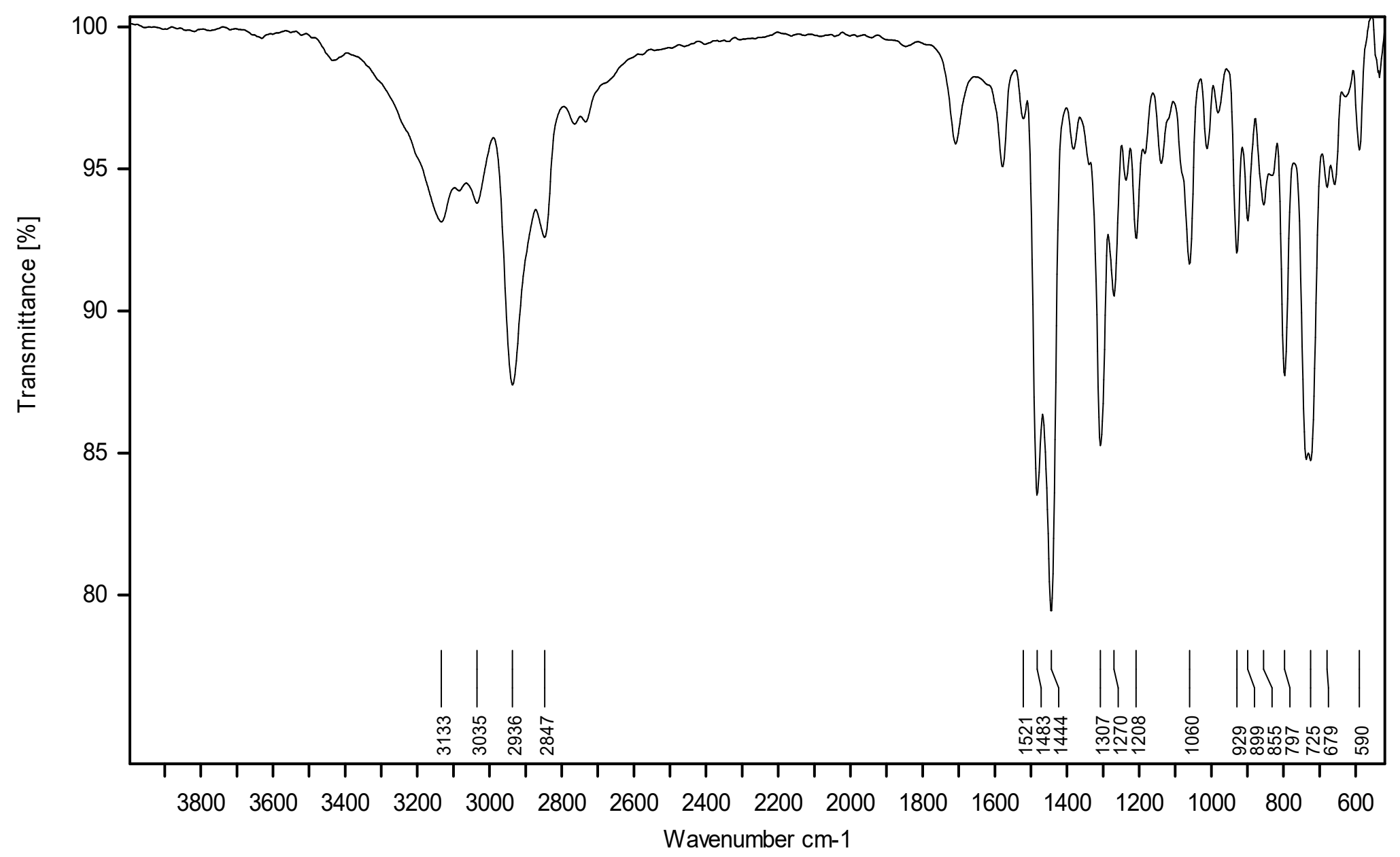

Figure S54 : IR spectrum 26c 
HRMS, NMR, and IR spectra for $26 \mathrm{~d}$

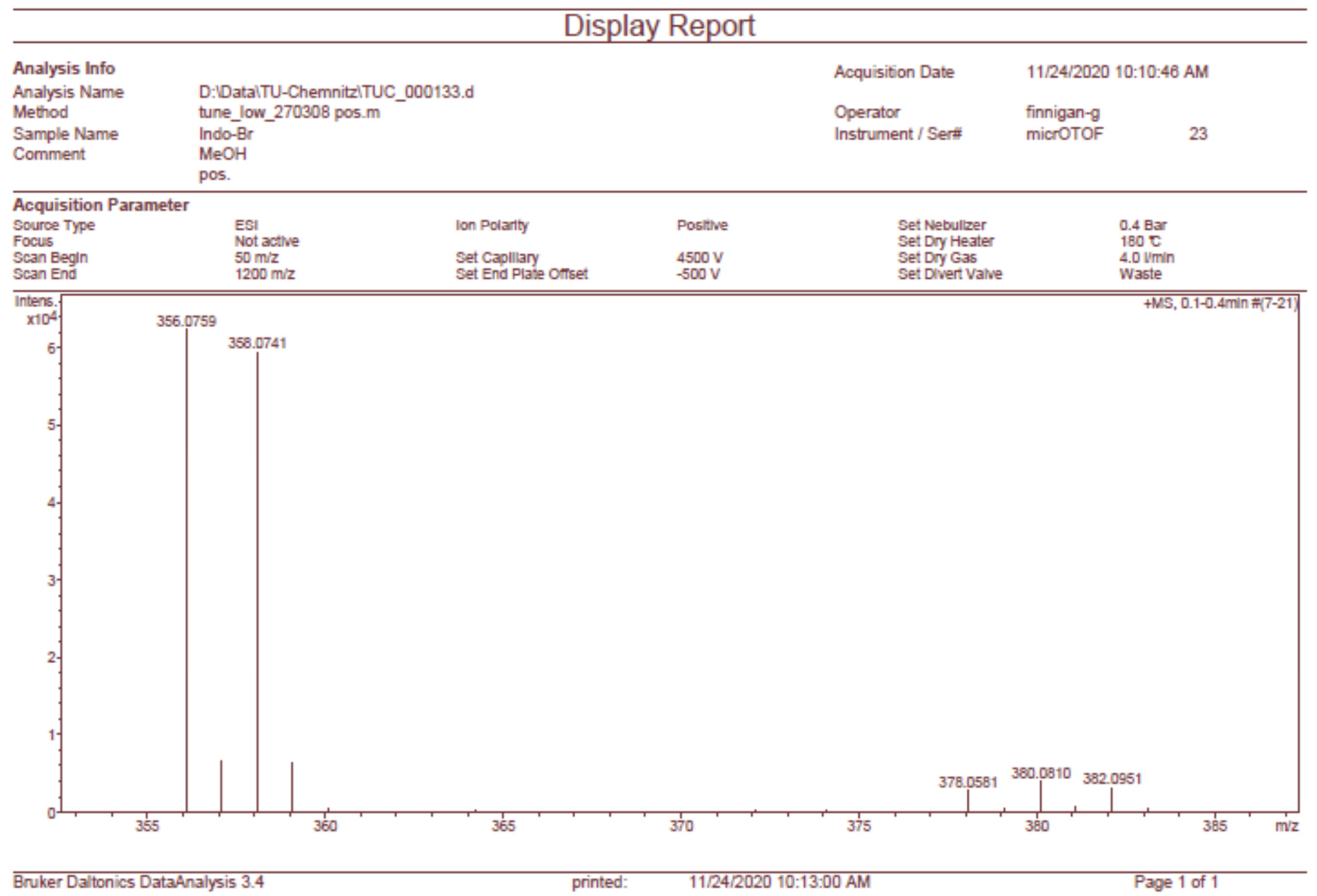

Figure S55: HRMS for 26d 


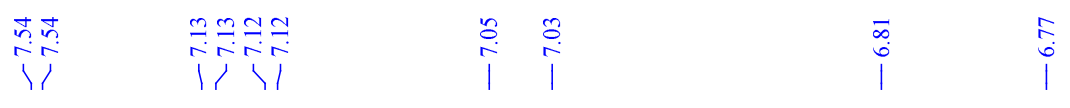

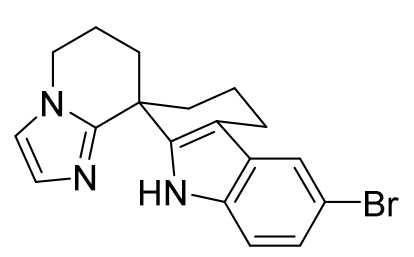

26d
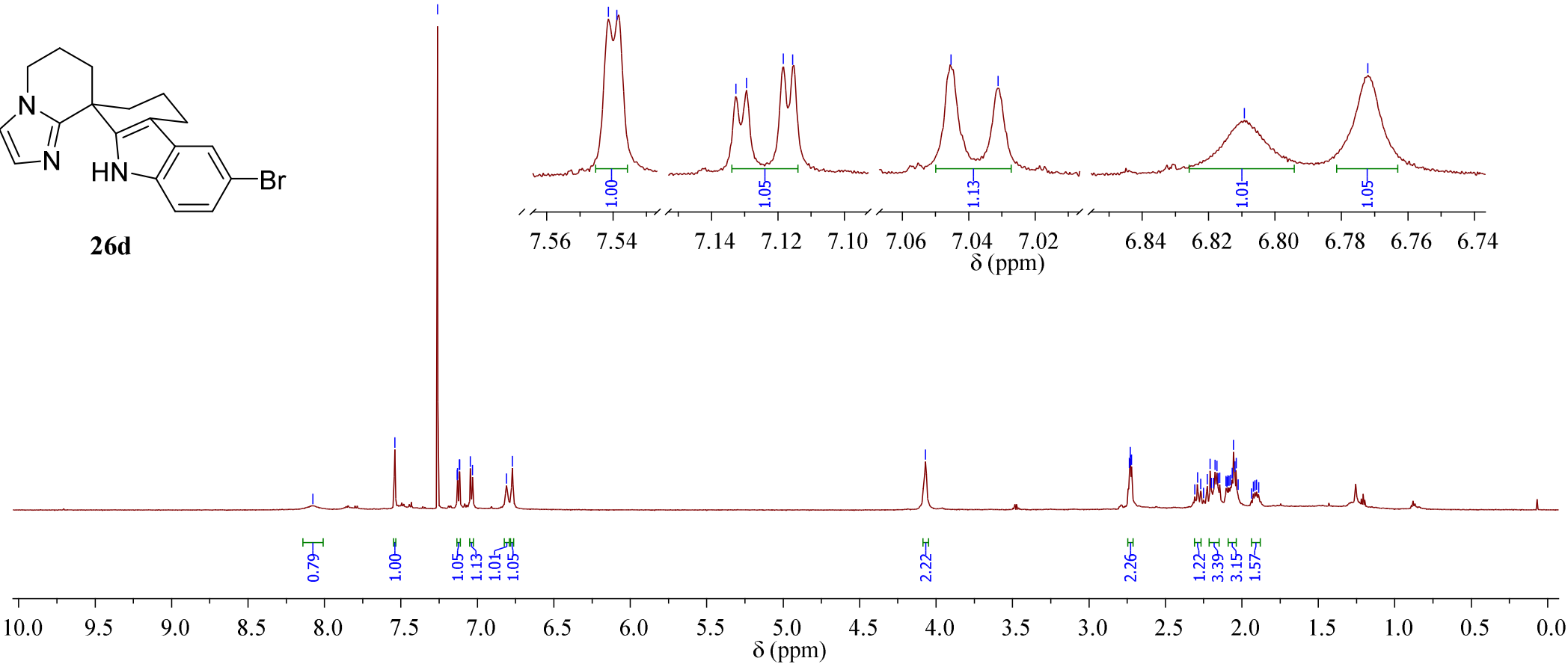

Figure S56: ${ }^{1} \mathrm{H} \mathrm{NMR}\left(\mathrm{CDCl}_{3}, 600 \mathrm{MHz}\right)$ spectrum of $26 \mathrm{~d}$ 


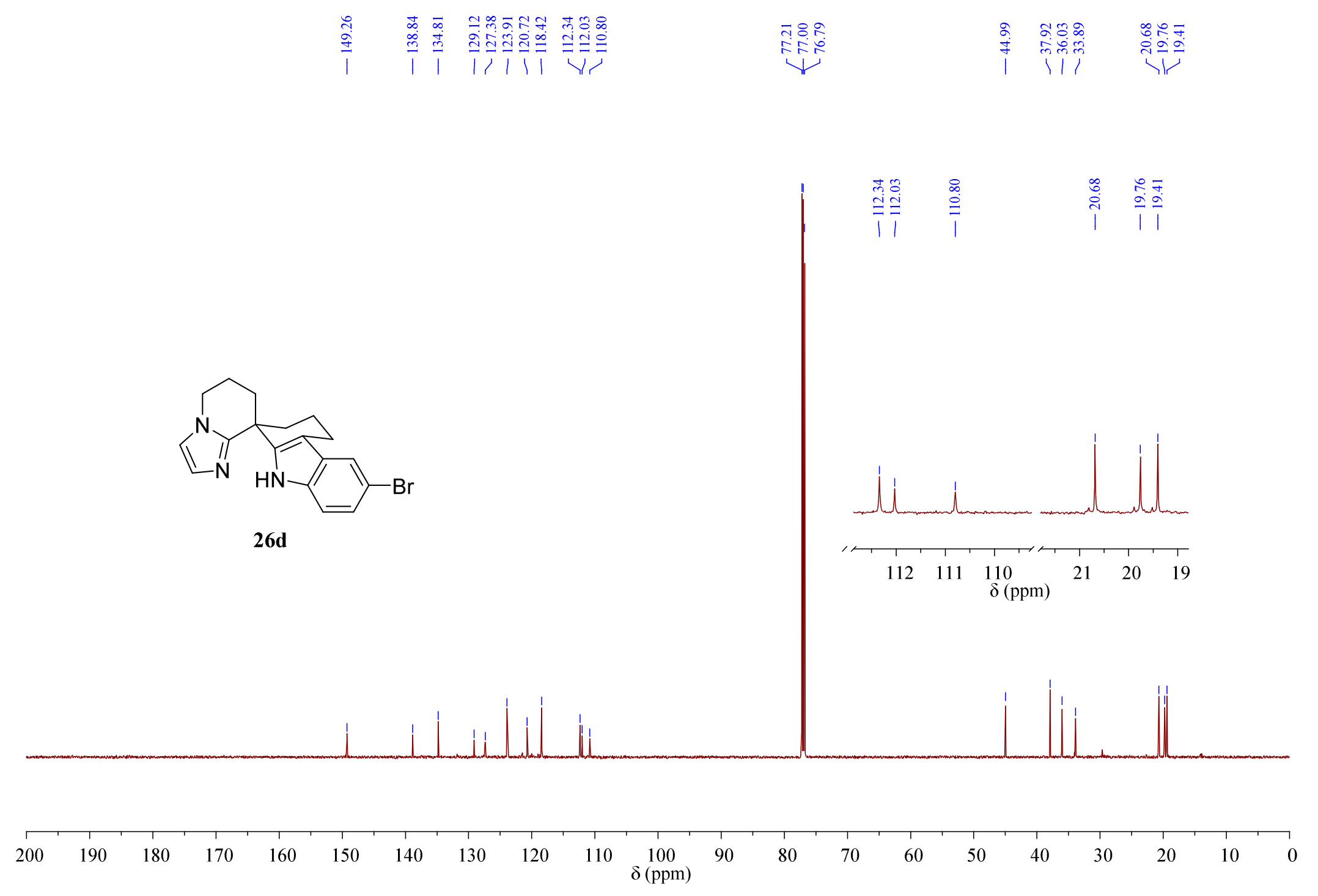

Figure S57: ${ }^{13} \mathrm{C}\left\{{ }^{1} \mathrm{H}\right\} \mathrm{NMR}\left(\mathrm{CDCl}_{3}, 150.9 \mathrm{MHz}\right)$ spectrum for $26 \mathrm{~d}$ 


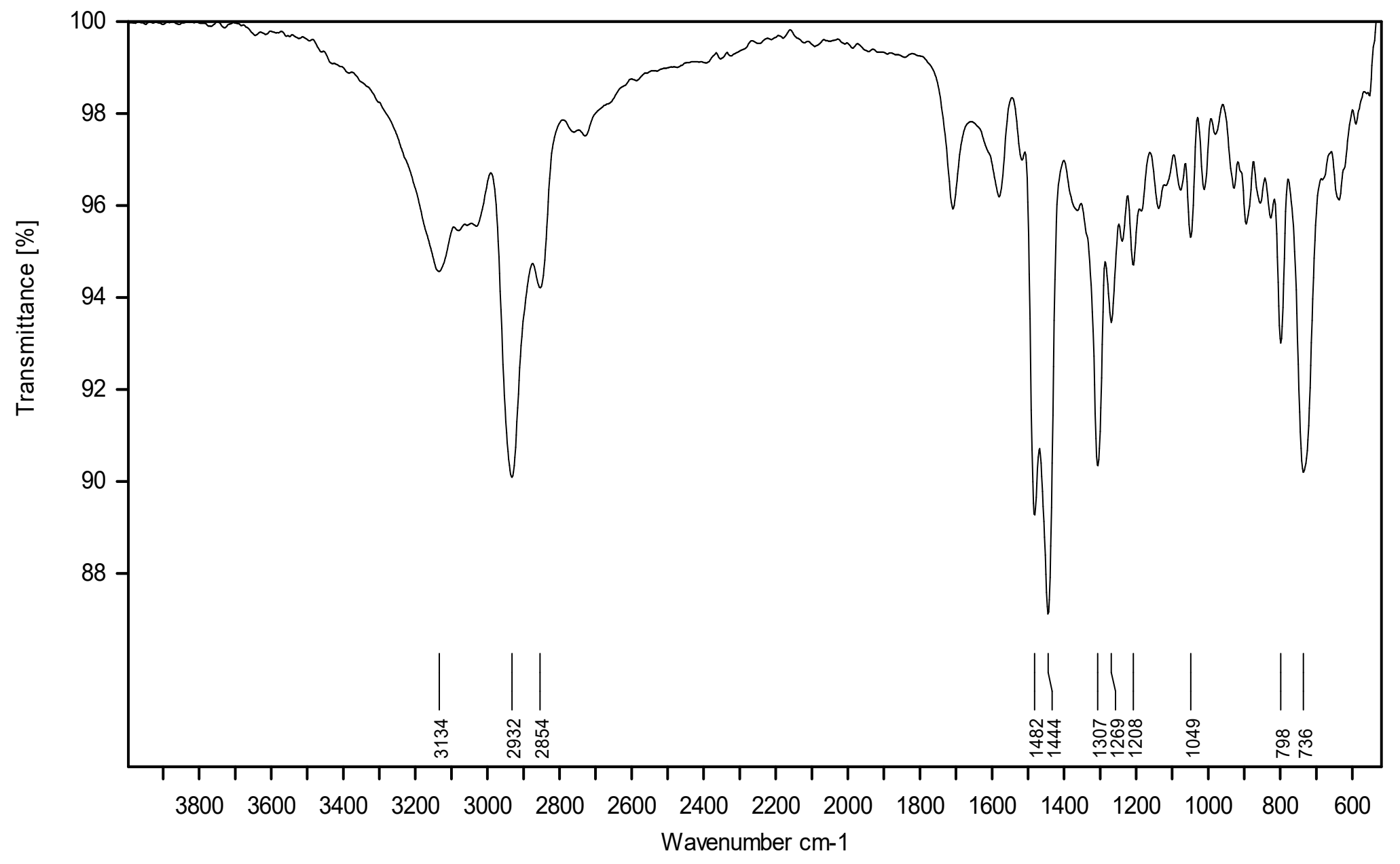

Figure S58: IR spectrum for $26 d$ 